\author{
Universidade de São Paulo \\ Instituto de Astronomia, Geofísica e Ciências Atmosféricas \\ Departamento de Ciências Atmosféricas
}

Natália Pillar da Silva

\title{
Estudo dos Mecanismos Vinculados ao Estabelecimento de um Evento de ZCAS Através de Simulações com o Modelo WRF
}

São Paulo 



\section{Estudo dos Mecanismos Vinculados ao Estabelecimento de um Evento de ZCAS Através de Simulações com o Modelo WRF}

Tese apresentada ao Departamento de Ciências Atmosféricas do Instituto de Astronomia, Geofísica e Ciências Atmosféricas da Universidade de São Paulo como requisito para a obtenção do título de Doutor em Ciências.

Orientador: Prof. Dr. Ricardo de Camargo

Versão Corrigida. O original encontra-se disponível na Unidade.

São Paulo 

À minha mãe, Marília da Silva. E à minha avó, Therezinha (In Memoriam). Minhas maiores incentivadoras. 



\section{Resumo}

No presente estudo, os mecanismos vinculados à formação de um intenso evento de Zona de Convergência do Atlântico Sul (ZCAS) foram investigados. Para isso, uma análise observacional foi realizada para identificação desse sistema e seguinte implementação de um estudo numérico em uma escala sub-sazonal. Uma vez que a atividade da ZCAS é predominantemente concentrada em uma das regiões de maior importância socioeconômica da América do Sul, os estudos de previsibilidade dessa feiçãosão extremamente importantes. O evento escolhido pela análise observacional foi caracterizado pelo suporte de uma estrutura em larga escala para seu desenvolvimento e persistência, através da presença de um vórtice ciclônico na região costeira do sudeste do Brasil. A representação numérica desse caso de ZCAS foi particularmente desafiadora, uma vez que trata-se de um sistema complexo, cujo desenvolvimento e evolução conectam-se a características atmosféricas de grande escala. Para aprimorar a representação numérica desse evento, várias aplicações utilizando-se nudging espectral foram testadas, para garantir que as características de grande escala que suportam o sistema fossem bem representadas pelo modelo numérico. Os resultados mostram que a alternativa menos restritiva para a aplicação do nudging espectral mostrou-se ideal para manter suas características importantes, e ainda permitindo que os componentes físicos do modelo contribuam com a representação da atmosfera em escalas menores. A partir disso, novos experimentos numéricos foram conduzidos para uma avaliação de como diferentes parametrizações convectivas e microfísica representam a banda de precipitação associada ao sistema. Os resultados mostram que, quando usados juntos, tanto a opção de microfísica WRF Single Moment 6-Class (WSM6) quanto a opção cumulus de Kain-Fritsch (KF) contribuíram para a formação da banda convectiva associada à ZCAS. Os resultados também mostram que é possível usar um esquema de microfísica 
mais simples (WSM3) para a representação do sistema, uma vez que os desempenhos entre os diferentes testes em microfísica foram semelhantes.

Palavras-chave: modelagem numérica, WRF, nudging espectral, Zona de Convergência do Atlântico Sul, avaliação de modelos numéricos 


\section{Abstract}

In the present study, the mechanisms and formation of an intense South Atlantic Convergence Zone (SACZ) event were investigated. For this, an observational analysis was performed to identify this system for the implementation of a numerical study on a subseasonal scale. Since the SACZ activity is predominantly concentraded over one of the most socioeconomically important regions of South America, precidtability studies for this system are extremely valuable. The SACZ event chosen by the observational analysis was supported by a large-scale structure that featured a cyclonic vortex in the coastal region of southeastern Brazil. The numerical representation of a SACZ case in this context was particularly challenging since the SACZ is a very complex system and its development and evolution are closely linked to large-scale atmospheric features. To improve the numerical representation of such event, several spectral nudging applications were tested to ensure the large scale features that support the systems are well represented by the numerical model. Results show that the less restrictive alternative for the spectral nudging application was ideal for maintaining important features in large scales while still allowing the physical components of the model to contribute the representation of the atmosphere on smaller scales. From this, numerical experiments were conducted for an evaluation of how different convective parametrizations and microphysics represent the precipitation band associated to the system. The results show that, when used together, both WRF Single Moment 6-Class (WSM6) microphysics option and Kain-Fritsch (KF) cumulus option contributed to the formation of convective band associated with the SACZ. Results also show that it is possible to use a simpler microphysics scheme (WSM3) for the representation of the system, since the performances between different tests in microphysics were similar.

Keywords: numerical modeling, WRF, spectral nudging, South Atlantic Convergence 
Zone, model evaluation 


\section{Lista de Figuras}

1.1 Sombreado: distribuição espacial da diferença entre a precipitação acumulada durante os meses de verão (Dezembro-Janeiro-Fevereiro no Hemisfério Sul e Junho-Julho-Agosto no Hemisfério Norte) e inverno (Junho-JulhoAgosto no Hemisfério Sul e Dezembro-Janeiro-Fevereiro no Hemisfério Norte). Linhas: delimitação de sistemas de monção regionais dada pelas diferenças de precipitação sazonais. Figura extraída de Wang, Ding e Liu (2011) . . .

1.2 Médias de precipitação [TRMM - Huffman et al. (2007)] e anomalias de vento em 850hPa [CFSR - Saha et al. (2011)] para os meses de verão (DJF - esquerda) e inverno (JJA - direita) . . . . . . . . . . . . .

1.3 Médias de precipitação [TRMM - Huffman et al. (2007)] e linhas de corrente [CFSR - Saha et al. (2011)] em 200hPa para os meses de verão (DJF esquerda) e inverno (JJA - direita $) \ldots \ldots \ldots$

2.1 Esquematização das principais estruturas associadas ao SMAS em altos e baixos níveis. Extraída de Zhou e Lau (1998) . . . . . . . . . . . . . .

2.2 Esquematização das principais estruturas associadas ao SMAS em um corte na orientação SW-NE. Extraída de Vera et al. (2006). . . . . . . . . . . . . .

2.3 Corte vertical do vento zonal na região centro-oeste do Brasil. Extraída de Gan et al. (2004) . . . . . . . . . . . . . . . .

2.4 Médias mensais de precipitação e linhas de corrente em 200hPa calculadas a partir de dados do TRMM e CFSR . . . . . . . . . . . . . . .

2.5 Médias mensais de precipitação e componentes do vento em 850hPa calculadas a partir de dados do TRMM e CFSR . . . . . . . . . . . . . 
2.6 Diagrama representando os diversos fatores que influenciam o sistema SMAS/ZCAS.

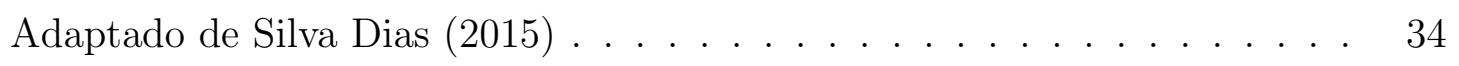

3.2 Periodograma da série temporal associada ao índice LISAM. . . . . . . . . 40

3.3 Periodograma da série temporal associada ao índice ZCAS. . . . . . . . . . 40

3.4 Periodograma da série temporal associada ao índice ZCAS detalhado para a banda intrasazonal. . . . . . . . . . . . . . . . . . . . . 41

3.5 Fluxograma que descreve os passos para a escolha de um evento de ZCAS intenso e de duração elevada. . . . . . . . . . . . . . . . . 42

3.6 Índice LISAM em barras (valores positivos indicam o início da estação chuvosa). As cores das barras indicam o percentil do índice ZCAS. Dados para a estação chuvosa de 2013-2014 . . . . . . . . . . . . . . . . . .

3.7 Diagrama RMM1 x RMM2 com destaque para o período de 11/12/2013 26/11/2013. A evolução do evento é assinalada das cores mais frias para cores mais quentes. . . . . . . . . . . . . . . . . . 44

3.11 Precipitação acumulada (em mm/dia) durante o evento de ZCAS (de 11/12 a 26/12) obtida por estações do INMET. . . . . . . . . . . . . . . . . 50 50

3.12 Imagens do satélite GOES-13, realçadas, para as 00Z de todos os dias do evento, de 11/12/2013 a 26/11/2013. . . . . . . . . . . . . . . . .

3.13 Linhas de corrente e divergência de umidade em 850hPa. Campos médios para o evento $(11 / 12 / 2013-26 / 12 / 2013 \ldots \ldots \ldots \ldots$

3.14 Linhas de corrente e velocidade vertical em 500hPa. Campos médios para o evento $(11 / 12 / 2013-26 / 12 / 2013 \ldots \ldots \ldots \ldots \ldots$

3.15 Linhas de corrente e divergência de massa em 200hPa. Campos médios para o evento $(11 / 12 / 2013-26 / 12 / 2013 \ldots \ldots \ldots$

4.1 Ilustração do domínio utilizado nos experimentos numéricos e da topografia da região. . . . . . . . . . . . . . . . . . . . 63

4.2 Erro Médio Quadrático da energia cinética detodos os experimentos e sua condição de referência (CFSR - esquerda) e uma base da dados externa (ERA-Interim, direita) $\ldots \ldots \ldots \ldots \ldots$ 
4.3 Erro Médio Quadrático dos espectros espaciais de energia cinética para todos os experimentos calculados com relação a uma base de dados externa (ERAInterim - esq.) e sua referência (CFSR - dir.) . . . . . . . . . . . . . . .

4.4 Umidade específica e linhas de corrente em 850hPa. Campos médios dos dias que antecedem (painéis superiores) e sucedem (painéis inferiores) o evento de ZCAS (painéis centrais) . . . . . . . . . . . . . . . .

4.5 Mesma esqumatização da figura 4.4 porém para temperatura e algura geopotencial em 500hPa. . . . . . . . . . . . . . . . . .

4.6 Mesma esquematização da figura 4.4 porém para linhas de corrente e velocidade do vento em $200 \mathrm{hPa} \ldots \ldots \ldots \ldots$. . . . . . . . . . . .

4.7 Umidade específica e linhas de corrente em 850hPa. Campos médios entre os dias 11/12-15/12 (painéis superiores), 16/12-20/12 (painéis centrais) e 21/12-25/12 (painéis inferiores) . . . . . . . . . . . . .

4.8 Mesma esqumatização da figura 4.7, para temperatura e algura geopotencial em 500hPa. . . . . . . . . . . . . . . . . .

4.9 Mesma esqumatização da figura 4.7, para linhas de corrente e velocidade do vento em $200 \mathrm{hPa} \ldots \ldots \ldots \ldots \ldots \ldots \ldots$

4.10 Precipitação acumulada nos períodos anteriores (painéis superiores) e posteriores (painéis inferiores) do evento de ZCAS (painéis centrais) . . . . . 78

4.11 Precipitação acumulada entre os dias 11/12-15/12 (superiores), 16/12-20/12 (centrais) e 21/12-25/12 (inferiores) . . . . . . . . . . . . . .

5.1 Interação entre principais esquemas de parametrização presentes no modelo WRF. Figura extraída de Zittis et al. (2014) . . . . . . . . . . . . . .

5.2 Precipitação acumulada durante o evento de ZCAS e eixo de atuação. . . . 84

5.3 Precipitação acumulada durante o evento de ZCAS para todos os testes numéricos e o eixo de atuação correspondente ao posicionamento do TRMM. 85

5.4 Integral de precipitação acumulada no eixo de atuação da ZCAS. . . . . 86

5.5 Acumulado de chuva convectiva para os experimentos CTRL, WSM3 e MORR. 86

5.6 Acumulado de chuva convectiva para os experimentos CTRL, BMJ e G3D. 87

5.7 Acumulado de chuva em pontos de grade (microfísica) para os experimentos CTRL, WSM3 e MORR. . . . . . . . . . . . . . . 87 
5.8 Acumulado de chuva em pontos de grade (microfísica) para os experimentos CTRL, BMJ e G3D. . . . . . . . . . . . . . . . . . 8 87

6.1 Diagrama representando os diversos fatores que influenciam o sistema SMAS/ZCAS. Adaptado de Silva Dias (2015) e com destaque para as áreas de contribuição do presente trabalho. . . . . . . . . . . . . . . . . 91 


\section{Lista de Tabelas}

3.1 Intervalos referentes às pêntadas anteriores, simultâneas e posteriores ao

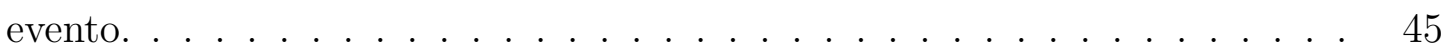

4.1 Parametrizações físicas utilizadas em todos os experimentos e suas principais

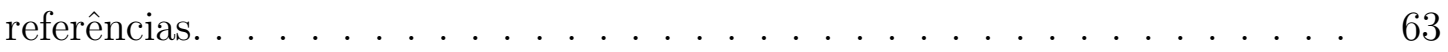

4.2 Principais características dos experimentos realizados para se determinar a sensibilidade do modelo. Nomenclatura para cada teste, números de onda em x $\left(W n_{x}\right)$ e y $\left(W n_{y}\right)$, e comprimentos associados a cada número de onda tanto em $\mathrm{x}\left(L_{x}\right)$ quanto em y $\left(L_{y}\right) \ldots \ldots \ldots \ldots$ 



\section{Sumário}

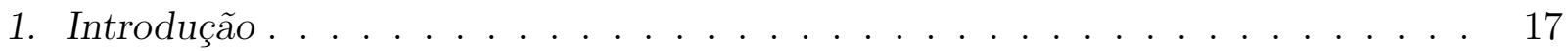

1.1 Objetivo Geral . . . . . . . . . . . . . . . . . . . . . . 21

1.2 Objetivos Específicos . . . . . . . . . . . . . . . . 21

2. Revisão Bibliográfica Sobre o Sistema de Monções da América do Sul (SMAS) e Zona de Convergência da América do Sul (ZCAS) . . . . . . . . . . . . . . . . . 23

2.1 Estrutura . . . . . . . . . . . . . . . . . . . . . 24

2.2 Ciclo de Vida . . . . . . . . . . . . . . . . . . . . . . . . . . . . . . . 27

2.3 Variabilidade . . . . . . . . . . . . . . . . . 32

3. Determinação e Descrição do Evento para Testes Numéricos . . . . . . . . . . . 35

3.1 Índices $\mathrm{LISAM} / \mathrm{SACZ} \ldots \ldots \ldots \ldots$

3.1 .1 Análise de EOF . . . . . . . . . . . . . . . 35

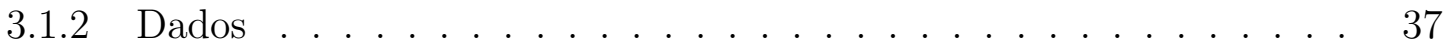

3.2 Descrição do Evento . . . . . . . . . . . . . . . . . . . . . 49

3.2.1 Aspectos de Larga Escala . . . . . . . . . . . . . . . . . 51

4. Experimentos Numéricos: Impactos na Aplicação de Relaxação Newtoniana . 57

4.1 Metodologia . . . . . . . . . . . . . . . . . . 59

4.1.1 Relaxação Newtoniana - Nudging . . . . . . . . . . . . . . 599

4.1 .2 Dados Utilizados . . . . . . . . . . . . . . . . . 61

4.1 .3 Modelo Numérico . . . . . . . . . . . . . . . . . . 62

4.1.4 Configuração dos Experimentos . . . . . . . . . . . . . . . . . 64

4.1.5 Avaliação dos Resultados . . . . . . . . . . . . . . . . 65 65 
4.2 Resultados . . . . . . . . . . . . . . . . . . . 67 67

5. Experimentos Numéricos: Impactos das Parametrizações de Cumulus e Microfísica 81

5.1 Configuração dos Experimentos . . . . . . . . . . . . . . 81

5.1.1 Parametrizações de Cumulus . . . . . . . . . . . . 81

5.1 .2 Parametrizações de Microfísica . . . . . . . . . . . . . 82

5.2 Resultados . . . . . . . . . . . . . . . . . . . . . . . 84

6. Conclusões . . . . . . . . . . . . . . . . . . . . . . 89

6.1 Conclusões Gerais . . . . . . . . . . . . . . . . . . 89

6.2 Sugestões para Trabalhos Futuros . . . . . . . . . . . . . . . . 91

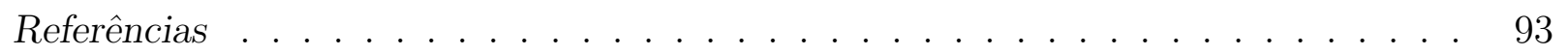


Capítulo 1

\section{Introdução}

Um sistema de monção é tipicamente caracterizado pela reversão na direção dos ventos em baixos níveis entre as estações de verão e inverno (Ramage, 1971), além de uma clara distinção entre estações chuvosas, durante meses de verão, e secas, nos meses de inverno (Webster et al., 1998). Tais mudanças na circulação em baixos níveis são induzidas pelo contraste térmico entre regiões oceânicas e continentais, caracterizando uma brisa de proporções continentais (Nogués-Paegle e Mo, 1997). Os sistemas de monção regionais são conduzidos e sincronizados pela variação anual de radiação solar incidente e, de acordo com Trenberth et al. (2000), estão conectados por uma circulação global divergente. Tendo em vista os princípios de conservação de massa, umidade e energia e como esses princípios se aplicam na atmosfera global, a análise da variabilidade dos sistemas de monção regionais sob uma perspectiva global é fundamental para a compreensão de sua dinâmica. Essa relação motivou estudos recentes na descrição de um sistema de monções global, como Wang e Ding (2006, 2008), que propuseram um critério para delimitar regiões com padrões de precipitação associados a sistemas de monções ao redor do globo. Sua proposta leva em consideração o contraste entre o volume de chuvas durante os meses de verão e inverno, uma das características fundamentais dos sistemas de monção (Webster et al., 1998). Seus resultados estão sumarizados na figura 1.1, extraída de Wang et al. (2011), que ilustra as regiões com maiores diferenças entre regimes pluviométricos de verão e inverno, com uma diferença de, ao menos, $2 \mathrm{~mm} /$ dia entre DJF e JJA, além de $70 \%$ da precipitação média anual concentrada nos meses de verão. Seus resultados apontam para sete regiões que com padrões de precipitação associados a um sistema de monção: Sul da Ásia (Webster et al., 1998), Leste da Ásia (Yihui e Chan, 2005), Austrália (Davidson et al., 1983), norte e sul do continente africano (Hastenrath et al., 1995), México e sudeste norte-americano 
(Higgins et al., 1997) e América do Sul (Zhou e Lau, 1998). Em todos os casos, a região delimitada incorpora parte do oceano adjacente. Uma exceção encontra-se na zona central do Pacífico Sul subtropical, onde uma região oceânica apresenta tais características e, devido à ausência de contraste continente-oceano, não é considerada um sistema de monção regional pelos autores.

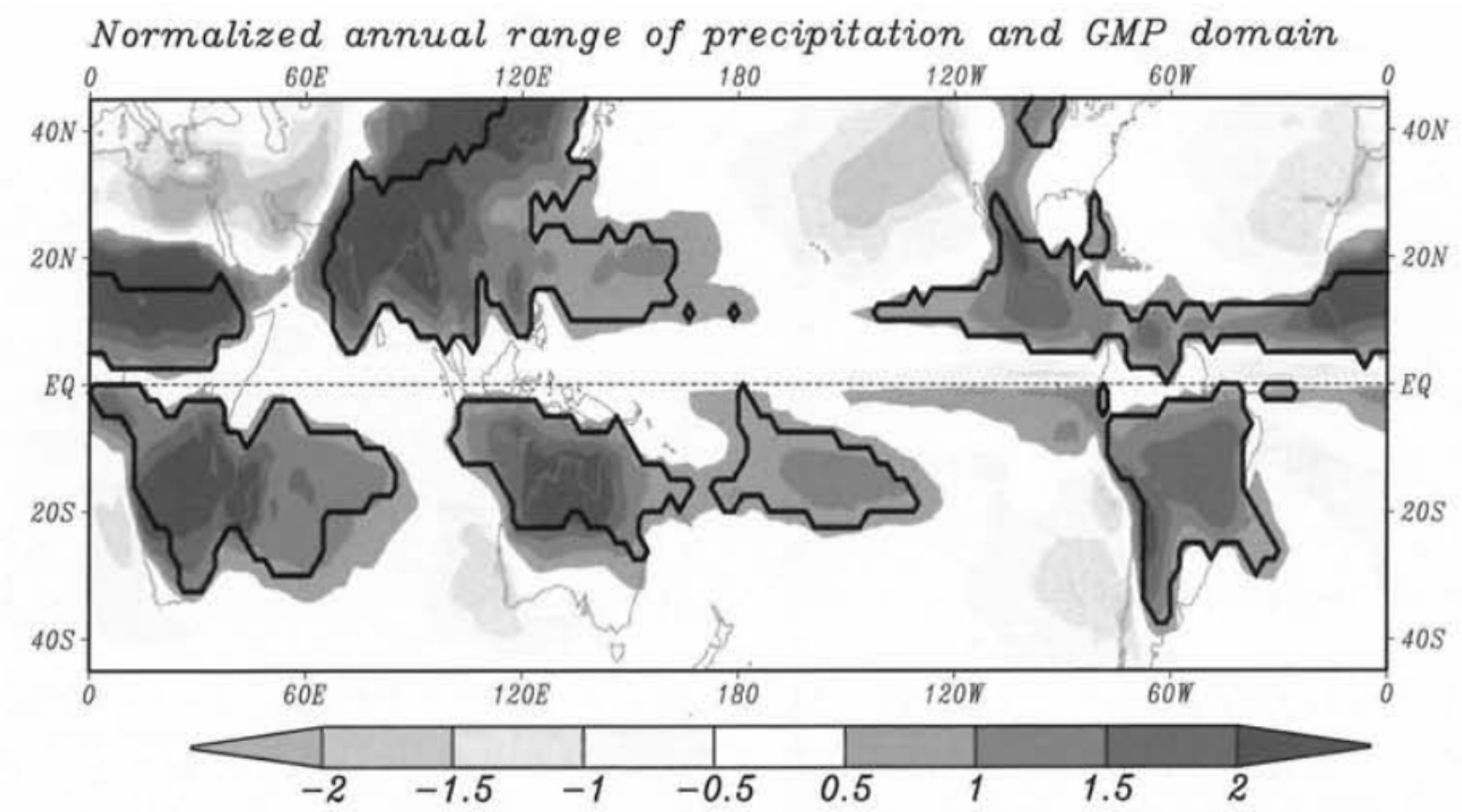

Figura 1.1: Sombreado: distribuição espacial da diferença entre a precipitação acumulada durante os meses de verão (Dezembro-Janeiro-Fevereiro no Hemisfério Sul e Junho-JulhoAgosto no Hemisfério Norte) e inverno (Junho-Julho-Agosto no Hemisfério Sul e DezembroJaneiro-Fevereiro no Hemisfério Norte). Linhas: delimitação de sistemas de monção regionais dada pelas diferenças de precipitação sazonais. Figura extraída de Wang, Ding e Liu (2011)

Esses estudos indicam que os sistemas regionais estão vinculados a um contexto dinâmico global e sua complexa variabilidade está associada a interações tanto locais quanto nãolocais. E, muito embora sistemas monçônicos regionais apresentem características estruturais comuns a um sistema de monções canônico, podem ser observadas algumas feições diferenciadas. O Sistema de Monções da América do Sul (SMAS) difere das demais monções regionais por não apresentar uma inversão direta dos ventos em superfície, uma vez que ventos de leste predominam ao longo de todo o ano sobre a América do Sul e Oceano Atlântico Tropical. O trabalho de Vulquin (1971) foi um dos precursores em oferecer argumentos para a existência de um sistema monçônico na América do Sul. Através da análise de mapas de vento em 900 metros de altura e isotermas de temperatura do bulbo úmido e 
do ponto de orvalho, são apresentadas evidências de "situações de monção", com fluxos de umidade cruzando o Equador em direção à Bacia Amazônica e atuação de nuvens do tipo cumulus sobre a região do Brasil central, predominantes durante os meses de verão. Além desse trabalho, caracterização do SMAS como um sistema de monções também foi feita por Zhou e Lau (1998) ao demonstrarem que, com a remoção da média anual da circulação superficial média de verão e inverno, há uma evidente reversão na direção das anomalias, semelhante àquelas apresentadas em outros sistemas de monção. Essa caracterização sazonal é ilustrada na figura 1.2 , construída a partir das componentes do vento em $850 \mathrm{hPa}$ do Climate Forecast System Reanalysis [CFSR - Saha et al. (2011)], e da precipitação diária do Tropical Rainfall Measuring Mission [TRMM - Huffman et al. (2007)]. Esses mapas ilustram as médias de precipitação e anomalias das componentes do vento, obtidas através da remoção da média anual baseada em uma climatologia de 1979 a 2015, para os meses de verão (DJF - esquerda) e inverno (JJA - direita).

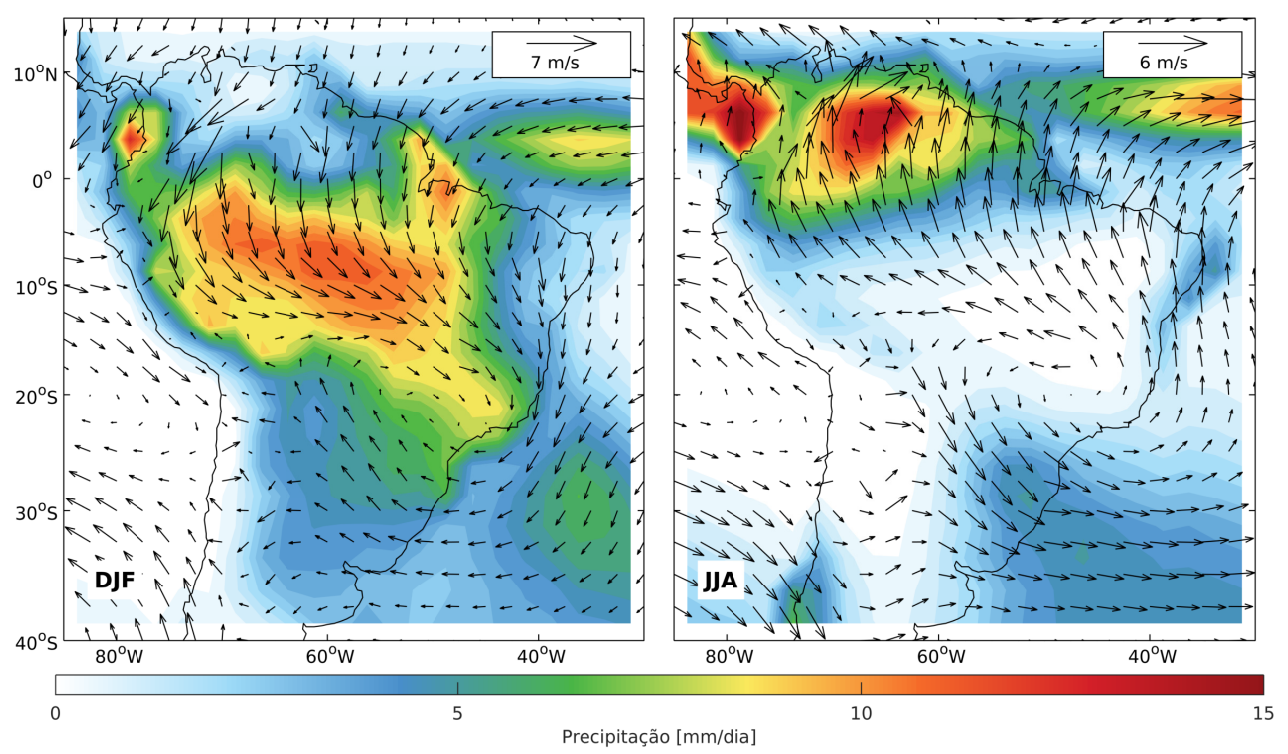

Figura 1.2: Médias de precipitação [TRMM - Huffman et al. (2007)] e anomalias de vento em $850 \mathrm{hPa}$ [CFSR - Saha et al. (2011)] para os meses de verão (DJF - esquerda) e inverno (JJA - direita).

Os campos de precipitação também evidenciam as acentuadas diferenças entre os regimes de verão e inverno. Já a figura 1.3 , composta por campos de precipitação média do TRMM e por linhas de corrente médias do CFSR em 200hPa, aponta para uma estrutura típica que conta com o anticiclone na alta troposfera localizado aproximadamente sobre a região da Bolívia (Alta da Bolívia - AB) e a persistência de um cavado em altos níveis na 
região nordeste do Brasil (Silva Dias et al., 1983). Além disso, em baixos níveis, é notável a intensificação de um centro de baixa pressão termicamente induzido, denominado "baixa do Chaco" (Gandu e Silva Dias, 1998). Além disso, o SMAS se desenvolve sob a influência da atuação do jato de baixos níveis (Marengo et al., 2004) a leste da Cordilheira dos Andes e a Zona de Convergência da América do Sul - ZCAS - (Kodama, 1992). A ZCAS é caracterizada pela extensão da banda de precipitação com orientação noroeste-sudeste (NW-SW) durante a estação chuvosa na América do Sul (Kodama, 1992, 1993) e trata-se de um dos componentes mais importantes do SMAS, resultante da convergência dos ventos em baixos níveis acompanhada do transporte de umidade da região da bacia amazônica até o Oceano Atlântico Subtropical.

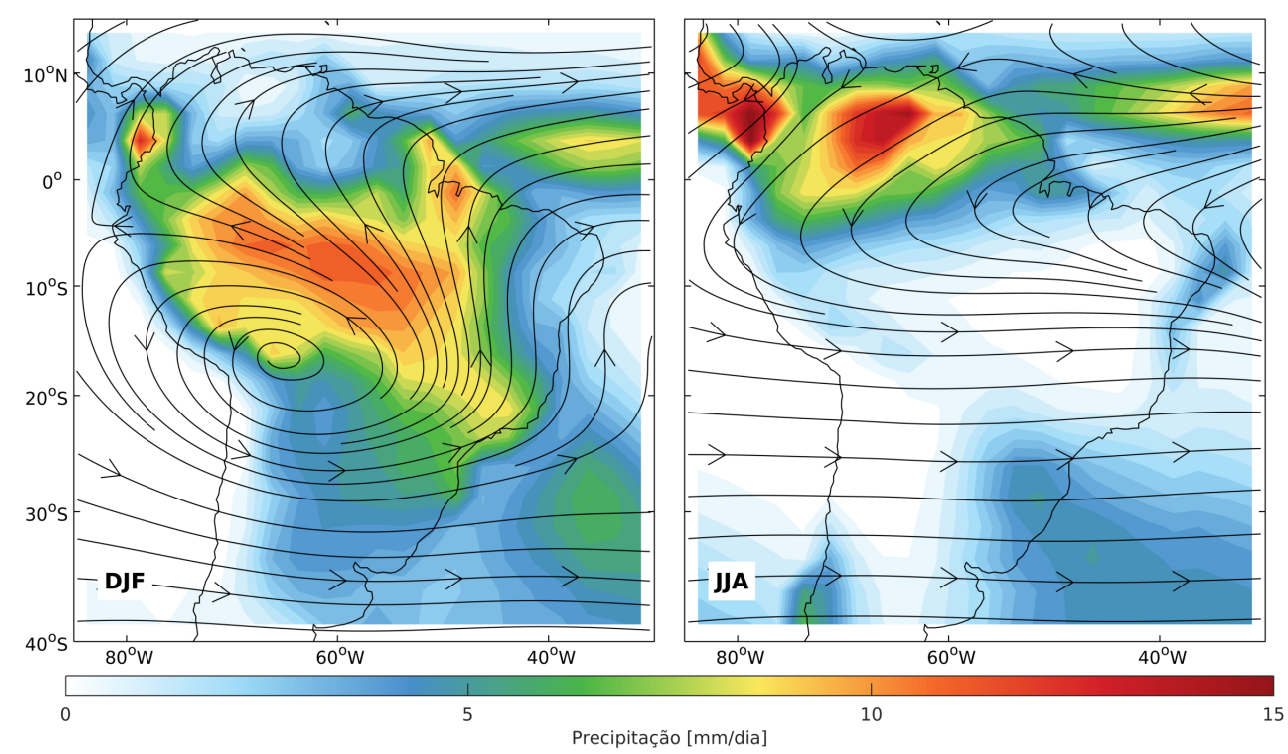

Figura 1.3: Médias de precipitação [TRMM - Huffman et al. (2007)] e linhas de corrente [CFSR - Saha et al. (2011)] em 200hPa para os meses de verão (DJF - esquerda) e inverno (JJA - direita)

É um sistema extremamente complexo cujo desenvolvimento é influenciado por fenômenos locais e não-locais em diversas escalas espaço-temporais. Isso torna a sua previsibilidade particularmente desafiadora e abordagens numéricas regionais devem levar em conta a estrutura em que o sistema se encontra e a avaliação de sua representação por modelos numéricos deve ser avaliada continuamente. A verificação de resultados com modelos numéricos se torna ainda mais importante uma vez que a ZCAS atua diretamente sobre uma das regiões mais densamente populadas da América do Sul. Portanto, inferências sobre seu posicionamento, sua intensidade e sua duração são fundamentais para previsões 
sazonais e subsazonais que adequadamente satisfaçam as necessidades dos setores de planejamento socioeconômicos e ambientais.

\subsection{Objetivo Geral}

Com os esforços investidos neste estudo, pode-se afirmar que o objetivo geral é contribuir efetivamente com o conhecimento dos mecanismos de formação e manutenção da ZCAS, tanto referentes a processos de origem local quanto de origem remota. Para alcançar esta meta, foi proposta uma análise observacional para identificar situações de interesse e selecionar um caso específico de ZCAS que fosse particularmente longo e intenso e que apresentasse características adequadas em sua estrutura para a realização de uma etapa com modelo numérico regional da atmosfera configurado para uma aplicação sub-sazonal.

\subsection{Objetivos Específicos}

1. Através da aplicação do índice para a determinação sistema SMAS/ZCAS, proposto por da Silva e de Carvalho (2007) e Carvalho et al. (2010), selecionar um caso de ocorrência de ZCAS com grande intensidade, duração e com menor influência de feições em escala intrasazonal e interanual;

2. Avaliar como o processo de relaxação newtoniana (do termo em inglês, nudging) impacta resultados com o modelo numérico WRF em uma aplicação para esse caso de ZCAS, e discutir como esse procedimento pode garantir que a estrutura de larga escala que ancora o sistema seja devidamente representada sem interferências no desempenho do modelo em escalas menores;

3. Avaliar como diferentes parametrizações de microfísica e cumulus impactam a geração de precipitação associada esse sistema ao longo do eixo central da ZCAS.

Os próximos capítulos estão dispostos da seguinte maneira: (2) oferece uma revisão bibliográfica a respeito do SMAS e da ZCAS a fim de expor a sua estrutura e variabilidade, além dos desafios que a complexidade desse sistema propõe a experimentos numéricos; (3) demonstra as etapas para a determinação de um evento particularmente intenso para avaliação numérica através da aplicação do índice Large-scale Index for the South American Monsoon (LISAM); (4) apresenta os passos para o desenvolvimento dos experimentos 
numéricos com o modelo Weather Research and Forecasting System (WRF), desde a descrição do fenômeno pelas condições iniciais e de fronteira, até a avaliação de diferentes aplicações de relaxação (nudging) e como cada aplicação reflete no comportamento interno do modelo; (5) oferece uma avaliação do desempenho do modelo e de como diferentes parametrizações de processos físicos disponíveis no modelo WRF representaram a distribuição da precipitação ao longo do eixo da ZCAS; (6) por fim, apresenta as conclusões gerais do trabalho e sugestões para estudos futuros. É importante salientar que o conteúdo desta tese contempla todas as etapas tradicionais de introdução, metodologia, resultados e discussão, porém subdivididas não exatamente desta maneira. A subdivisão utilizada busca alcançar uma melhor fluidez do texto, de modo a manter relativamente próximo cada resultado obtido com cada metodologia. Desta forma, espera-se que o leitor acompanhe com maior facilidade a apresentação dos argumentos que fundamentam a linha de raciocínio que conduziu esta pesquisa, bem como a elaboração deste documento. 
Capítulo 2

\section{Revisão Bibliográfica Sobre o Sistema de Monções da América do Sul (SMAS) e Zona de Convergência da} América do Sul (ZCAS)

A noção de transição entre estações com características distintas já era abordada nos estudos de de Figueiredo Monteiro (1971) através de uma análise rítmica em climatologia, proposta através da observação de séries temporais de precipitação e componentes do vento obtidas por estações em superfície. No entanto, o diagnóstico da presença de um sistema monçônico na América do Sul foi formalmente proposto por Zhou e Lau (1998). Segundo os autores, muito embora os ventos em superfície sobre essa a região tropical sejam predominantemente de leste ao longo de todo o ano, a remoção da média anual dos campos de verão (DJF) e inverno (JJA) evidencia uma reversão na circulação induzida pelo contraste térmico entre continente-oceano. Essa característica, aliada à presença de outras estruturas típicas a esse sistema, indicam a presença de um Sistema de Monções na América do Sul (SMAS). Descrições detalhadas do SMAS podem ser encontradas nos trabalhos de Vera et al. (2006) e nos esforços de revisão oferecidos por Marengo et al. (2010) e Silva e Kousky (2012). E, sua grande influência no clima regional e complexa variabilidade em várias escalas espaço-temporais, motivou o desenvolvimento de programas internacionais, tais como o Monsoon Experiment in South America (MESA, www.clivar.org/vamos) para o desenvolvimento de estudos observacionais e de modelagem numérica sobre o sistema. 


\subsection{Estrutura}

As principais estruturas presentes no SMAS são sumarizadas na figura 2.1, extraída de Zhou e Lau (1998). Nota-se a presença de um fluxo de baixos níveis (figura 2.1, item 1), desde o noroeste do continente africano até a região da baixa térmica do Chaco (figura 2.1. item 3) descrita em Gandu e Silva Dias (1998), fluxo que desvia do padrão de leste dos ventos alíseos esquematizados pelas linhas tracejadas e acompanha a região da Cordilheira dos Andes (figura 2.1, item 2), abordado em Marengo et al. (2004). Os autores apontam também a presença da Zona de Convergência do Atlântico Sul (figura 2.1, item 5) gerada pelo encontro entre o ramo norte da Alta Subtropical do Atântico Sul (figura 2.1, item 4) e ventos de oeste/sudoeste oriundos de latitudes médias (figura 2.1, item 6) e extensamente abordada por Casarin e Kousky (1986); Kodama (1992, 1993). Como citado no capítulo 1 e ilustrado através da figura 1.3, em altos níveis é evidente a formação de um anticiclone sobre a região da Bolívia (figura 2.1, item 7) e um cavado na região nordeste do Brasil (Silva Dias et al. (1983); Lenters e Cook (1997)) ligados a um fluxo que cruza o equador em uma direção contrária ao fluxo de superfície. Tal padrão espacial é encontrado em outros sistemas de monções regionais. Figueroa et al. (1995) também apontam para o papel desempenhado pela Cordilheira dos Andes no desenvolvimento do SMAS e da formação da ZCAS. Muito embora a fonte de calor latente da região amazônica seja fundamental para a geração da ZCAS, a presença da cordilheira é essencialmente importante para a determinação de seu posicionamento. 


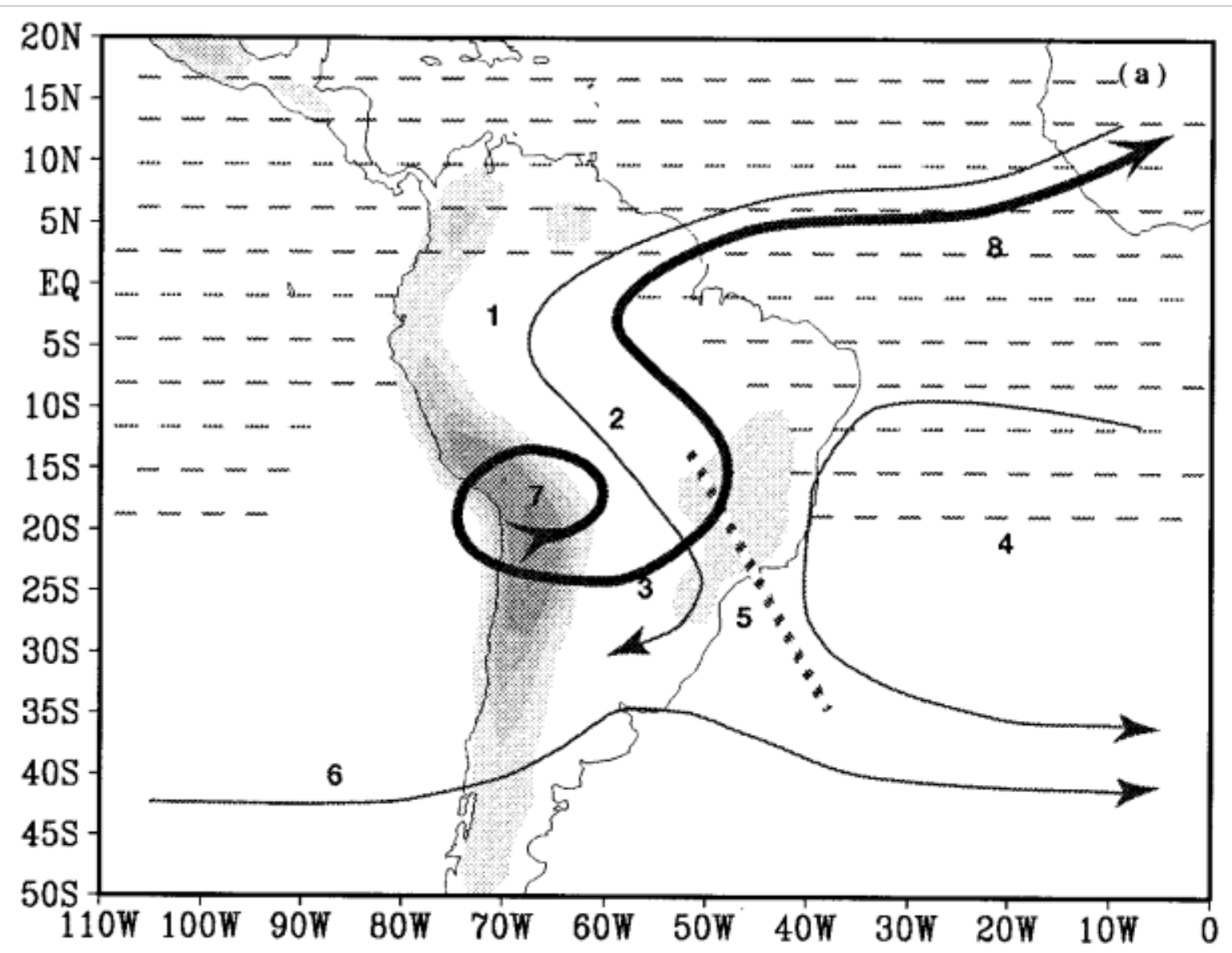

Figura 2.1: Esquematização das principais estruturas associadas ao SMAS em altos e baixos níveis. Extraída de Zhou e Lau (1998).

A esquematização de um corte com orientação SW-NE encontra-se na figura 2.2. Essa imagem, extraída de Vera et al. (2006), apresenta a disposição vertical das estruturas descritas anteriormente e oferece uma visão geral de como suas principais componentes de larga escala interagem. 


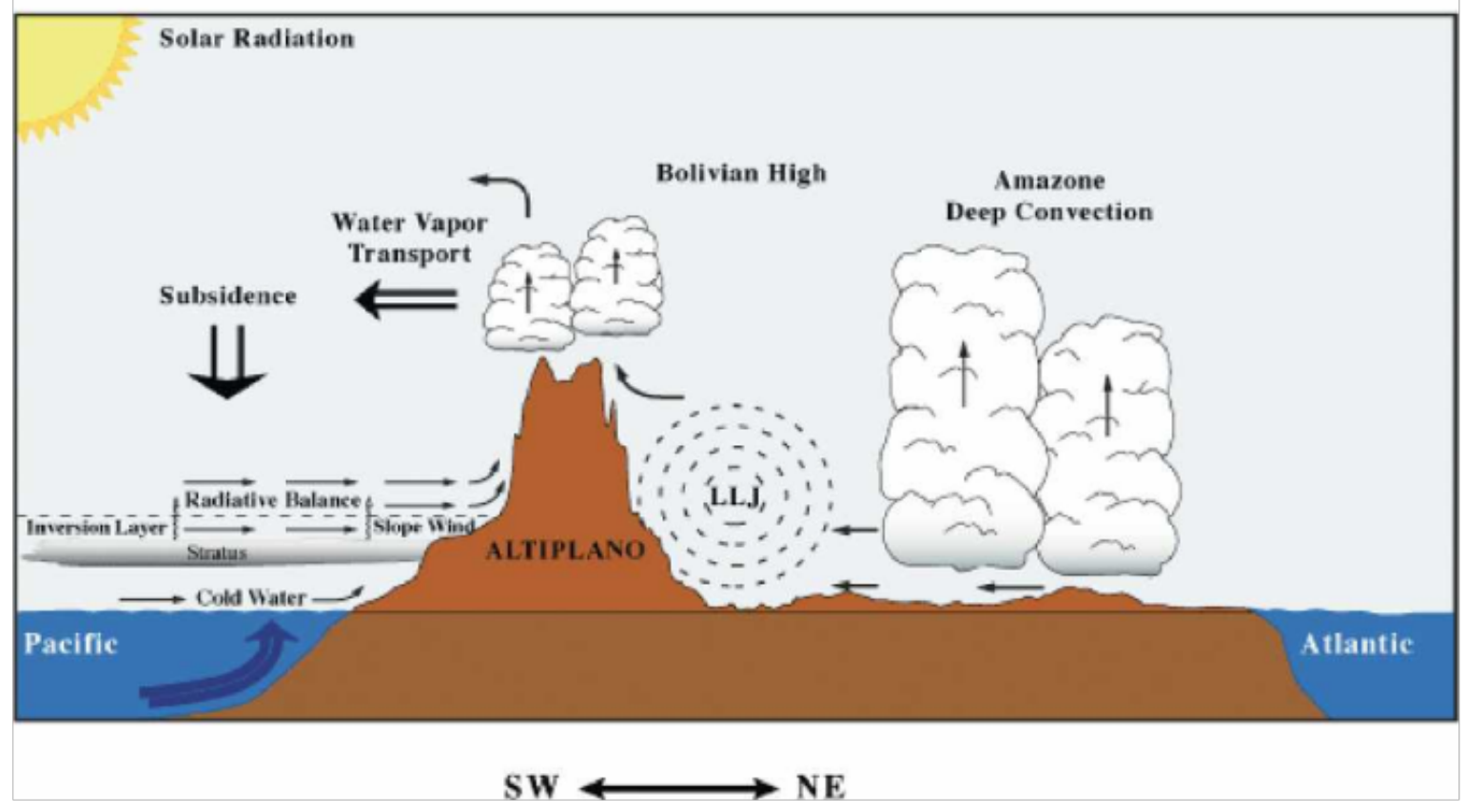

Figura 2.2: Esquematização das principais estruturas associadas ao SMAS em um corte na orientação SW-NE. Extraída de Vera et al. (2006).

Esses esquemas remetem a uma circulação divergente em altos níveis e convergente em baixos níveis sumarizada na figura 2.3, extraída de Gan et al. (2004). O corte vertical do vento zonal na região centro-oeste do Brasil apresenta um regime de ventos zonais em baixos níveis predominantemente de oeste entre outubro e abril, durante a estação chuvosa. Ao passo que o inverso é constatado para a estação seca. Essa é uma outra maneira de se representar a reversão dos ventos característica de sistemas de monção, uma vez que o cisalhamento vertical é revertido entre as estações. 


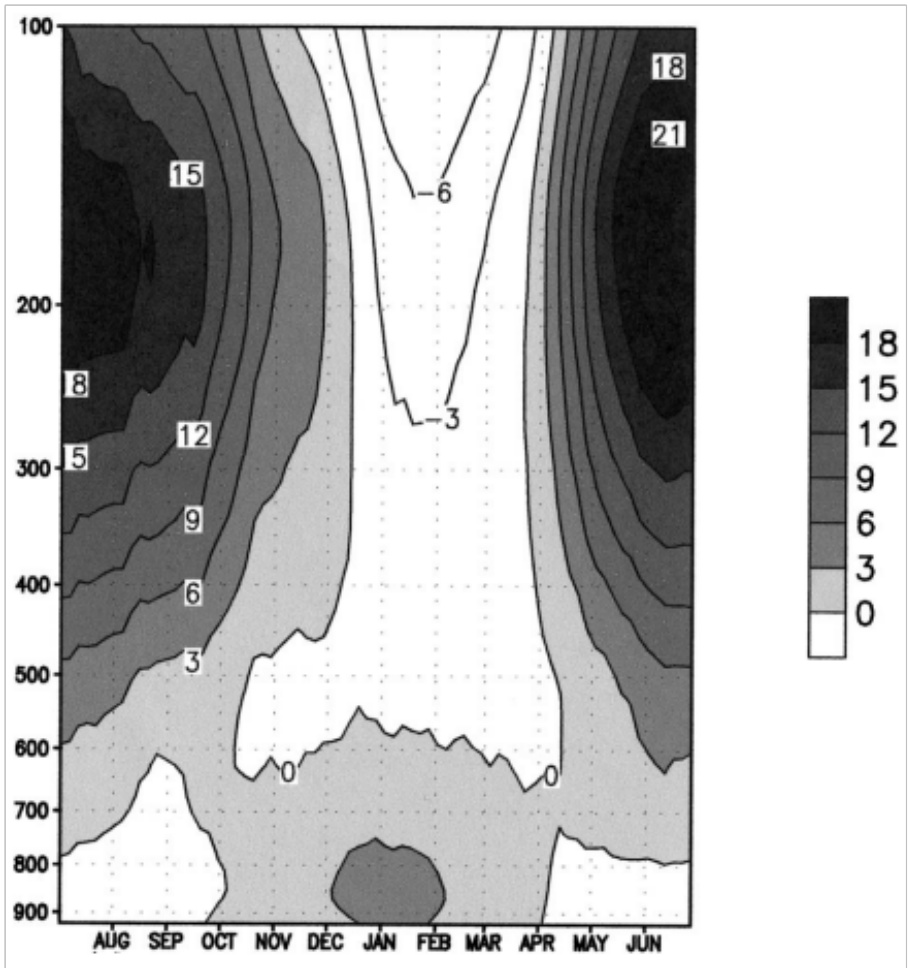

Figura 2.3: Corte vertical do vento zonal na região centro-oeste do Brasil. Extraída de Gan et al. (2004).

\subsection{Ciclo de Vida}

O ciclo de vida do SMAS foi investigado em diversos trabalhos com diferentes conjuntos de dados e metodologias. A principal meta desses trabalhos foi determinar o estabelecimento do sistema (onset), sua duração e seu enfraquecimento (demise). Dado que trabalhos distintos utilizaram metodologias e/ou dados diferentes para a determinação dessas características, é comum que discrepâncias sejam encontradas entre seus resultados. Por exemplo, os primeiros estudos a respeito do tema utilizaram dados de Radiação de Onda Longa Emitida (ROLE) como um indicador para a precipitação (Kousky, 1988; Horel et al., 1989), sendo os valores para estabelecimento e enfraquecimento variáveis de acordo com o limiar escolhido para valores de ROLE. Liebmann e Marengo (2001) propuseram uma metodologia para se determinar características da evolução do SMAS através da variabilidade temporal dos valores acumulados diários de anomalias de precipitação entre duas estações secas. De acordo com seus resultados, uma estação chuvosa é iniciada quando os incrementos se tornam positivos e é finalizada quando se tornam negativos. Essas datas 
podem variar em alguns dias, de acordo com o critério utilizado. Bombardi e Carvalho (2011) utilizaram o mesmo método com uma aplicação para dados pentadais de estimativas de precipitação do Global Precipitation Climatology Project [GPCP - Adler et al. (2003); Huffman et al. (2009)] e determinaram ocorrências do início da estação chuvosa em meados de outubro e início de novembro para a região centro-leste do Brasil. Além disso, outras metodologias foram desenvolvidas para a descrição em larga escala do ciclo de vida do SMAS. Gan et al. (2004) oferecem a definição de início para a estação chuvosa quando valores de precipitação se encontram acima (abaixo) de $4 \mathrm{~mm} /$ dia por até $75 \%$ das pêntadas subsequentes e quando há a primeira ocorrência de ventos em $850 \mathrm{hPa}$ de oeste (leste) em $60^{\circ} \mathrm{W}$ entre as latitudes $10-20^{\circ} \mathrm{S}$. Outra proposta, feita por Gan et al. (2006), aponta para quatro índices para a determinação do início, final e para a variabilidade intrasazonal da monção sobre a região centro-oeste do Brasil. Esses índices foram calculados a partir de valores de circulação em baixos níveis $(850 \mathrm{hPa})$. Os autores sugerem que tais índices, baseados em valores de circulação, são mais eficientes na determinação dessas características evolutivas do SMAS em comparação com outros índices baseados em dados de precipitação. Um método proposto por da Silva e de Carvalho (2007) e detalhado por Carvalho et al. (2010) foi proposto utilizando-se múltiplas variáveis que caracterizam o ciclo de vida do SMAS. Esse índice, denominado Large-scale Index for South American Monsoon (LISAM), é construído através de uma análise de funções orgonais empíricas (Empirical Orthogonal Functions - EOF) das anomalias precipitação, umidade específica, temperatura e circulação em baixos níveis. A série temporal que acompanha o primeiro modo resultante da análise de EOF é contínuo no tempo e exibe variações em uma grande amplitude de escalas, desde a sinótica à escalas multianuais. Além disso, Raia e Cavalcanti (2008) demonstram a aplicação de critérios diferentes baseados no fluxo de umidade da atmosfera em uma região mais intensa do SMAS, onde ventos zonais são revertidos e a umidade exibe variabilidade sazonal pronunciada. Seus resultados são comparáveis com os descritos em da Silva e de Carvalho (2007) e Gan et al. (2004). Muito embora as metodologias supracitadas sejam diferentes entre si, há um consenso geral que indica o estabelecimento da estação chuvosa entre meados de outubro e novembro. O auge da prepitação associada ao SMAS ocorre entre os meses de dezembro e fevereiro e o enfraquecimento do sistema ocorre entre março e abril. A evolução mensal dos campos de precipitação e circulação em altos e baixos níveis são apresentadas nas figuras 2.4 e 2.5. respectivamente. Tais figuras 
foram desenvolvidas a partir de médias mensais dos campos de precipitação estimados pelos satélites do projeto TRMM e das componentes zonal e meridional do vento do projeto de reanálise CFSR. É notável, através da análise dos padrões espaciais de precipitação, uma excursão de noroeste para sudeste durante o desenvolvimento do SMAS. Durante os meses de verão no hemisfério sul (DJF) há uma grande distribuição das chuvas na região de atuação do SMAS acompanhada de uma projeção na direção NW-SE vinculada à formação da ZCAS, ao passo que na região equatorial os máximos de precipitação ocorrem nos meses seguintes. A região equatorial da bacia amazônica exibe um predomínio de núcleos de precipitação intensos ao longo de todo o ano. Contrastes entre as chuvas de verão e inverno são proeminentes principalmente na região central e leste da Amazônia. Os campos de ventos em baixos níveis exibem o predomínio de ventos do quadrante leste ao longo de todo o ano e, em altos níveis, a estrutura de larga escala associada ao SMAS encontra-se presente entre os meses de novembro e março, com maior robustez em sua estrutura, tanto no posicionamento da Alta da Bolívia quanto do Cavado do Nordeste, durante os meses de verão. 

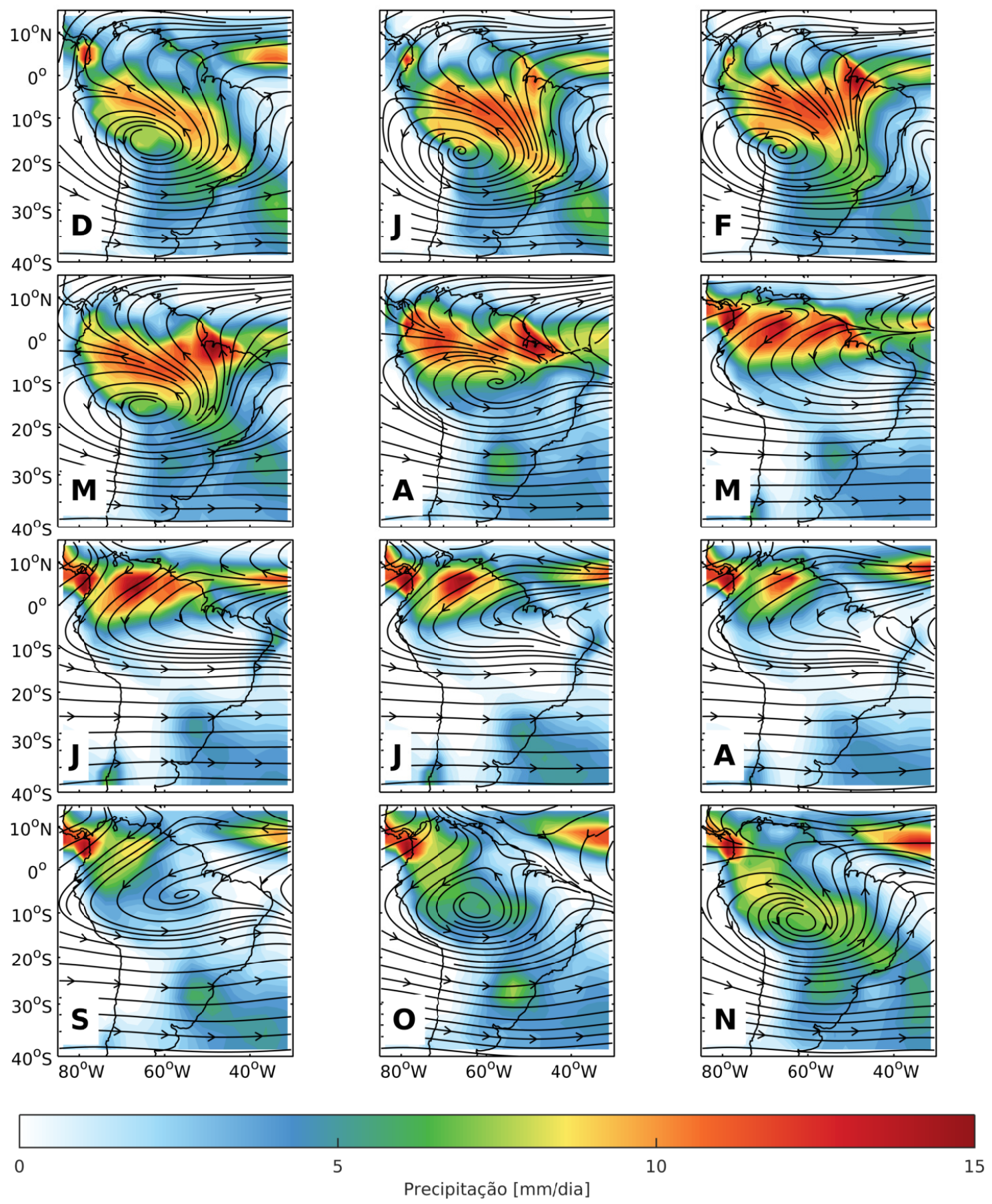

Figura 2.4: Médias mensais de precipitação e linhas de corrente em 200hPa calculadas a partir de dados do TRMM e CFSR 

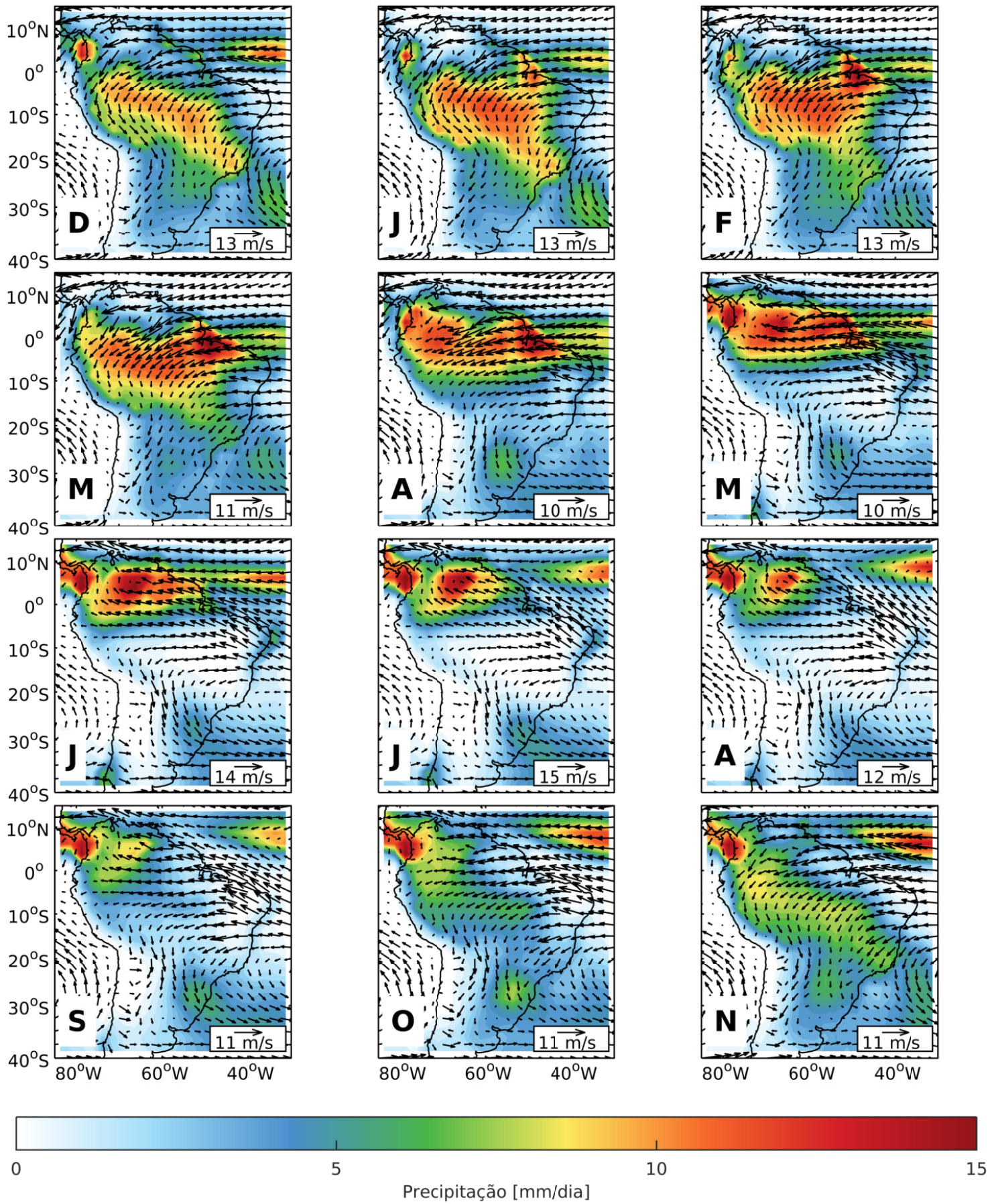

Figura 2.5: Médias mensais de precipitação e componentes do vento em $850 \mathrm{hPa}$ calculadas a partir de dados do TRMM e CFSR 


\subsection{Variabilidade}

O SMAS/ZCAS possui uma ampla variabilidade em escalas espaciais e temporais, dadas as complexidades de suas interações com outras feições. Seu desenvolvimento pode ser influenciado por variabilidade nas escalas diurna, de mesoescala, sinótica e decadal. Muito embora distúrbios sinóticos sejam mais frequentes durante os meses de inverno, há registros de sua ocorrência durante o verão e de sua influência no sistema de monções (Seluchi e Marengo, 2000). Siqueira e Machado (2004) apresentaram a influência de sistemas frontais na organização da precipitação associada ao sistema SMAS/ZCAS. Em muitos casos, nota-se o desenvolvimento de feições de mesoescala embebidos no sistema SMAS/ZCAS que, por sua vez, podem influenciar diretamente o jato de baixos níveis, responsável pelo transporte de umidade da região da bacia amazônica até os subtrópicos (Stensrud, 1996). Também podem se formar vórtices ciclônicos de mesoescala no interior da área de atuação do SMAS/ZCAS. Essas feições, abordadas por Quadro (2012); de Quadro et al. (2016), atuam em um sistema de retroalimentação em meio à precipitação estratiforme da ZCAS, ganhando umidade em seu desenvolvimento e acarretando em uma aceleração dos ventos. Assim como em outros sistemas de monção, o SMAS apresenta fases ativas (inativas) que contam com o favorecimento (supressão) de precipitação em sua região de atuação. Essas mudanças de fase alteram padrões de transporte de umidade e circulação em baixos níveis (Carvalho, 2002; Herdies et al., 2002; Jones e Carvalho, 2002) e podem contribuir através de oscilações na banda intrasazonal, entre 20-100 dias. Ferraz (2004) verificou o comportamento dos modos de variabilidade na escala intrasazonal durante os meses de verão na América do Sul. Seus resultados apontam para um centro de intensa atividade na região central do Brasil, com a presença da ZCAS na borda sul desse núcleo e uma região com fraca atividade na região subtropical da América do Sul, caracterizando-se uma feição com do tipo dipolo. Esse resultado corrobora com as contribuições de Casarin e Kousky (1986); Nogués-Paegle e Mo (1997); Nogués-Paegle et al. (2000) e o modo atua em todas as escalas na banda intrasazonal. Os estudos de Grimm e Silva Dias (1995a); Grimm e Ambrizzi (2009) sugerem que padrões em escala intrasazonal associados ao sistema SMAS/ZCAS podem ser influenciados por teleconexões propagando-se da região do Pacífico. Grimm e Silva Dias (1995a) indicam não somente uma influência remota através de distúrbios oriundos do Oceano Pacífico, mas também para a influência regional de um 
cavado em altos níveis sobre a zona de atuação da ZCAS. Além disso, padrões associados à Oscilação de Madden-Julian [OMJ - Madden e Julian (1994)] podem ser responsáveis pela persistência de intensos casos de ZCAS (Carvalho et al., 2004). Tendo em vista que muitos modelos numéricos não representam adequadamente as oscilações em escala intrasazonal, as transições entre fases da OMJ podem influenciar a destreza de modelos numéricos regionais em representar feições associadas ao sistema SMAS/ZCAS para simulações de médio e longo período (Jones e Schemm, 2000). Ferraz et al. (2013) realizaram um estudo numérico com o modelo BRAMS para o diagnóstico da precipitação sobre a região sul do Brasil e evidenciaram a dificuldade do modelo em representar adequadamente a variabilidade intrasazonal do regime de chuvas, o que implica diretamente a estrutura da ZCAS. Outros estudos numéricos foram realizados através da integração de modelos atmosféricos de circulação global. Os trabalhos de Cavalcanti et al. (2002); Liebmann et al. (2007); Kitoh et al. (2011) demonstraram que MCGs apresentam viés recorrente sobre a região da América do Sul e, com isso, seus resultados subestimam a precipitação sobre a região Amazônica e superestimam as chuvas em outras áreas de atuação da ZCAS. Os resultados desses experimentos foram baseados em testes com que utilizaram temperatura da superfície do mar fixas nas condições iniciais e de fronteira e, portanto, não são capazes de representar as interações entre o sistema e o oceano adjacente. Chaves (2004); Jorgetti (2009) demonstraram, através de estudos numéricos, que a nebulosidade gerada pela ZCAS reduz as anomalias de TSM regionais, atuando em um processo de retroalimentação negativa.

Um dos principais estudos abordando a variabilidade decadal do sistema SMAS/ZCAS foi realizado por Carvalho et al. (2011). Nesse trabalho, o ciclo de vida do SMAS (início, decaimento e duração) é investigado através de longas séries temporais (1948-2008) e seus resultados indicam mudanças significativas nas características do SMAS a partir da década de 70 devido a um aumento expressivo no fluxo de umidade verticalmente integrado sobre a região da América do Sul.

Todas as características levantadas apontam para um alto grau de complexidade para o sistema SMAS/ZCAS, dado o amplo alcance de sua variabilidade espaço-temporal. A interação com atividades convectivas em regiões remotas, através de oscilações na escala intrasazonal, pode não ser representada adequadamente por simulações sub-sazonais e a previsibilidade de sistemas de longa duração deve ser aprimorada. O diagrama apresentado 
na figura 2.6 e adaptado de Silva Dias (2015), apresenta os principais controles da dinâmica em maior escala que interage com o sistema SMAS/ZCAS. Efeitos locais, representados pela cobertura, umidade e tipo de solo podem interferir diretamente no particionamento de energia entre calor latente e sensível. A topografia pode afetar a estrutura de vórtices embebidos na ZCAS. Além disso, a presença de aerosóis pode alterar o desenvolvimento da convecção, principalmente no início e ao final, de eventos de ZCAS. Alguns estudos apontam para interações entre o ciclo diurno e frequências mais baixas. E, pelos trabalhos de Raupp e Silva Dias (2009), sabe-se que a interação entre oscilações não lineares pode provocar alterações nas teleconexões globais. Todos esse fatores exercem forte influência sobre modelos numéricos em simulações mais longas.

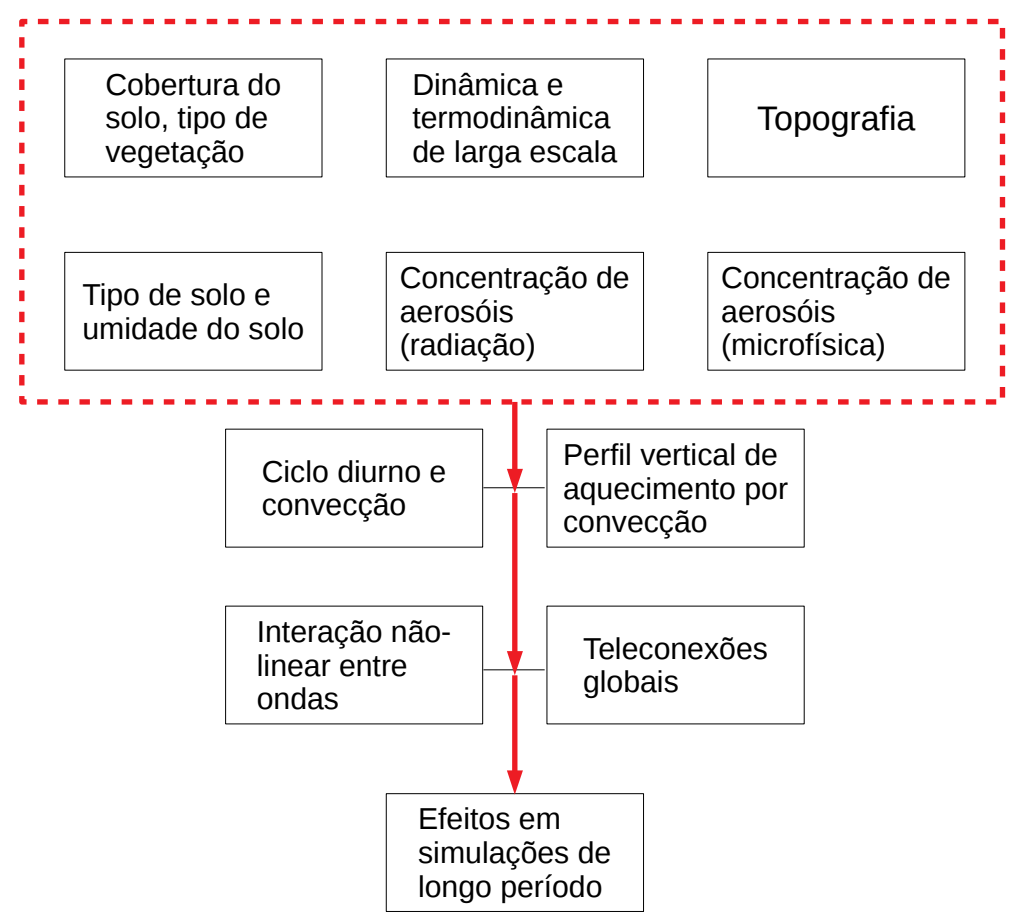

Figura 2.6: Diagrama representando os diversos fatores que influenciam o sistema SMAS/ZCAS. Adaptado de Silva Dias (2015) 
Capítulo 3

\section{Determinação e Descrição do Evento para Testes Numéricos}

Para a determinação de um evento de ZCAS formado durante a estação chuvosa e com grande intensidade e duração, os resultados de uma aplicação com o LISAM da Silva e de Carvalho, 2007; Carvalho et al. 2010) foram analisados. Em seguida, as séries temporais associadas aos modos de variabilidade resultantes da análise de EOF foram analisadas no domínio da frequência, através do espectro de potência das séries, e o caso determinado foi detalhadamente descrito.

\section{1 Índices LISAM/SACZ}

\subsubsection{Análise de EOF}

Em meteorologia, uma análise de EOF é usualmente utilizada para a obtenção de modos espaciais, ou padrões, que demonstrem a variabilidade do sistema representado pelas variáveis analisadas e como esses padrões se alternam com o tempo Monahan et al., 2009). Em estudos estatísticos, esse procedimento também pode ser denominado Análise de Componentes Principais (do inglês, Principal Components Analysis - PCA) e tal método é comumente classificado como uma análise estatística multivariada, muito embora não seja estabelecida uma hipótese baseada em distribuições de probabilidades em uma amostra e, assim, não é realizado um teste estatístico. Portanto, uma análise de EOF não é fundamentada em princípios físicos, mas sim em um particionamento matemático de modos ortogonais e independentes que podem ser interpretados como estruturas constatadas na atmosfera. Para o seu cálculo, são tomados os autovalores e os autovetores da matriz de 
covariância associada a uma (ou mais) variável de interesse. Os autovalores resultantes da análise geram uma medida da variância explicada por cada modo espacial. Por definição, os padrões resultantes de uma análise de EOF e seus componentes principais são independentes, devido à ortogonalidade. No entanto, sistemas físicos não são necessariamente ortogonais entre si e podem depender do domínio sendo estudado. Ainda assim, análises clássicas de EOF (PCA) mostram-se úteis para aplicações em meteorologia.

O índice LISAM resulta da análise de EOF combinada entre as anomalias de variáveis diagnósticas do sistema SMAS/ZCAS: umidade específica (850hPa), temperatura do ar (850hPa), componentes zonal e meridional do vento $(850 \mathrm{hPa})$ e precipitação.

No presente trabalho, a análise foi conduzida através do cálculo de Decomposição em Valores Singulares (do inglês, Singular Value Decomposition - SVD), extensivamente detalhado emBjornsson e Venegas (1997) e Bretherton et al. (1992).

Considerando-se uma matriz $S(t \times s)$, sendo $t$ as medidas tomadas no tempo e $s$ a posição do ponto de grade, e uma matriz de outra variável $P(t \times p)$, com medidas tomadas nos mesmos $t$ passos de tempo em uma grade distinta com $p$ pontos, a matriz de covariância entre as duas variáveis pode ser calculada por:

$$
C=S^{t} P
$$

A aplicação da SVD nesse caso baseia-se no cálculo das matrizes $U$ (com dimensões $s \times s), V($ do tipo $p \times p)$ e $L($ diagonal, com dimensões $s \times p)$ que satisfaçam a seguinte relação:

$$
C=U L V^{t}
$$

Segundo Bjornsson e Venegas (1997), os vetores singulares para a variável $S$ são dados pelas colunas de $U$, ao passo que os vetores singulares para a variável $P$ são dados pelas colunas de $V$ e cada par de vetores singulares representam um modo de covariabilidade entre as variáveis. Através de $L$, pode-se obter a

contribuição de cada modo para a variabilidade total do sistema através da fração do quadrado da variância (do inglês, Squared Covariance Fraction) expressão 3.3.

$$
S C F_{i}=\frac{l_{i}}{\sum L}
$$


Sendo $l_{i}$ cada valor diagonal da matriz $L$.

\subsubsection{Dados}

Foram obtidos dados diários de umidade específica, temperatura do ar, componentes zonal e meridional do vento no nível de $850 \mathrm{hPa}$ do conjunto de reanálise NCEP/NCAR-R1 (Kalnay et al., 1996) do National Center for Environmental Prediction vinculado ao National Center for Atmospheric Research. O projeto utiliza um sistema de análise-previsão para a assimilação de dados desde 1948 até o presente. Esses dados contemplam o período entre $1979-2015$ e estão dispostos em uma grade regular de $2.5^{\circ}$ x $2.5^{\circ}$ e foram restritos à região de estudo entre $40^{\circ} \mathrm{S}$ e 0 de latitude e $65^{\circ} \mathrm{W}$ e $20^{\circ} \mathrm{W}$ de longitude. As séries temporais associadas a cada ponto de grade foram filtradas para a remoção do ciclo anual através da exclusão dos harmônicos referentes aos modos anual e semi-anual. Em seguida, as séries foram convertidas em pêntadas.

Também foram obtidos dados de estimativas de precipitação do Global Precipitation Climatology Project (GPCP), baseadas em uma combinação de observações (Xie et al., 2003). A utilização de estimativas oferecidas por satélites garante uma das bases de dados mais completas sobre os oceanos, além de ser apropriadamente detalhada sobre o continente. Esses dados são pentadais e também estão dispostos em uma grade regular de $2.5^{\circ} \mathrm{x}$ $2.5^{\circ}$, restrita ao domínio de análise $\left(40^{\circ} \mathrm{S}-0\right.$ e $\left.65^{\circ} \mathrm{W} 20^{\circ} \mathrm{W}\right)$. Assim como para os dados da reanálise do NCEP-R1, essas estimativas de precipitação foram filtradas para a remoção do ciclo anual através de uma análise harmônica.

Em seguida, os dados foram normalizados através da subtração do valor médio e divisão pelo seu desvio padrão. Além disso, todas as variáveis foram combinadas em uma matriz do tipo [tempo x coordenadas] para a análise de EOF:

$$
A=\left[\begin{array}{ccccc}
a_{1,1} & a_{1,2} & \ldots & a_{1, j-1} & a_{1, j} \\
\vdots & \ddots & & & \\
a_{i, 1} & & & & a_{i, j}
\end{array}\right]
$$

Na matriz A, $i$ representa os passos de tempo da série temporal e $j$ as posições em latitude $\mathrm{x}$ longitude. Com a matriz representando todas as anomalias das variáveis de interesse e corrigida pela amplitude no eixo da latitude, um cálculo de SVD foi realizados e os padrões espaciais associados à cada modo de variabilidade foram calculados, bem 
como as séries temporais associadas a cada um dos modos. Segundo da Silva e de Carvalho (2007); Carvalho et al. (2010) o primeiro modo resultante da análise corresponde ao LISAM e está associado com o estabelecimento da estação chuvosa sobre a região da América do Sul e o segundo modo de variabilidade está associado à presença da ZCAS com predomínio sobre a região oceânica. A correlação entre as séries temporais dos modos 1 e 2 com as séries de anomalias utilizadas para a análise oferecem os mapas da figura 3.1.

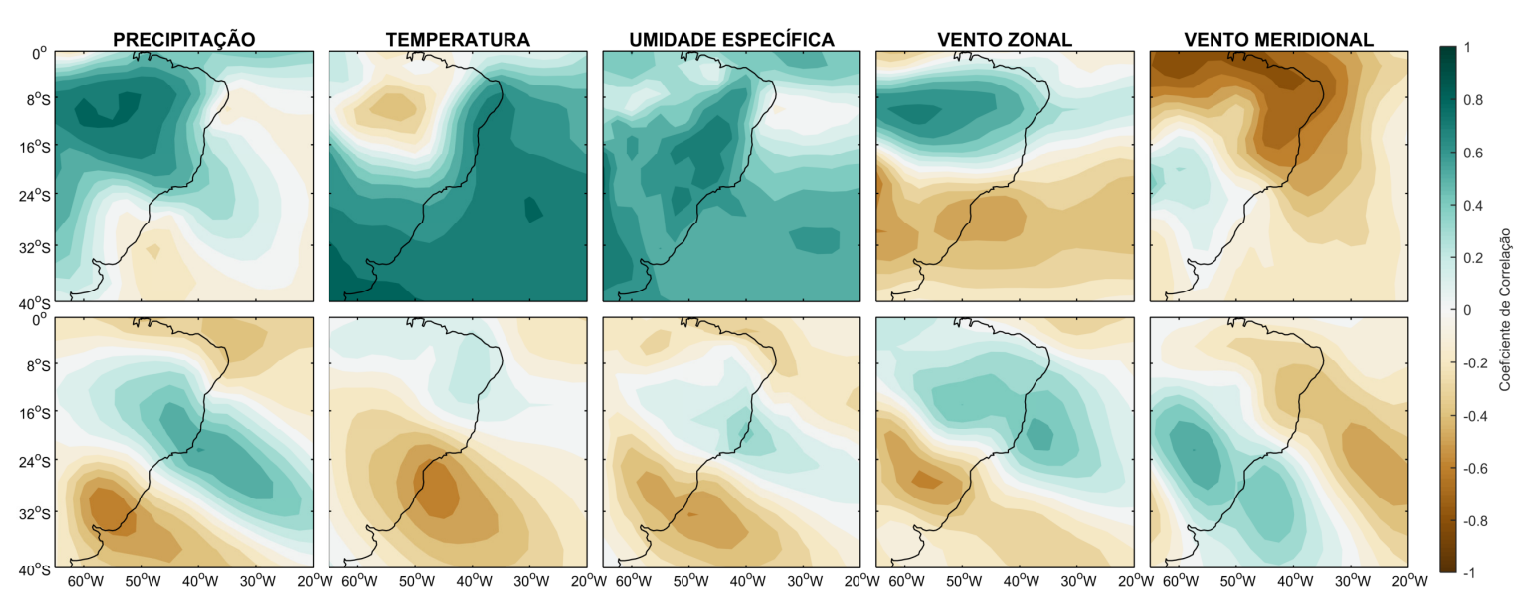

Figura 3.1: Correlação entre as séries temporais dos coeficientes de expansão associados aos modos de variabilidade resultantes da análise de EOF combinada. O painel superior corresponde ao LISAM e o painel inferior corresponde ao modo associado à ZCAS. Da esquerda para a direita, estão dispostos os mapas de: precipitação, temperatura, umidade específica, vento zonal e vento meridional.

Os padrões espaciais apresentados na figura 3.1 são correspondentes aos abordados em da Silva e de Carvalho (2007); Carvalho et al. (2010) e, são apresentados apenas os pontos de grade que passaram no teste de significância t a 95\% de confiança. Para o primeiro modo (23.85\% de variância explicada), representado pelo painel superior na figura 3.1 , nota-se maior contribuição da precipitação estende-se desde a região de atuação da Zona de Convergência Intertropical (ZCIT) até a região sudoeste do Brasil e regiões com máxima atuação sobre a Amazônia central. Essa disposição espacial corrobora com o aumento da umidade em $850 \mathrm{hPa}$ sobre grande parte do continente sul-americano. Os padrões de vento zonal e meridional estão associados diretamente com os resultados descritos em Jones e Carvalho (2002) e indicam a persistência de ventos e oeste (leste) em baixos níveis sobre a região central (sul) do continente sul-americano com o estabelecimento da estação chuvosa. Já o segundo modo de variabilidade (com contribuição de $11.23 \%$ da variância explicada), 
têm seus padrões espaciais de correlação apresentados no painel inferior da figura 3.1 . Para a correlação entre entre a série temporal do modo de variabilidade e as anomalias de precipitação, é notável a presença de uma região positiva realçada com orientação NWSW na região sudeste do Brasil e grande extensão oceânica similar à região de atuação da ZCAS. Tal padrão é acompanhado por correlações negativas sobre a região sul do Brasil e Uruguai. Essa estrutura é acompanhada por correlações positivas de ventos de oeste sobre o núcleo positivo de correlação com a precipitação. Ventos oriundos de norte (sul) predominam a norte (sul) desse padrão. Todos esses fatores estão associados à uma feição do tipo "gangorra" (do inglês, seesaw) que atua na organização de eventos de ZCAS (Nogués-Paegle e Mo, 1997; Carvalho et al., 2004, 2010).

Uma vez que as séries temporais associadas aos dois primeiros modos de variabilidade resultantes da análise de EOF combinada podem corresponder à atuação do SMAS e ZCAS, uma análise do espectro de energia desses índices pode oferecer importantes informações quanto à sua variabilidade. A análise espetral dessas séries temporais trata do processo de particionamento da informação na escala do tempo para a escala das frequências. O espectro resultante da análise oferece a variância da série temporal em componentes discretos, cada um associado a uma determinada frequência. Essa transformação foi feita através da aplicação da transformada rápida de Fourier (do inglês Fast Fourier Transform - FFT). Tendo em vista que a FFT assume séries temporais cíclicas para sua aplicação, foi realizado um pré-tratamento com a remoção da tendência linear das séries temporais e aplicação de um taper em 10\% da séries (suavização das extremidades). Com os resultados dessa análise, foram estimados os periodogramas para cada série temporal. Nas figuras 3.2 e 3.3 encontram-se os periodogramas para os índices LISAM (esquerda) e ZCAS (direita), respectivamente. Em ambos os casos também estão ilustrados os intervalos de confiança e o ruído vermelho, estimado a partir do comprimento da série para a determinação dos graus de liberdade. Além disso, os espectros resultantes foram filtrados através de médias móveis com 9 pontos. 


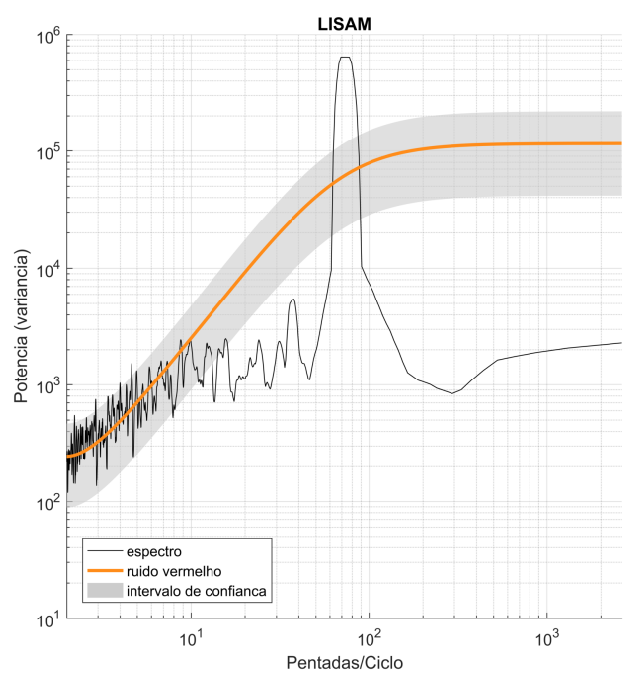

Figura 3.2: Periodograma da série temporal associada ao índice LISAM.

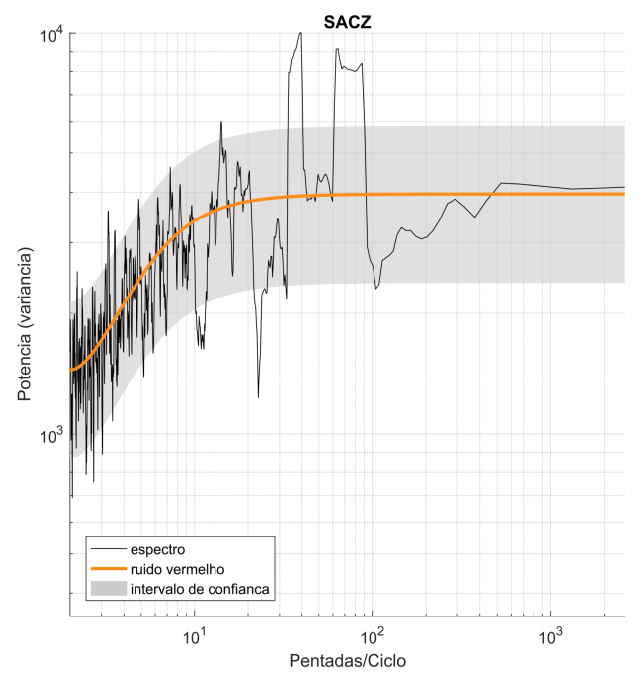

Figura 3.3: Periodograma da série temporal associada ao índice ZCAS.

O índice LISAM (figura 3.2, esquerda), apresenta um pico significativo evidente associado à variabilidade anual. O que é consistente com a variabilidade do SMAS, cuja estrutura é predominante nos meses de verão e praticamente desaparece durante os meses de inverno. Portanto, é conveniente associar esse índice ao início e ao final da estação chuvosa. Nota-se também, uma série de picos significativos em períodos mais curtos, dentro da banda de frequência intrasazonal (entre 20 e 100 dias). Já o índice associado à ZCAS (figura 3.3 , direita), também apresenta um pico significativo para o período anual e, por sua vez, outro pico na escala semi-anual, o que pode estar associado a padrões espaciais de precipitação com uma estrutura em superfície semelhante à ZCAS em outras estações do ano, descritos em Hirata e Grimm (2016). Tendo em vista que há grande particionamento de energia em frequências na banda intrasazonal representadas no espectro ilustrado na figura 3.3 (direita), a figura 3.4 apresenta um detalhamento do espectro para a banda intrasazonal. 


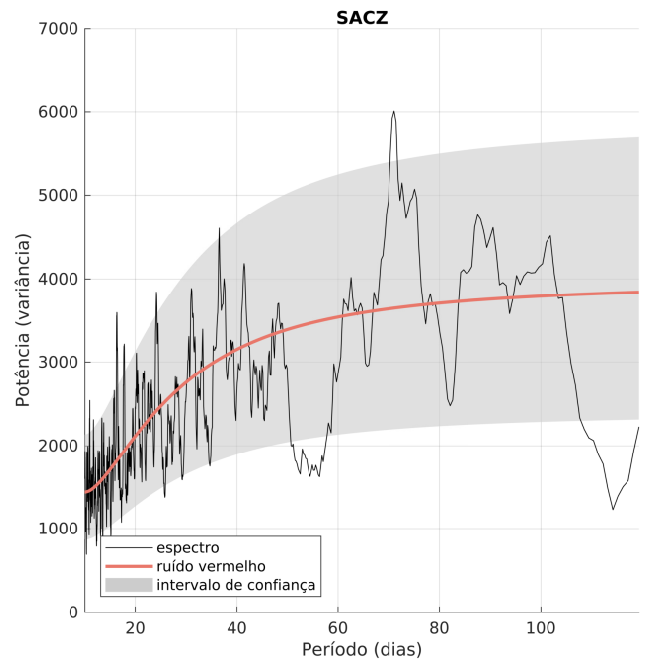

Figura 3.4: Periodograma da série temporal associada ao índice ZCAS detalhado para a banda intrasazonal.

É notável que o espectro exibe picos significativos em porções distintas do espectro. Uma série de picos excedem o ruído vermelho e, alguns deles até mesmo o intervalo de confiança superior, no intervalo entre 20 e 40 dias. O mesmo é notável entre 30 e 100 dias. Isso indica que a oscilação intrasazonal que atua no padrão de variabilidade da ZCAS pode ter componentes de frequência curta e longa. Como o discutido em Grimm e Silva Dias (1995b), através da análise de funções de influência de um modelo linear, a oscilação intrasazonal pode ser propagada por diversos caminhos, desde excursões equatoriais a caminhos via latitudes mais elevadas. E, dessa forma, cada trajetória possui um período distinto dentro da escala intrasazonal. Além disso, de acordo com a intensidade da precipitação associada à OMJ, a propagação das ondas convectivamente acopladas em escala intrasazonal pode ter sua velocidade alterada (Dias et al., 2013).

A escolha de um evento de ZCAS para estudo numérico passou pela análise de ambos os índices LISAM e ZCAS e é descrito nas seguintes etapas e ilustrado no fluxograma da figura 3.5 .

1. Limitação de ocorrências para LISAM $\geq 0$, i.e. durante a estação chuvosa;

2. Escolha de ocorrências dos índices SMAS/ZCAS $\geq$ percentil de $75 \%$ das séries;

3. Restrição de casos com duração maior do que 3 pêntadas consecutivas e com, no mínimo, 3 pêntadas de intervalo; 
4. No índice ZCAS, ao menos uma das pêntadas excedendo o percentil de $90 \%$.

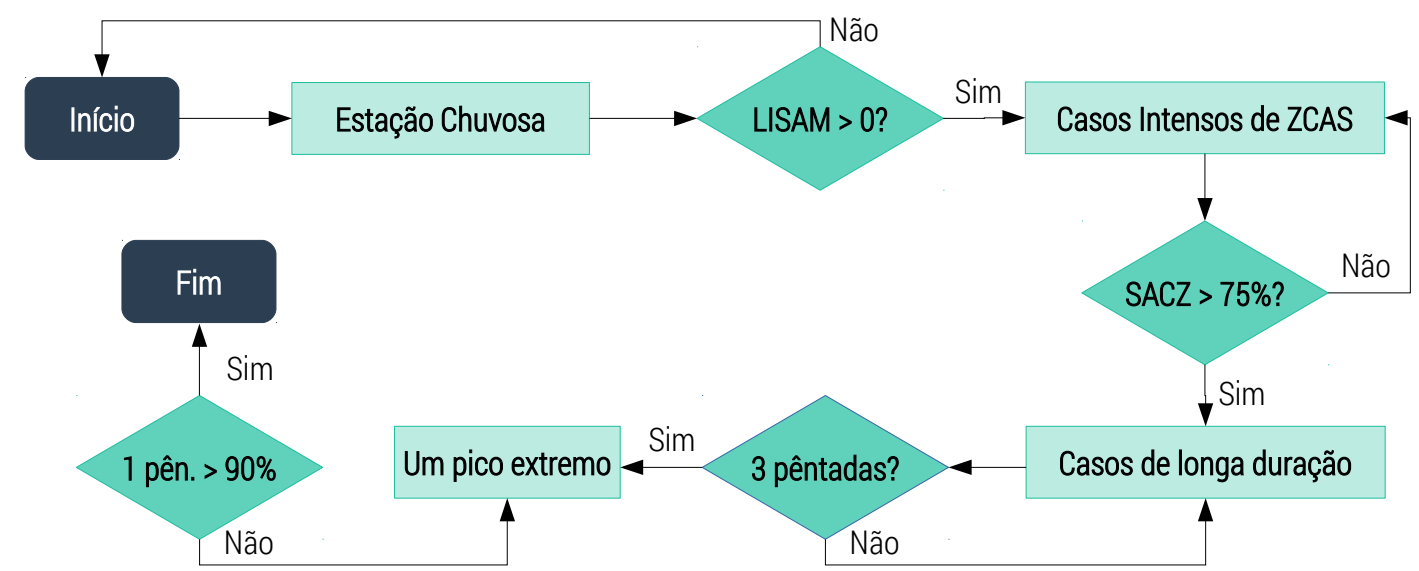

Figura 3.5: Fluxograma que descreve os passos para a escolha de um evento de ZCAS intenso e de duração elevada.

O procedimento resultou em 49 ocorrências de ZCAS que obedecem a essas condições. Um dos casos de ZCAS mais significativos, de acordo com esse critério, ocorreu nas pêntadas dos dias 9, 14, 19 e 24 do mês de dezembro de 2013. Tal episódio continua presente nos casos quando a restrição é elevada para o percentil de 90\%. Essa peculiaridade, aliada aos severos danos que o evento causou à região sudeste do Brasil, foi determinante na escolha do mesmo para os estudos numéricos. A figura 3.6 ilustra a ocorrência desse caso. Curiosamente, após a ocorrência desse evento predominaram índices de ZCAS com valores inferiores. Tal período corresponde a uma severa seca na região sudeste do Brasil, cujas condições desfavoreceram a ocorrência da ZCAS. As possíveis causas para esse evento são discutidas em Coelho et al. (2015). 


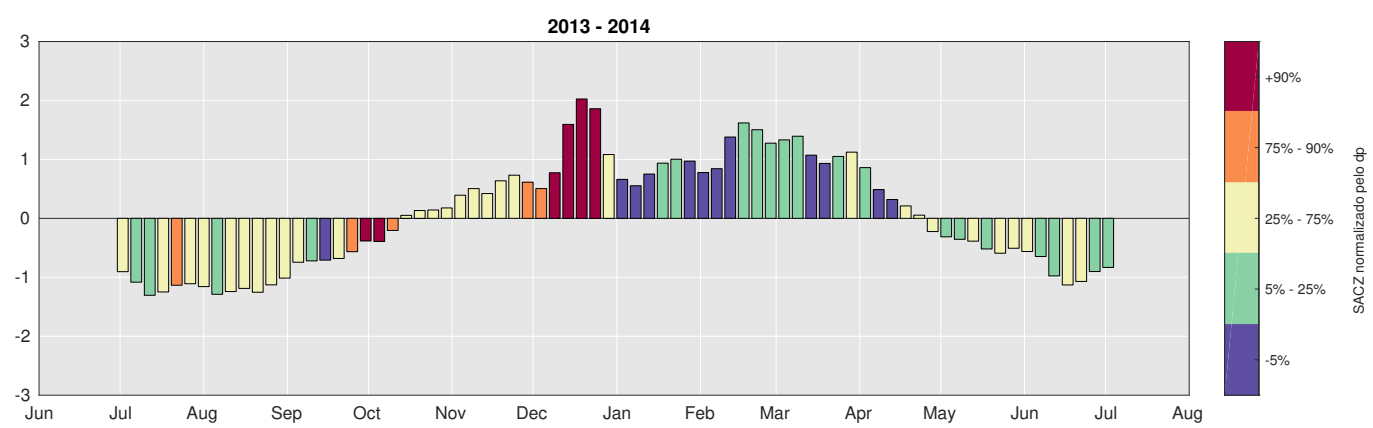

Figura 3.6: Índice LISAM em barras (valores positivos indicam o início da estação chuvosa). As cores das barras indicam o percentil do índice ZCAS. Dados para a estação chuvosa de 2013-2014.

Para se avaliar a progressão da OMJ durante o evento determinado, o diagrama de fases da OMJ (figura 3.7) foi construído a partir do índice RMM (Wheeler e Hendon, 2004) para todo o mês de dezembro de 2013, com destaque para o período de ocorrência do evento escolhido. Esse diagrama ilustra a progressão da OMJ por diferentes fases que usualmente coincidem com as regiões assinaladas ao longo do equador. Os valores RMM1 e RMM2 resultam de uma análise de EOF combinada entre as médias ao longo do equador de vento zonal em $850 \mathrm{hPa}$, vento zonal em $200 \mathrm{hPa}$ e radiação de onda longa emitida (ROLE). As séries temporais relacionadas aos dois primeiros modos de variabilidade resultantes compõem os valores de RMM1 e RMM2. Quando os índices ilustrados encontram-se no interior do círculo delimitado, a OMJ é considerada mais fraca. Ao passo que valores que ultrapassam esse limite indicam uma atuação mais forte. No diagrama, giros no sentido anti-horário equivalem à excursão da OMJ de oeste para leste. Detalhes para a obtenção desse diagrama são encontrados em Wheeler e Hendon (2004). 


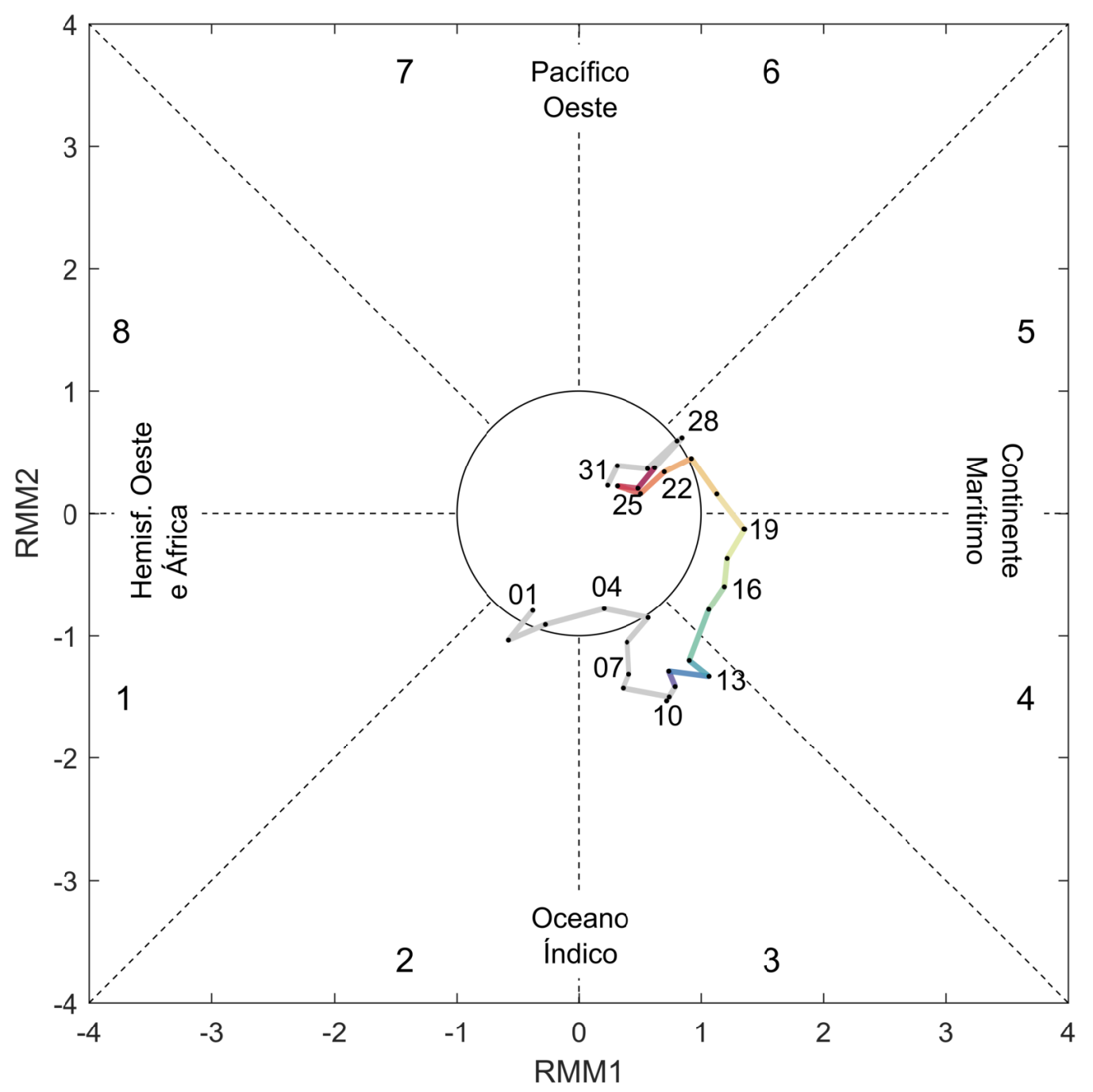

Figura 3.7: Diagrama RMM1 x RMM2 com destaque para o período de 11/12/2013 26/11/2013. A evolução do evento é assinalada das cores mais frias para cores mais quentes.

Nota-se que há um sinal de atuação da OMJ na região do continente marítimo durante o evento. A progressão do evento indica um decaimento da OMJ. Isso é corroborado pelas figuras 3.8- 3.10, que apresentam a progressão de anomalias de ROLE e velocidade potencial em $200 \mathrm{hPa}$ para as pêntadas desde três pêntadas anteriores ao evento até as três pêntadas que sucederam o mesmo. Seus intervalos são descritos na tabela 3.1.2.

Tais figuras foram construídas a partir de dados de ROLE do NOAA Interpolated Outgoing Longwave Radiation (Liebmann e Smith, 1996) e a velocidade potencial em 200hPa 


\begin{tabular}{ccc}
\hline Pêntada & Intervalo & \\
\hline \hline P1 & $26 / 11-30 / 11$ & \\
P2 & $01 / 12-05 / 12$ & Pré-ZCAS \\
P3 & $06 / 12-10 / 12$ & \\
\hline P4 & $11 / 12-15 / 12$ & \\
P5 & $16 / 12-20 / 12$ & ZCAS \\
P6 & $21 / 12-25 / 12$ & \\
\hline P7 & $26 / 12-30 / 12$ & \\
P8 & $31 / 12-05 / 01$ & Pós-ZCAS \\
P9 & $06 / 01-10 / 01$ & \\
\hline
\end{tabular}

Tabela 3.1 - Intervalos referentes às pêntadas anteriores, simultâneas e posteriores ao evento.

derivada da reanálise do CFSR.

As imagens de ROLE apontam para a ocorrência da ZCAS persistente nas pêntadas P4, P5 e P6. No entanto, mapas de velocidade potencial em 200hPa, que atua como um indicativo da divergência em altos níveis (para valores negativos), não apontam para a progressão de ondas tipicamente relacionadas com interação entre a OMJ e a convecção na América do Sul. Para pêntadas posteriores ao evento, no entanto, há o indicativo de que a convecção associada à ZCAS pode ter organizado a progressão da OMJ. Isso é visto pela organização de trens de ondas nos mapas de velocidade potencial em 200hPa nas pêntadas posteriores ao evento (P7, P8, P9), o que pode estar associado aos mecanismos descritos em Grimm e Silva Dias (1995b). Isso está em concordância com um aumento da atividade da OMJ apontada pelo diagrama da figura 3.7 após o evento de ZCAS. 

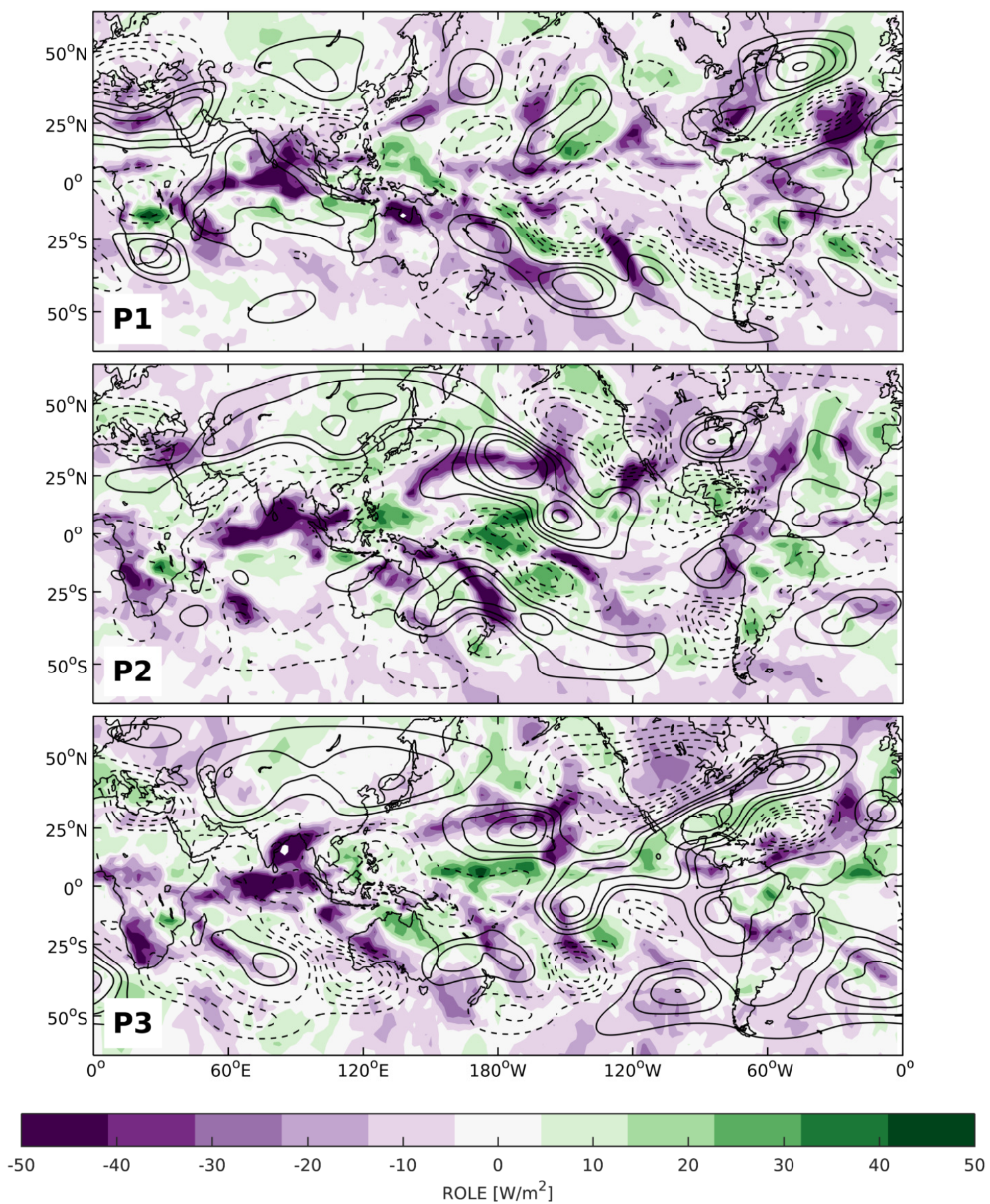

Figura 3.8: Anomalias de radiação de onda longa emitida (contornos preenchidos) e velocidade potencial em $200 \mathrm{hPa}$ (linhas) para as pêntadas que antecedem o evento. P1: 26/11 30/11, P2: 01/12 - 05/12, P3: 06/12 - 10/12 

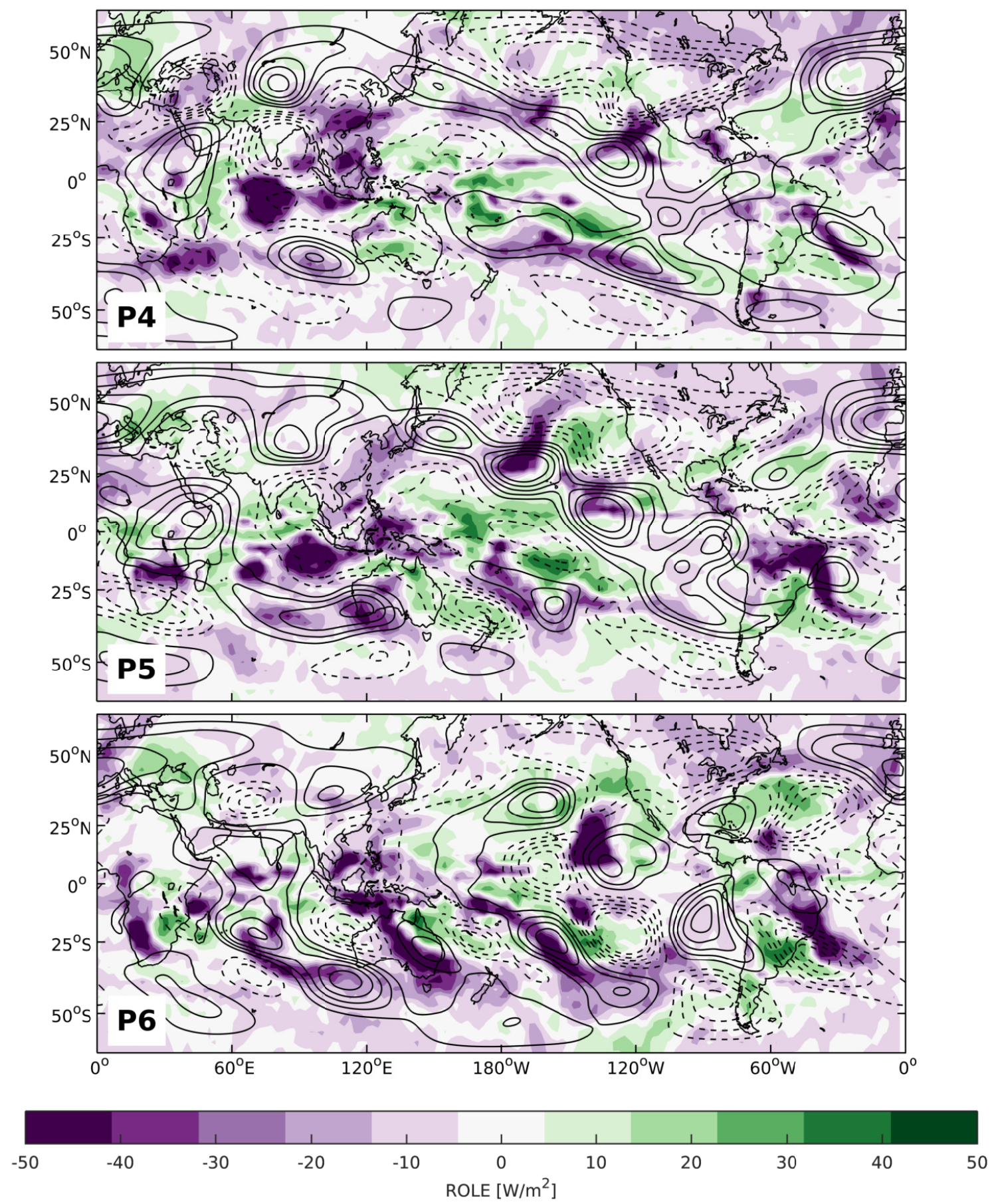

Figura 3.9: Anomalias de radiação de onda longa emitida (contornos preenchidos) e velocidade potencial em $200 \mathrm{hPa}$ (linhas) para as pêntadas do evento. P4: 11/12 - 15/12, P5: 16/12 - 20/12, P6: 21/12 - 25/12. 

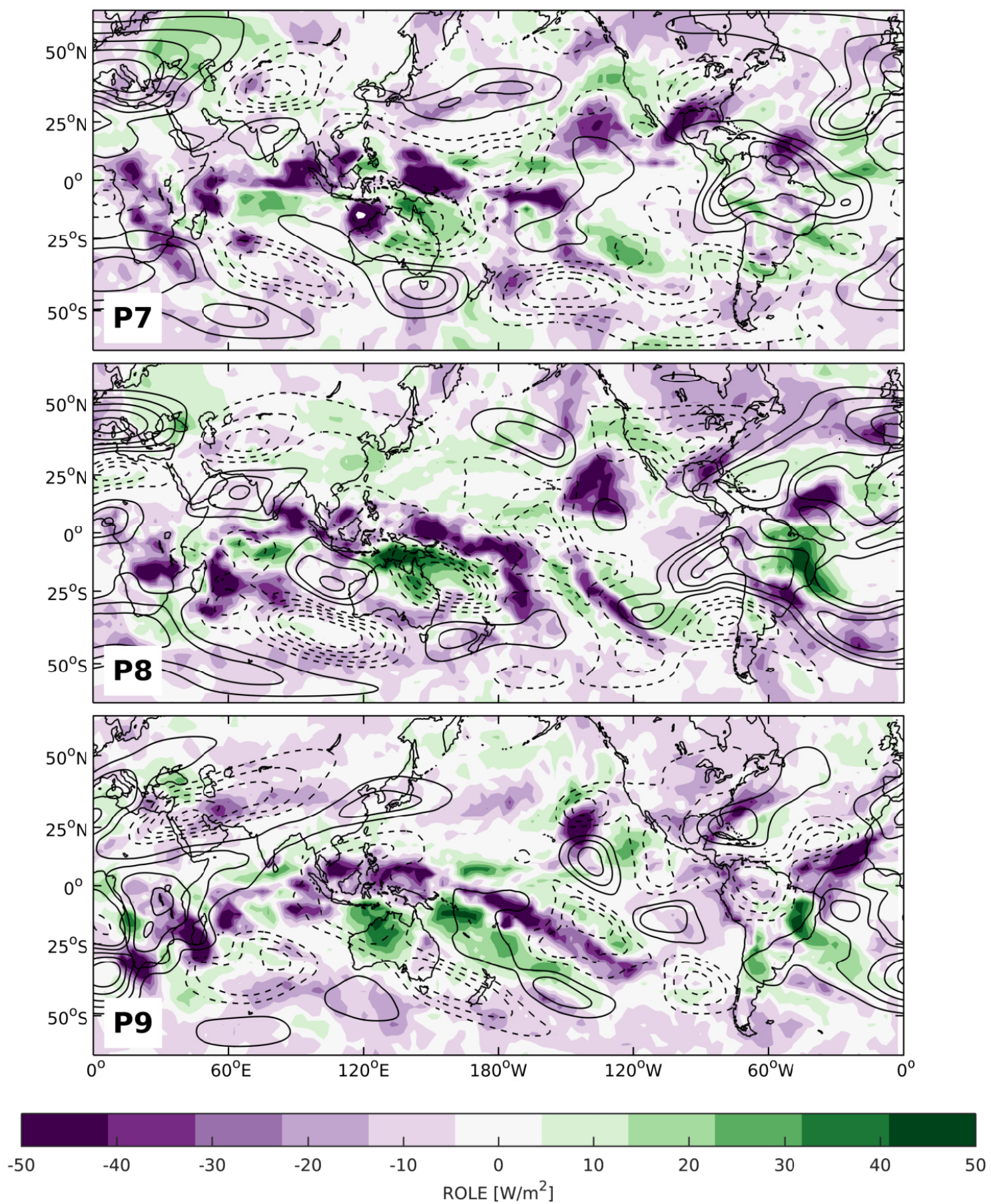

Figura 3.10: Anomalias de radiação de onda longa emitida (contornos preenchidos) e velocidade potencial em $200 \mathrm{hPa}$ (linhas) para as pêntadas que sucedem o evento. P7: 26/12 30/12, P8: 31/12 - 05/01, P9: 06/01 - 10/01. 


\subsection{Descrição do Evento}

O caso de ZCAS, com atuação entre 11 e 26 de dezembro de 2013 (ZCASDez2013), provocou diversos processos geo-hidrológicos resultando em danos à população, principalmente nos municípios ao redor da Bacia Hidrográfica do Rio Doce (Saraiva et al., 2015). De acordo com o Centro Nacional de Monitoramento e Alertas de Desastres Naturais (CEMADEN), foram 171 municípios atingidos nos estados de Minas Gerais e Espírito Santo e 47 óbitos causados principalmente por movimentos de massa. As graves consequências desse evento ressaltam a importância da persistência de casos de ZCAS na região e como as contribuições para aprimorar sua previsibilidade devem ser continuamente revisadas. A figura 3.11 apresenta os acumulados de precipitação durante o evento ZCASDez2013 registrados por estações meteorológicas do Instituto Nacional de Meteorologia (INMET). De acordo com o boletim climatológico do Centro de Previsão de Tempo e Estudos Climáticos vinculado ao Instituto Nacional de Pesquisas Espaciais (CPTEC/INPE), a formação desse episódio de ZCAS gerou acumulados de cerca de 400 - $600 \mathrm{~mm}$, valores que excederam mais de $300 \mathrm{~mm}$ a climatologia mensal para algumas estações (CLIMANALISE, 2013). 


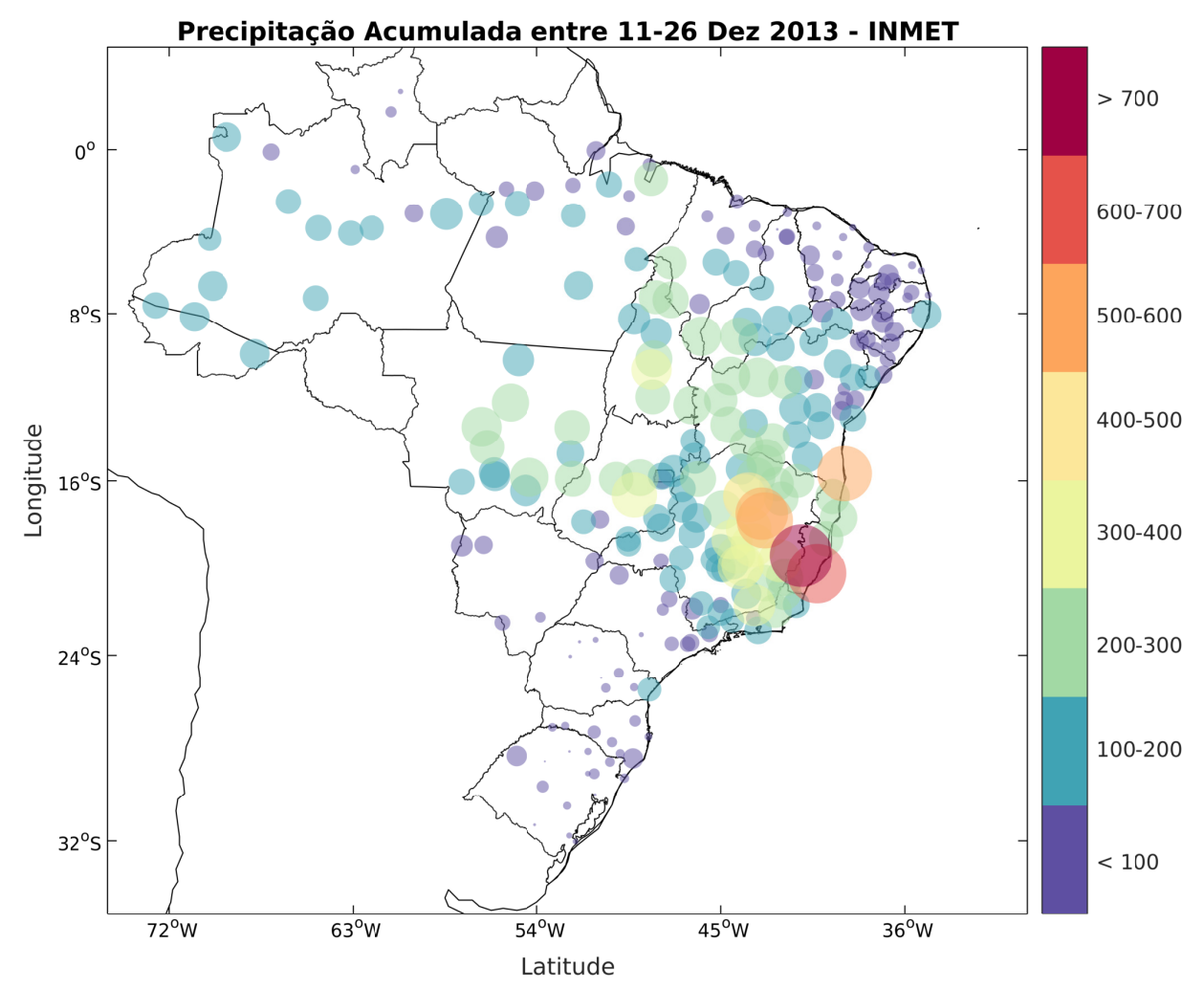

Figura 3.11: Precipitação acumulada (em mm/dia) durante o evento de ZCAS (de 11/12 a 26/12) obtida por estações do INMET.

Já a figura 3.12 ilustra as imagens do satélite GOES-13, fornecidas pelo CPTEC/INPE, para as $00 \mathrm{Z}$ de todos os dias de atuação do evento. A banda de nebulosidade em direção NW-SW, que indica o posicionamento da ZCAS, persiste no decorrer de todo o evento e demonstra intensa atividade convectiva na região central do Brasil. 

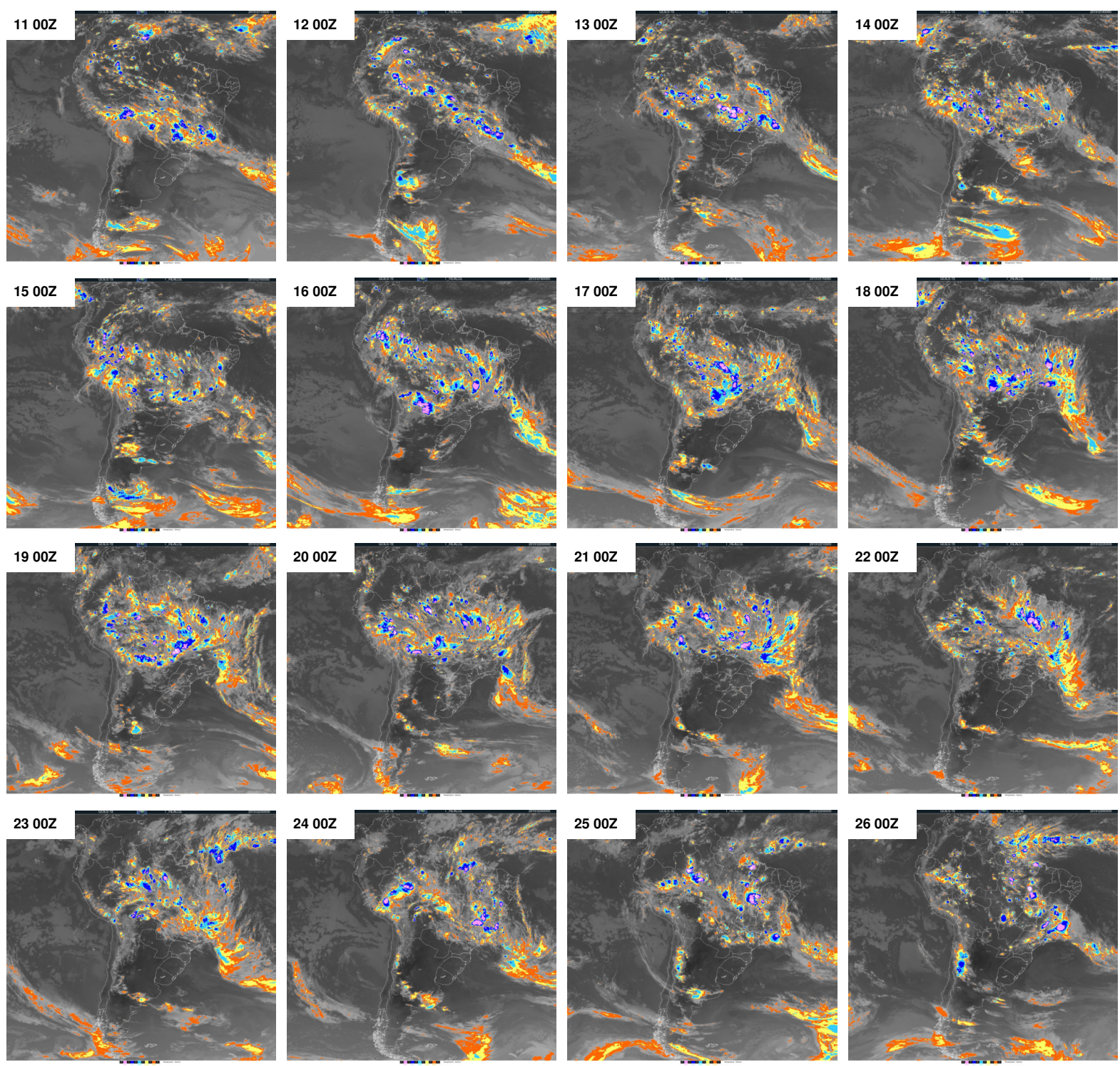

Figura 3.12: Imagens do satélite GOES-13, realçadas, para as 00Z de todos os dias do evento, de $11 / 12 / 2013$ a $26 / 11 / 2013$.

\subsubsection{Aspectos de Larga Escala}

Para a descrição dos aspectos de larga escala associados ao evento em estudo, foram calculadas médias de variáveis diagnósticas para o sistema a partir de dados de reanálise do Climate Forecast System Reanalysis (Saha et al., 2011).

Na figura 3.13 encontra-se a média para o evento do campo de divergência de umidade e linhas de corrente em $850 \mathrm{hPa}$. É notável a zona de convergência na região de atuação do sistema e as linhas de corrente apontam para a estrutura típica que suporta a ZCAS em baixos níveis, com ventos trazendo umidade tanto da região da bacia amazônica quanto 
do ramo oeste da Alta Subtropical do Atlântico Sul. Nota-se também a presença de uma estrutura ciclônica na região costeira do sudeste do Brasil. Esse vórtice atuou no posicionamento do sistema de forma significativa, como pode ser visto nesta figura aliada às imagens de satélite da figura 3.12 .

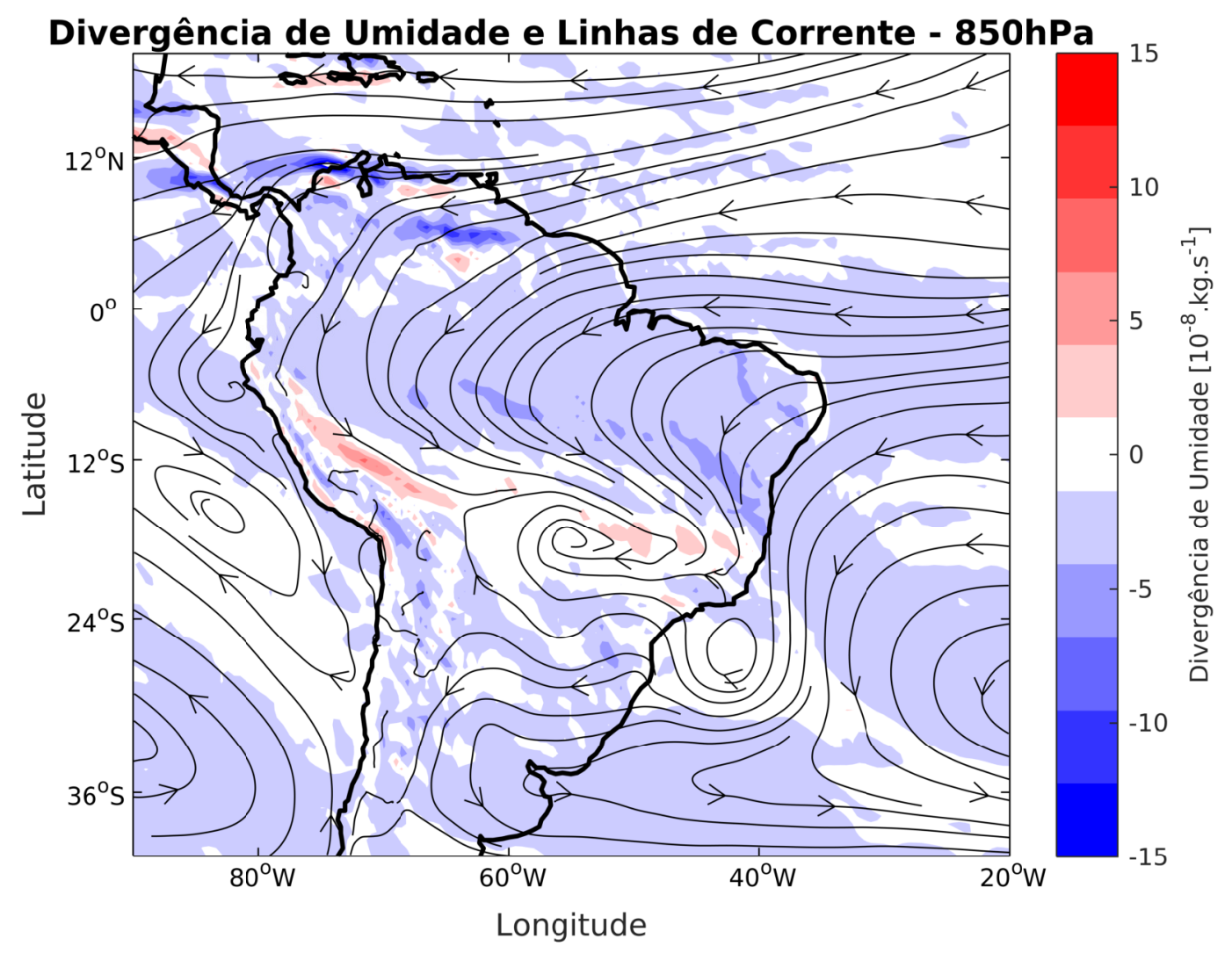

Figura 3.13: Linhas de corrente e divergência de umidade em 850hPa. Campos médios para o evento $(11 / 12 / 2013-26 / 12 / 2013$.

Já a figura 3.14 apresenta o campo médio para o período de atuação da ZCAS para velocidade vertical e linhas de corrente em 500hPa. Além do intenso núcleo indicando movimento ascendente na região costeira do Espírito Santo com uma extensa projeção oceânica, nota-se a presença de um cavado sobre a região de atuação do vórtice ciclônico em 850hPa. Tal configuração também atua na estabilidade desse evento de ZCAS. 


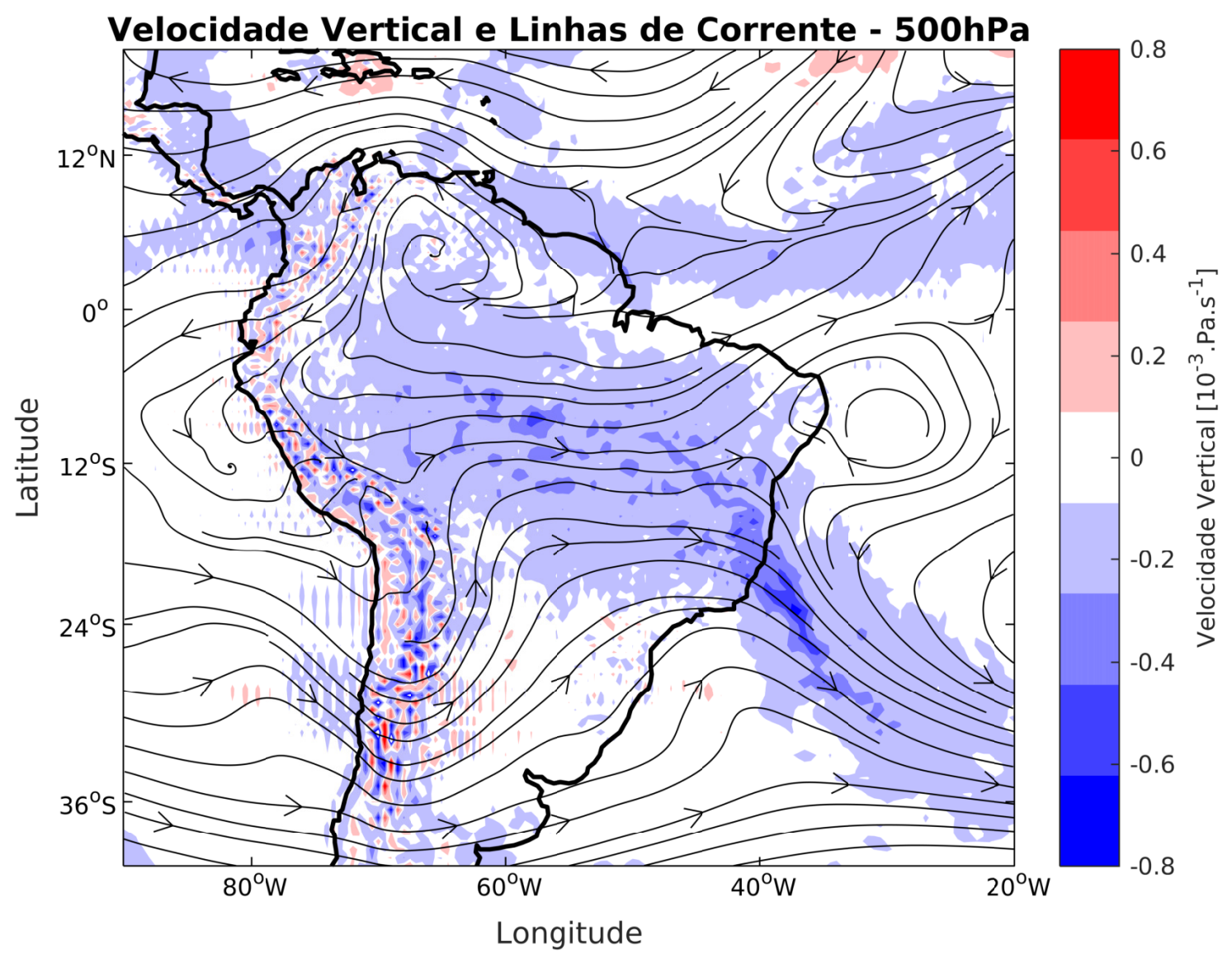

Figura 3.14: Linhas de corrente e velocidade vertical em 500hPa. Campos médios para o evento $(11 / 12 / 2013-26 / 12 / 2013$.

Já a figura 3.15 apresenta a média para o período do evento de linhas de corrente e divergência de massa em 200hPa. Nota-se uma ampla região divergência sobre a zona de atuação da ZCAS. Além de uma estrutura no campo de circulação típica para a atuação do sistema SMAS/ZCAS, com a presença da Alta da Bolívia e de um cavado sobre a região nordeste. Também é interessante notar que há um cavado sobre a região de formação do vórtice ciclônico em $850 \mathrm{hPa}$. Há, portanto, uma robusta estrutura de larga-escala suportando o posicionamento do sistema. 


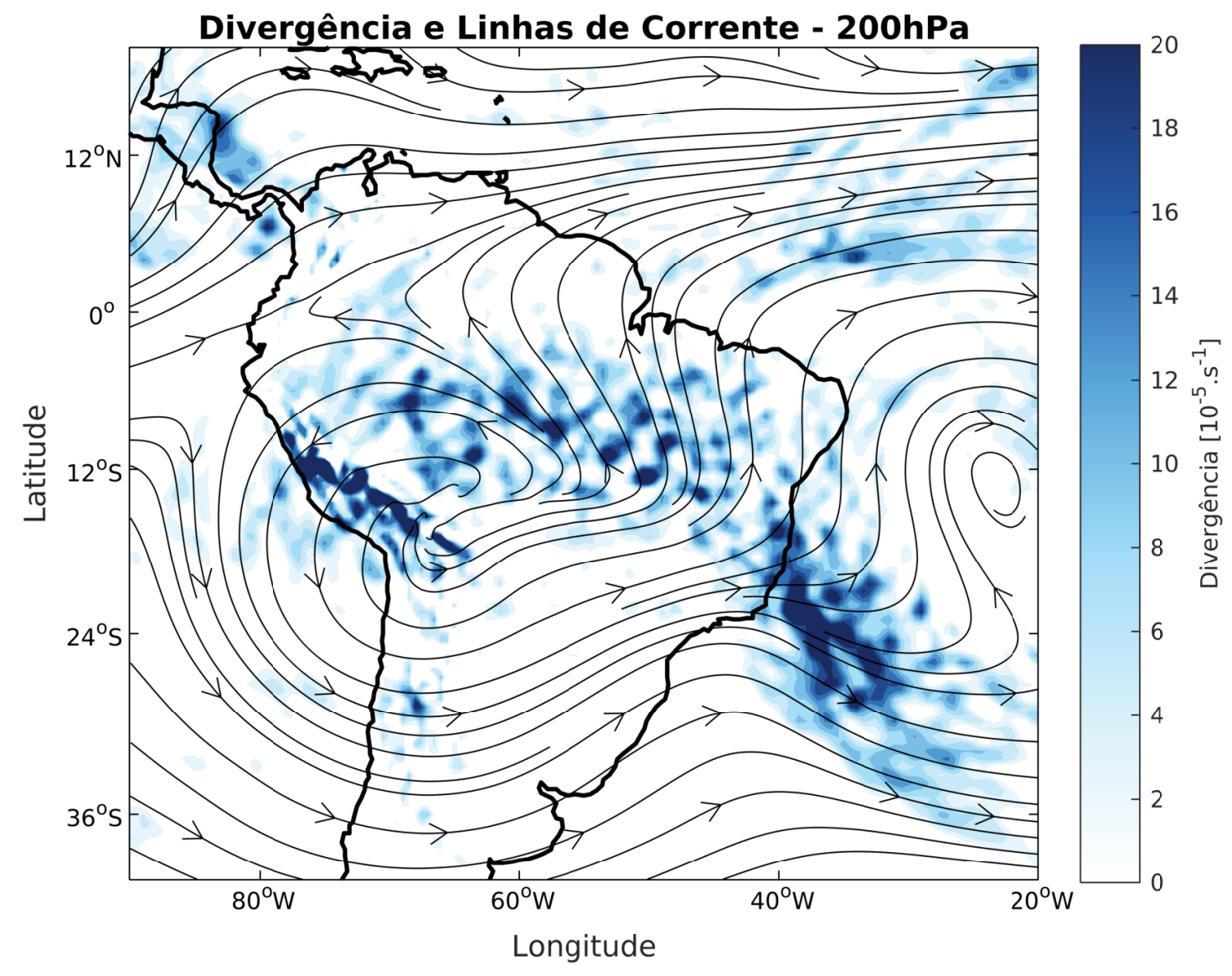

Figura 3.15: Linhas de corrente e divergência de massa em 200hPa. Campos médios para o evento $(11 / 12 / 2013-26 / 12 / 2013$.

Como o discutido nas seções desse capítulo, o episódio diagnosticado para análise numérica, de 11/12/2013 a 26/12/2013, foi anomalamente intenso e duradouro. Esse evento de ZCAS foi sustentado por uma estrutura em larga escala que contou com a atuação de um vórtice ciclônico na região costeira do sudeste do Brasil.

A presença de vórtices ciclônicos na região costeira do Atlântico e Brasil Central mostrou-se fundamental para garantir a permanência do evento a norte de sua posição climatológica. Através das imagens de satélite apresentadas na figura 3.12 , é possível dis- 
tinguir a influência do vórtice ciclônico, presente na região costeira do sudeste do Brasil, na geração de ondulações. Além disso, o mapa de divergência de umidade e linhas de corrente em $850 \mathrm{hPa}$ (figura 3.13), aponta para uma forte atuação desse núcleo ciclônico na retenção de umidade refletida na intensificação do movimento ascendente em $500 \mathrm{hPa}$ (figura 3.14) e da divergência em 200hPa (figura 3.15). Tais processos podem ter sido responsáveis pela organização da convecção que, aliada à interação com transientes que interagiram com o sistema, pode ter sido determinante para a manutenção das condições favoráveis ao desenvolvimento dessa situação de ZCAS.

Um estudo numérico para um evento desse tipo é especialmente desafiador em um contexto de simulações mais longas, em subsazonais e climáticas. Nesses casos, muitas vezes as informações externas transmitidas para o interior da grade numérica através das condições de fronteira (CF) não são incorporadas nas soluções numéricas. Para a representação de casos fortemente influenciados por estruturas de larga escala, distorções na simulação desses campos pode comprometer a representação do fenômeno de interesse. E essa problemática será abordada nas seções seguintes. 
Capítulo 4

\section{Experimentos Numéricos: Impactos na Aplicação de Relaxação Newtoniana}

A representação numérica regional de eventos de longa duração fortemente relacionados com feições de larga escala pode ser desafiadora, uma vez que a amplificação de erros no interior da grade numérica contribui para o aumento de viés no interior do domínio e acarretar em uma ruptura das feições necessárias para a formação e desenvolvimento do sistema de interesse. Davies e Turner (1977); Davies (1983) abordaram como simulações numéricas longas podem divergir das observações, uma vez que o fluxo de informações nas condições de fronteira podem não ser devidamente levadas para o interior da grade. Uma das maneiras de se mitigar esses efeitos consiste na aplicação de um processo de relaxação newtoniana, ou nudging, em experimentos numéricos. O método consiste fundamentalmente em aproximar as soluções numéricas a campos de referência (Stauffer e Seaman, 1990) em um ou mais pontos de grade. As referências são obtidas dos próprios conjuntos oferecidos pelas condições iniciais. Recentemente, uma variação da aplicação da relaxação, denominada relaxação espectral, ou nudging espectral, vem sendo utilizada (Miguez-Macho et al., 2004; Gómez e Miguez-Macho, 2017; Vincent e Hahmann, 2015) com o propósito de atenuar erros nas simulações. A técnica utiliza filtros espectrais para que apenas uma banda do espectro seja utilizada no processo de relaxação. Quando a técnica é utilizada para aproximar apenas a larga escala do modelo a conjuntos de referência, há uma maior liberdade para que os módulos físicos e dinâmicos do próprio modelo contribuam para a solução final nas escalas que não sofrem interferência do processo de relaxação. As primeiras investigações dos efeitos da utilização da relaxação espectral foram realizadas por Waldron et al. (1996). Os autores descrevem a utilização da técnica para um modelo 
de área limitada para que feições de larga escala sejam amplificadas no interior da grade numérica e, assim, garantindo a eliminação de modos internos, relacionados às discretizações das equações utilizadas pelo modelo, gerados por uma topografia complexa. Além disso, a amplificação de erros pode resultar da incompatibilidade entre as resoluções das condições iniciais e da grade utilizada para a discretização. von Storch et al. (2000) aplicaram nudging espectral em um modelo de clima regional e demonstraram que, quando apenas as condições de fronteira são incorporadas em modelos de clima regional, modos computacionais passam a interagir com campos em larga escala e provocar aumento significativo no viés. Uma vez que simulações em escalas subsazonais, sazonais e regionais são bastante sensíveis ao tamanho e posicionamento dos domínios, Miguez-Macho et al. (2004) sugerem a aplicação da varição espectral do processo de relaxação para reduzir a dependência dos resultados simulados a esses fatores. Os autores sugerem que apenas feições de larga escala sejam utilizadas na aplicação (comprimentos superiores a $2500 \mathrm{~km}$ ) para restringir a representação da escala sinótica pelo modelo e ainda permitir que seus módulos ofereçam soluções em escalas não afetadas pela relaxação. Miguez-Macho et al. (2005) investigaram como uma aplicação de nudging espectral, ao lado de melhorias na representação das condições do solo no modelo RAMS, aprimoram simulações na região da América do Norte. Wang e Kotamarthi (2013) testaram a sensibilidade de um modelo climático regional a diferentes configurações de relaxação espectral. Os autores verificaram que a utilização do procedimento ao longo de todo o tempo de integração, para camadas acima de $850 \mathrm{hPa}$ acarretaram em melhoras de performance superiores a 30\%. Vincent e Hahmann (2015) avaliaram os efeitos de uma aplicação de nudging para a representação de velocidade do vento no modelo WRF. Gómez e Miguez-Macho (2017) testou a sensibilidade do modelo WRF a diferentes números de onda de corte para o espectro na aplicação da relaxação em experimentos com o modelo WRF na região da América do Norte. Os autores indicam resultados que estimulam a utilização do método para larga escala. Seus resultados apontam para a utilização de números de onda de corte correspondentes a, no mínimo, 1000 km. Essa escala é comparável com o raio de deformação de Rossby para a região, valor que indica a separação entre escalas sinóticas e convectivas Gómez e Miguez-Macho, 2017), escala na qual a resposta para ondas inerciais se equivale a ondas de gravidade. Em grandes escalas, sob o domínio das relações geostróficas, a força de Coriolis torna-se responsável pela restauração das perturbações. A aplicação desse método pode 
ser particularmente útil para a representação de eventos de ZCAS longos, uma vez que feições de larga escala são extremamente importantes para garantir a estrutura necessária para o desenvolvimento e persistência da zona de convergência.

\subsection{Metodologia}

\subsubsection{Relaxação Newtoniana - Nudging}

O processo de relaxação newtoniana, também denominado nudging, aproxima as soluções do modelo a uma referência. Em uma aplicação de relaxação, tal processo pode ser feito tanto no tempo quanto no espaço. No modelo WRF, o nudging no espaço segue os passos descritos por Stauffer e Seaman (1990), detalhados na documentação técnica do modelo por Skamarock e Klemp (2008). Uma aplicação espacial de nudging em pontos de grade é implementada no modelo a partir da seguinte formulação:

$$
\frac{\partial \theta}{\partial t}=F(\theta)+G_{\theta} W_{\theta}\left(\hat{\theta_{0}}-\theta\right)
$$

Onde $F_{\theta}$ representa a solução numérica do modelo dada por seus sistemas físicos e dinâmicos, $G_{\theta}$ trata de um termo que controla a força da aplicação da relaxação, $W_{\theta}$ representa um fator peso utilizado para implementar restrições ao processo de aplicação do nudging, $\hat{\theta_{0}}$ é o campo de referência interpolado para a grade do modelo, para o qual as soluções numéricas são aproximadas. O modelo WRF apresenta maneiras de se controlar o processo de aplicação da relaxação newtoniana:

- Duração da aplicação e período de decaimento: a aplicação da técnica pode ser interrompida durante a simulação. No entanto, uma vez que o desligamento abrupto da metodologia pode suscitar a geração de erros, esse processo de desligamento pode ser feito gradualmente;

- Intensidade: vinculada à escala temporal do processo de aplicação da relaxação e pode ser controlada para cada variável que se deseja relaxar. O valor $0.0003 s^{-1}$ é comumente utilizado, o que corresponde a aproximadamente uma hora. Para aplicações de longo período, trata-se de uma intensidade bastante elevada;

- Localização vertical: a metodologia pode ser aplicada em apenas alguns níveis do modelo. Tal opção é importante uma vez que as condições iniciais tipicamente utilizadas (reanálises) encontram-se em escalas muito distintas das grades numéricas e 
adequado permitir que as próprias parametrizações do modelo representem os processos de interação com a superfície, especialmente em regiões com topografia complexa;

- Aninhamento: o modelo também oferece controle sobre quais grades terão suas soluções relaxadas. O único fator que deve ser comum a todas as opções de aninhamento consiste no período de decaimento.

Já uma aplicação de relaxação espectral é bastante similar ao procedimento descrito anteriormente. Sua formulação inclui um termo referente a um filtro espectral, utilizado tanto na direção zonal quanto na meridional, na relação descrita em 4.1:

$$
\frac{\partial \theta}{\partial t}=F(\theta)+G_{\theta} W_{\theta} F_{x y}\left(\hat{\theta_{0}}-\theta\right)
$$

O termo $F_{x y}$, que representa o filtro espectral, restringe a aplicação do nudging a um número de onda de corte. O processo de aplicação dessa variação do método segue os seguintes passos, descritos em Gómez e Miguez-Macho (2017):

1. Cada linha do campo dado pelas diferenças entre as soluções numéricas e as referências $\left(\hat{\theta_{0}}-\theta\right)$, é convertida para o domínio da frequência através do cálculo de uma transformada rápida de Fourier (do inglês, Fast Fourier Transform - FFT);

2. Frequências cujos números de onda correspondem ao valor de corte são anulados;

3. Os coeficientes restantes são novamente convertidos para o domínio espaço-temporal e a operação do nudging é retomada.

Esses passos são seguidos para cada linha e cada coluna dos campos escolhidos para a aplicação do método. O filtro espectral $F_{x y}$ é responsável por anular frequências que encontram-se acima do número de onda de corte e isso garante com que apenas alguns comprimentos de onda sejam utilizados no procedimento. Gómez e Miguez-Macho (2017) demonstram que, para números de onda equivalentes à maior frequência de corte possível, o filtro $F_{x y}$ passa a incorporar todo o espectro e, assim, seu cálculo equivale a utilização da relaxação clássica nos pontos de grade. Os autores apresentam resultados que corroboram a ideia de que tanto a utilização da relaxação em todo o espectro (procedimento clássico em pontos de grade) quanto a não utilização de qualquer técnica de relaxação oferecem soluções extremas de aplicações espectrais. Além disso, Gómez e Miguez-Macho (2017) 
oferecem uma relação para garantir que a larga escala seja relaxada a uma referência ao passo que ainda permita liberdade ao modelo para contribuir com a solução final em escalas menores:

$$
n=\frac{D_{x, y} N_{x, y}}{R}+1
$$

Em 4.3, $n$ é o número de onda ideal nas direções $x, y, D_{x, y}$ representa a resolução do modelo, $N_{x, y}$ equivale ao número de pontos de grade em ambas as direções e $R$ representa o raio de deformação de Rossby. É importante ressaltar que tal formulação relaciona-se apenas com a aplicação da relaxação no espaço. E a aplicação no tempo, oferecida pelo termo de intensidade, também deve ser levada em consideração no desenvolvimento dos experimentos numéricos.

\subsubsection{Dados Utilizados}

Como condição inicial e de fronteira de todos os experimentos numéricos foram utilizados os dados do The Climate Forecast System Reanalysis (CFSR). O CFSR (Saha, 2010) é um produto de reanálise global, em um esforço de terceira geração, com alta resolução (espaçamentos de $0.5^{\circ} \times 0.5^{\circ}$ ) e acoplamento entre oceano e atmosfera em seu processo de assimilação. Conta com quarenta níveis verticais e possui uma cobertura temporal de 1979 até o presente. Além disso, esse conjunto foi considerado por Quadro (2012) como um dos esforços de reanálise que melhor representa a atuação do SMAS e da ZCAS. Os resultados dos experimentos foram comparados com o conjunto do CFSR, sua condição inicial, para uma avaliação de como cada simulação diverge ou se aproxima de sua referência. Para uma avaliação do desempenho dos experimentos de uma maneira geral, foram utilizados os dados de reanálise ERA-Interim (Dee e et al., 2011), gerados pelo European Centre for Medium-Range Weather Forecasts (ECMWF). Também trata-se de um conjunto global, com uma cobertura temporal de 1979 até o presente. É um conjunto continuamente atualizado e construído a partir de um processo de assimilação de observações com um sistema robusto. Sua resolução espacial é de aproximadamente $80 \mathrm{~km}$ (disposta em uma grade espectral do tipo T255) e conta com 60 níveis verticais desde a superfície até o nível de pressão de $0.1 \mathrm{hPa}$. Além disso, foram adquiridos dados de estimativas de precipitação oriundos da Tropical Rainfall Measuring Mission (TRMM). O produto diário da análise TRMM Multi-satellite Precipitation Analysis (TMPA) 3B42 foi adquirido para o período do evento. Tal projeto foi criado com o intuito de oferecer uma base de estimativas de pre- 
cipitação nas regiões tropical e subtropical (Huffman et al., 2007). Os dados encontram-se dispostos em uma grade regular com $0.25^{\circ}$ de espaçamento horizontal.

\subsubsection{Modelo Numérico}

Os experimentos numéricos foram integrados com o modelo WRF, em sua versão 3.9. Trata-se de um modelo totalmente compressível, não hidrostático e com um núcleo dinâmico euleriano (Skamarock e Klemp, 2008). São dois núcleos dinâmicos disponíveis e, no presente trabalho, o núcleo Advanced Research WRF (ARW) foi utilizado. Trata-se de um núcleo continuamente atualizado pelo National Center for Atmospheric Research (NCAR). O conjunto WRF-ARW inclui diversas opções para a parametrização de processos físicos. Sua integração no tempo é realizada através de um esquema Runge-Kutta de terceira ordem. O modelo foi desenvolvido para garantir a conservação de massa e momento. Além disso, suas equações prognósticas são descritas na forma de fluxo e encontram-se amplamente descritas em Skamarock e Klemp (2008). Todos os experimentos foram integrados desde as 0000UTC de 26 de novembro de 2013 até 0000UTC de 10 de Janeiro de 2014. Tal intervalo amplo foi considerado uma vez que o foco do estudo encontra-se na avaliação do desempenho de uma simulação subsazonal. A grade numérica possui as seguintes características: 320 pontos na direção leste-oeste e 300 pontos na direção norte-sul estão dispostos em uma grade com espaçamento de $25 \mathrm{~km}$ em uma projeção Mercator. O domínio dos experimentos está ilustrado na figura 4.1. A região da Cordilheira dos Andes foi saturada para que a zona central do Brasil, extremamente relevante no contexto do presente trabalho, fosse ressaltada. 


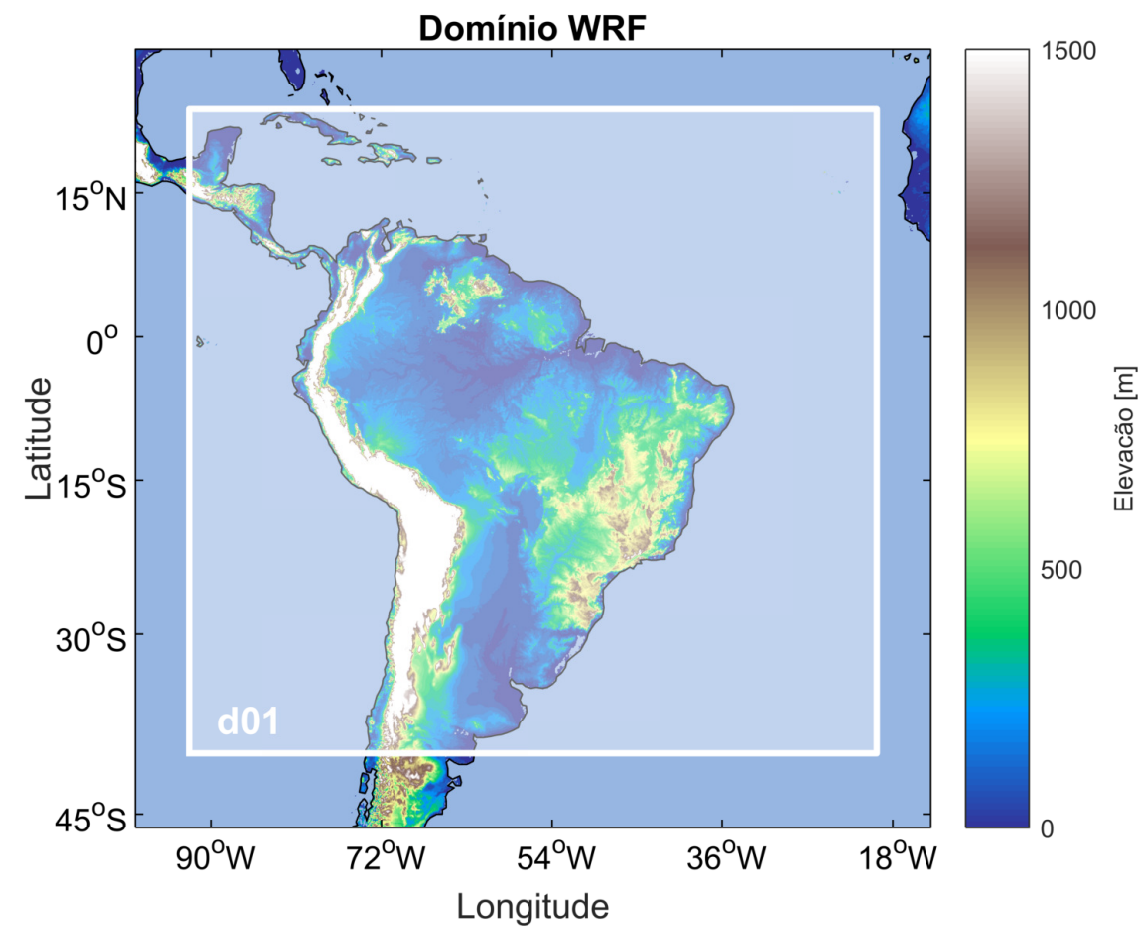

Figura 4.1: Ilustração do domínio utilizado nos experimentos numéricos e da topografia da região.

A grade está centrada em $10^{\circ} \mathrm{S}$ de latitude e $56^{\circ} \mathrm{W}$ de longitude. Foram considerados 40 níveis verticais e pressão de $50 \mathrm{hPa}$ na camada de topo. Para garantir estabilidade numérica durante a integração do modelo, foi determinado um passo de tempo de 60 segundos. Saídas são disponibilizadas a cada 6 horas. As opções para parametrizações de processos físicos estão sumarizadas na tabela 4.1.

\begin{tabular}{ccc}
\hline Parametrização Física & Opção & \multicolumn{1}{c}{ Referência } \\
\hline Microfísica de Nuvens & WRF Single-Moment 6-Class & Hong e Lim $(2006)$ \\
Cumulus & Kain-Fritsch & Kain $(2004)$ \\
Radiação de Onda Longa & CAM3 & Collins et al. $(2004)$ \\
Radiação de Onda Curta & CAM3 & Collins et al. \\
Superfície & MM5 & Zhang e Anthes $(1982)$ \\
Camada Limite Planetária & Yonsei University & Hong e Lim (2006) \\
Land Surface & Noah-MP & Niu et al. (2011) \\
\hline
\end{tabular}

Tabela 4.1 - Parametrizações físicas utilizadas em todos os experimentos e suas principais referências.

Processos em superfície oferecidos pela parametrização Land Surface $\mathscr{E}$ Noah-MP são extremamente importantes para a presente aplicação, tendo em vista que tratam das trocas de calor entre camadas superficiais do solo e a atmosfera adjacente. Nesse esquema, 4 
camadas de solo são utilizadas $(10,30,60,100 \mathrm{~cm})$, além de prognósticas para temperatura e umidade nessas camadas. Todas essas propriedades são derivadas das condições iniciais oferecidas ao modelo. Mais detalhes sobre como se dá a troca de calor sensível e latente nessa interface, além de como é calculado o coeficiente de troca em superfície (surface exchange coefficient) são oferecidos por Chen et al. (2007).

A Temperatura da Superfície do Mar (TSM) pertence ao conjunto de dados Optimum Interpolation Sea Surface Temperature (OISST) da NOAA (Reynolds et al., 2007; Banzon et al., 2016). Trata-se de uma base de dados com $0.25^{\circ}$ de espaçamento com um longo período de dados de satélite e in situ. Para os experimentos realizados no presente estudo, a TSM foi atualizada a cada passo de tempo de simulação.

\subsubsection{Configuração dos Experimentos}

Para se testar a sensibilidade do modelo WRF a diferentes escolhas no número de onda para aplicações de nudging espectral, foram realizados seis experimentos, cujas principais características encontram-se na tabela 4.2. A relaxação newtoniana foi ativada em todos os

\begin{tabular}{ccccc}
\hline Experimento & $W n_{x} \mathrm{x}$ & $W n_{y}$ & $L_{x}$ & $L_{y}$ \\
\hline ndgnone & - & - & 8000 & 7500 \\
ndg2000 & 5 & 5 & 2000 & 1875 \\
ndg1000 & 9 & 9 & 1000 & 937 \\
ndg500 & 17 & 16 & 500 & 500 \\
ndg250 & 33 & 31 & 250 & 250 \\
ndggrid & - & - & 50 & 50 \\
\hline
\end{tabular}

Tabela 4.2 - Principais características dos experimentos realizados para se determinar a sensibilidade do modelo. Nomenclatura para cada teste, números de onda em x $\left(W n_{x}\right)$ e y $\left(W n_{y}\right)$, e comprimentos associados a cada número de onda tanto em $\mathrm{x}\left(L_{x}\right)$ quanto em y $\left(L_{y}\right)$

experimentos realizados, exceto ndgnone. Do experimento ndg2000 para o ndg250 há uma progressão no número de onda determinado, acompanhado de uma consequente diminuição do comprimento associado. Por fim, foi realizado um experimento com uma aplicação convencional de nudging ndggrid, representando uma aplicação do espectro completo Gómez e Miguez-Macho, 2017). Para todos os experimentos citados, a aplicação foi realizada nas componentes zonal e meridional do vento, temperatura e geopotencial. O procedimento foi realizado apenas para camadas acima da CLP, durante todo o período de integração, em intervalos de 6 em 6 horas. O coeficiente que atua na força do nudging foi fixado no valor 
típico de $3 \times 10^{-4} s^{-1}$, o que corresponde a aproximadamente $1 h^{-1}$. Dado que a ZCAS é estabelecida através da convergência de umidade em baixos níveis, essa variável sofreu efeitos do processo de relaxação através da circulação, ao passo que campos de umidade resultam da resposta do modelo numérico à sua introdução pelas fronteiras laterais.

\subsubsection{Avaliação dos Resultados}

Resultados das simulações foram avaliados através de comparações entre os principais campos associados à representação da ZCAS e sua condição inicial, dada pelo CFSR. O contraste entre os resultados dos experimentos e o campo de referência utilizado na aplicação do nudging oferece informações sobre a contribuição dos núcleos físicos e dinâmicos do modelo em menores escalas mesmo diante das imposições geradas pela utilização do processo de relaxação. Já a comparação entre os resultados dos modelos com um conjunto de reanálise externo (ERA-Interim) pôde oferecer uma ideia do desempenho dos experimentos em um contexto geral. A quantificação dessas diferenças foi feita através do cálculo do Erro Médio Quadrático (EMQ):

$$
E M Q=\sqrt{\sum_{i=1}^{N} \frac{\left(z_{f_{i}}-z_{o_{i}}\right)^{2}}{N}}
$$

Na equação 4.4, $z_{f}$ é correspondente aos valors previstos pelo modelo, ao passo que $i$ indica a posição desses valores em uma grade com $N$ elementos no total. O procedimento foi aplicado para a grade completa, ao passo que os campos espaciais resultantes destacam a região de atuação da ZCAS. A performance das simulações também é avaliada através do cálculo do espectro espacial da energia cinética. Os valores de energia cinética permitem a avaliação das componentes zonal e meridional do vento em um único valor escalar. Além disso, a análise do espectro espacial para energia cinética pode oferecer valiosas informações sobre como se dá a dissipação de energia entre a larga escala e a mesoescala Nastrom et al., 1984). O procedimento de geração do espectro espacial consiste nos seguintes passos:

1. Remoção da tendência linear para garandir periodicidade: segundo Errico (1985), uma análise espectral deve ser feita em campos periódicos. No entanto, domínios regionais não obedecem a essa condição e a remoção da tendência linear do primeiro e último elementos de cada linha/coluna do oferece um resultado periódico que não rompe a estrutura espectral do domínio regional (Errico, 1985). O primeiro passo 
para o procedimento envolve o cálculo da inclinação da reta de tendência linear. Isso

é feito a partir da equação 4.6 .

$$
s_{j}=\frac{a_{N_{I}, j}-a_{1, j}}{N_{I}-1}
$$

Para linhas em $i$ e colunas em $j$, cada qual com $N_{I}$ e $N_{J}$ elementos, respectivamente.

2. Em seguida, esse cálculo é realizado para cada coluna $j$ /

3. A tendência linear é, então, removida para cada $i, j$ :

$$
a_{i, j}^{\prime}=a_{i, j}-\frac{1}{2}\left(2 i-N_{I}-1\right) s_{j}
$$

4. Os passos são repetidos invertendo-se a ordem entre linhas e colunas.

Dados os campos espaciais periódicos, os espectros espaciais foram determinados de acordo com Vincent e Hahmann (2015). Primeiramente, os coeficientes de Fourier são calculados através da relação:

$$
A(k)=\sum_{j=0}^{N-1}[a(j)-\bar{a}] W(j) e^{\frac{-2 k \sqrt{-1}}{N}}
$$

Em 4.7 a representa a variável sendo analisada ao longo de uma linha do campo espacial. Os índices dos pontos de grade, de tamanhoa $N$, são dados por $j$. Já $W$ representa uma função janela e $k$ representa o número de onda. A função janela utilizada é definida como uma função janela Hanning (Vincent e Hahmann, 2015) e é definida por:

$$
W(j)=0.5\left[1-\cos \left(\frac{2 \pi j}{N-1}\right)\right]
$$

Com isso, a densidade espectral $S$ é obtida através de:

$$
S(k)=\frac{2}{C_{w} N f_{s}}|A(k)|^{2}
$$

Em 4.9 o número de onda $k$ varia de $0 \leqslant k \leqslant N / 2, f_{s}$ representa a resolução espacial $1 / d x$. Também é aplicada uma correção para a função janela, $C_{w}$, calculada a partir da relação:

$$
C_{w}=\frac{1}{N} \sum_{j=0}^{N-1} W^{2}(j)
$$

Esses cálculos foram realizados para valores de energia cinética em três níveis verticais 850hPa, 500hPa e 200hPa. Para baixos níveis, não há influência direta do nudging, ao passo que o mesmo se torna determinante em níveis verticais mais elevados. 


\subsection{Resultados}

Cálculos do EMQ encontram-se na figura 4.2. A comparação com dados do ERAInterim (painel direito) demonstra que qualquer aplicação de relaxação oferece uma melhora no desempenho dos resultados. Isso é observado sem grandes distinções entre os casos. Esse é um resultado esperado uma vez que, com a aplicação da relaxação em qualquer escala, feições de larga escala que oferecem suporte à ZCAS são incorporadas à solução no interior da grade. Já a comparação com a própria referência utilizada, aponta para diferenças graduais entre os experimentos. Isso indica que a escolha do número de onda oferece um impacto para a solução.

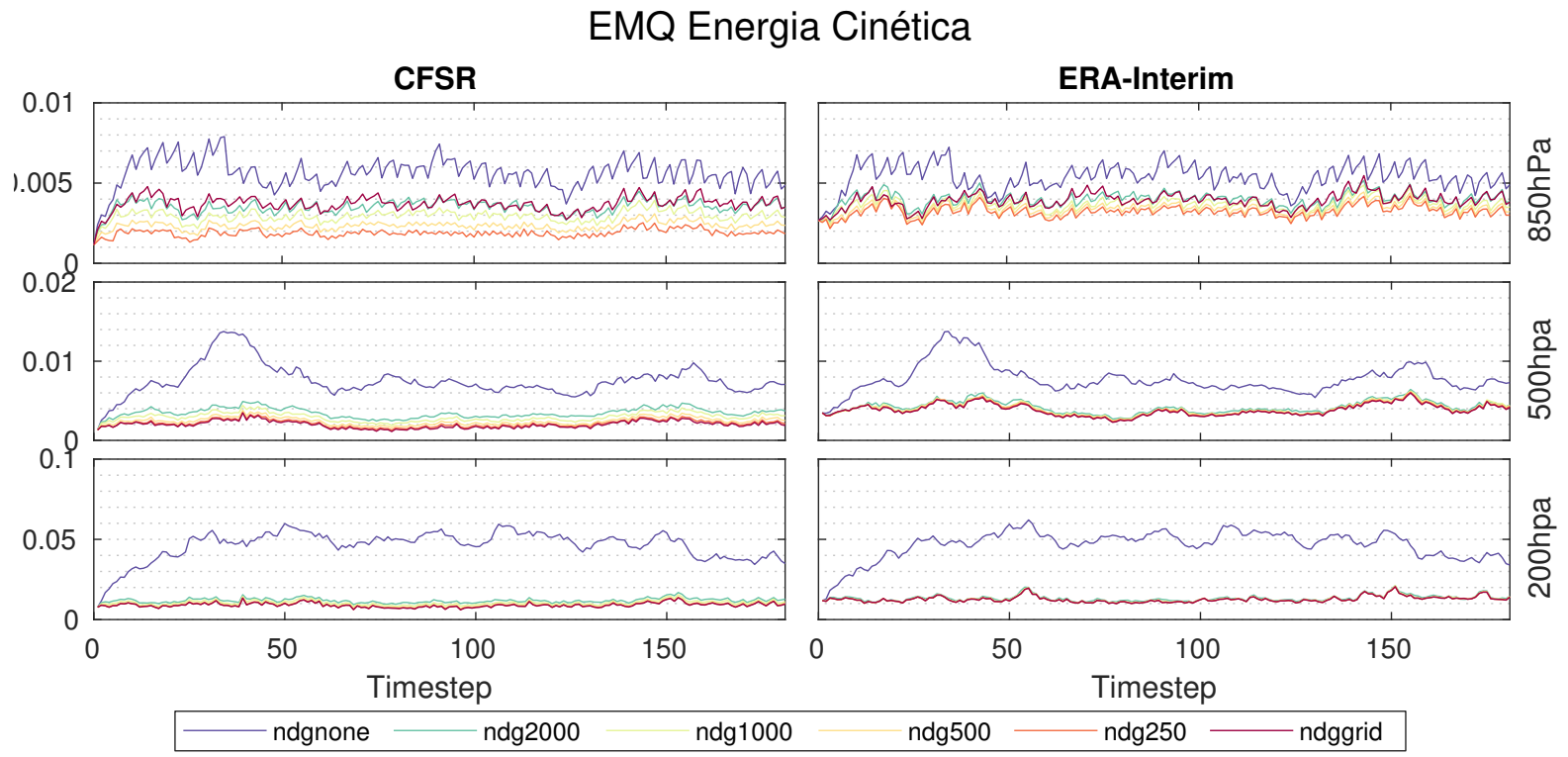

Figura 4.2: Erro Médio Quadrático da energia cinética detodos os experimentos e sua condição de referência (CFSR - esquerda) e uma base da dados externa (ERA-Interim, direita)

Essa relação também pode ser observada para os valores de EMQ dos espectros de energia cinética, ilustrados na figura 4.3. Para o nível de $850 \mathrm{hPa}$, verificam-se diferenças notáveis entre todos os experimentos quando comparados com suas referências. Isso mais uma vez indica que a escolha de diferentes números de onda para a relaxação espectral pode impactar os resultados. Esse padrão também é verificado para médios e altos níveis, porém o espalhamento entre as curvas é menos pronunciado. Mais uma vez, a comparação com uma reanálise externa (figura 4.3 , esquerda) aponta para uma melhora no desempenho do modelo de uma maneira geral. 


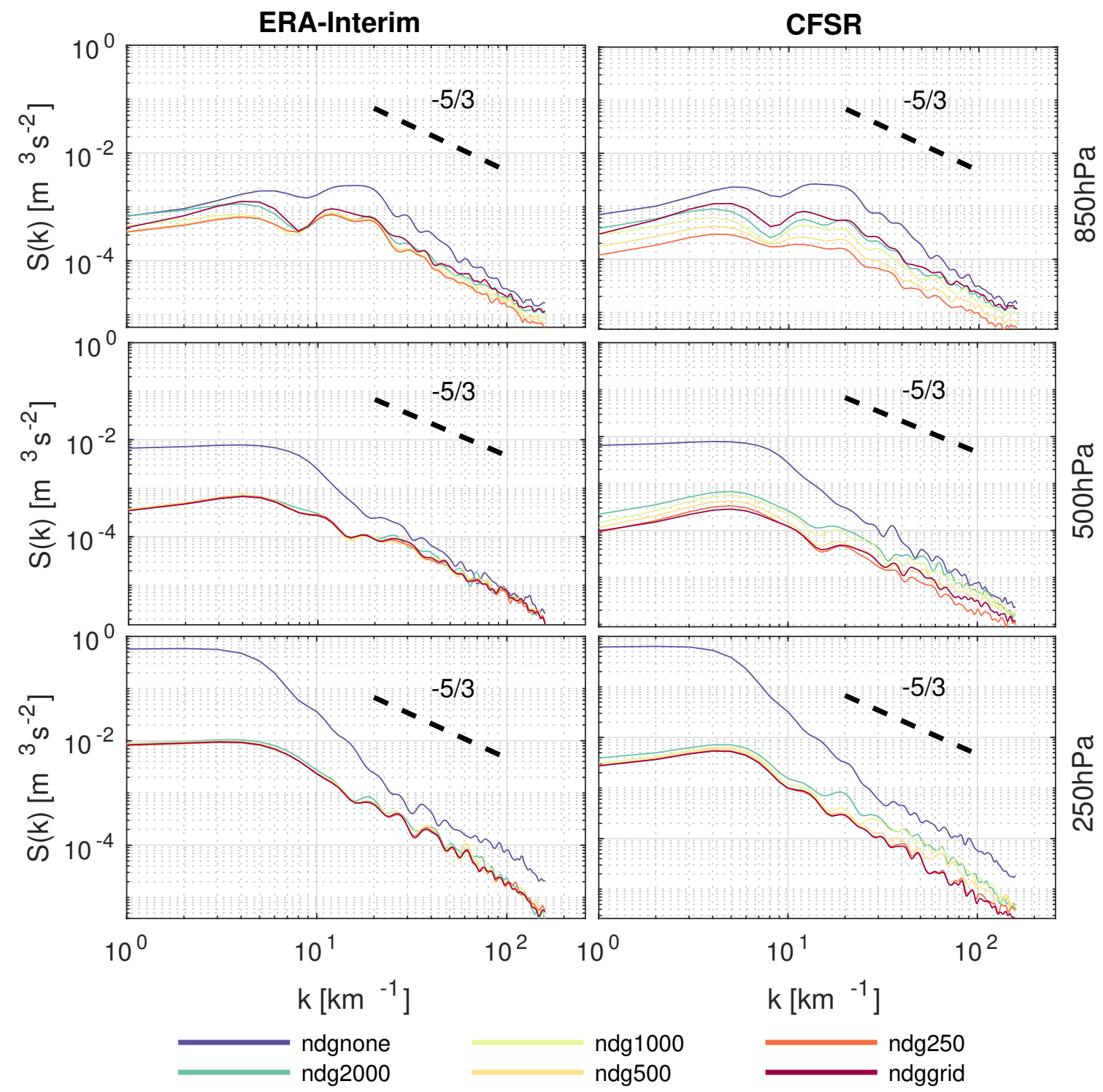

Figura 4.3: Erro Médio Quadrático dos espectros espaciais de energia cinética para todos os experimentos calculados com relação a uma base de dados externa (ERA-Interim - esq.) e sua referência (CFSR - dir.)

Para avaliar como os diferentes experimentos representaram as feições associadas à ocorrência do evento, os seguintes mapas foram gerados: umidade específica e linhas de corrente $850 \mathrm{hPa}$, que oferecem uma noção da convergência de umidade que atua como fonte de umidade para o desenvolvimento da ZCAS, além de apontar para estruturas que influenciem em seu posicionamento; temperatura e altura geopotencial em 500hPa, podem apontar para estruturas que dão suporte à ZCAS; linhas de corrente e velocidade do vento em $200 \mathrm{hPa}$, apontam para o posicionamento dos jatos em altos níveis e para a repre- 
sentação de estruturas de larga escala importantes para o desenvolvimento e manutenção do sistema. Na figura 4.4 é evidente a distorção da estrutura de larga escala presente nas soluções com o experimento ndgnone. Isso pode estar diretamente relacionado com a amplificação de erros no interior do domínio, impedindo o desenvolvimento de feições importantes. A aplicação do nudging espectral para comprimentos maiores ou iguais a 2000 km (ndg2000) já é suficiente para o desenvolvimento de estruturas que favorecem o desenvolvimento e a persistência da ZCAS. As figuras da coluna à direita apresentam os campos médios do CFSR (referência para o nudging) e, para todos os experimentos, desde o menos restritivo ( $n d g 2000)$ até o mais restritivo ( $n d g 250)$ nota-se a presença do vórtice ciclônico na região costeira do sudeste do Brasil. A representação dessa feição é importante para garantir a correta localização do fenômeno. Já na figura 4.5, persiste a distorção da larga escala para a simulação sem a implementação do nudging e, assim como para a figura 4.4, há uma melhora substancial mesmo com uma aplicação menos restritiva. Em todos os experimentos, verificou-se a presença de um cavado acima da região de atuação do vórtice ciclônico apontado na figura 4.4, oferecendo suporte dinâmico para o estabelecimento da ZCAS. Em altos níveis, a figura 4.6 apresenta uma condição parecida com os campos apresentados para níveis inferiores. A ausência da relaxação durante a simulação compromete o desempenho do modelo severamente. Ao passo que a utilização do método, ainda que para feições de larga escala apenas, é suficiente para uma melhora significativa no desempenho. 
Linhas de corrente e umidade específica em 850hPa

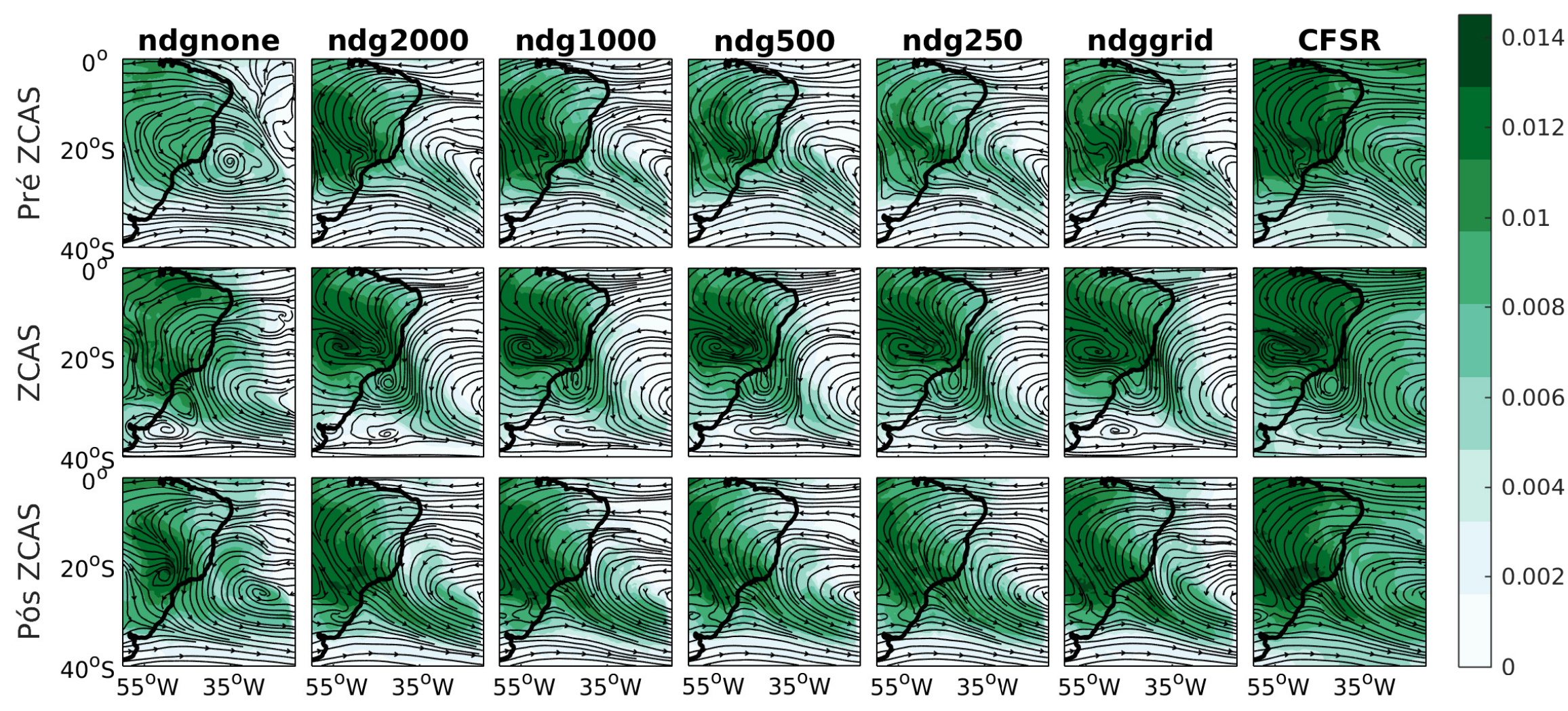

Figura 4.4: Umidade específica e linhas de corrente em $850 \mathrm{hPa}$. Campos médios dos dias que antecedem (painéis superiores) e sucedem (painéis inferiores) o evento de ZCAS (painéis centrais) 
Temperatura e altura geopotencial [gpm] em 500hPa

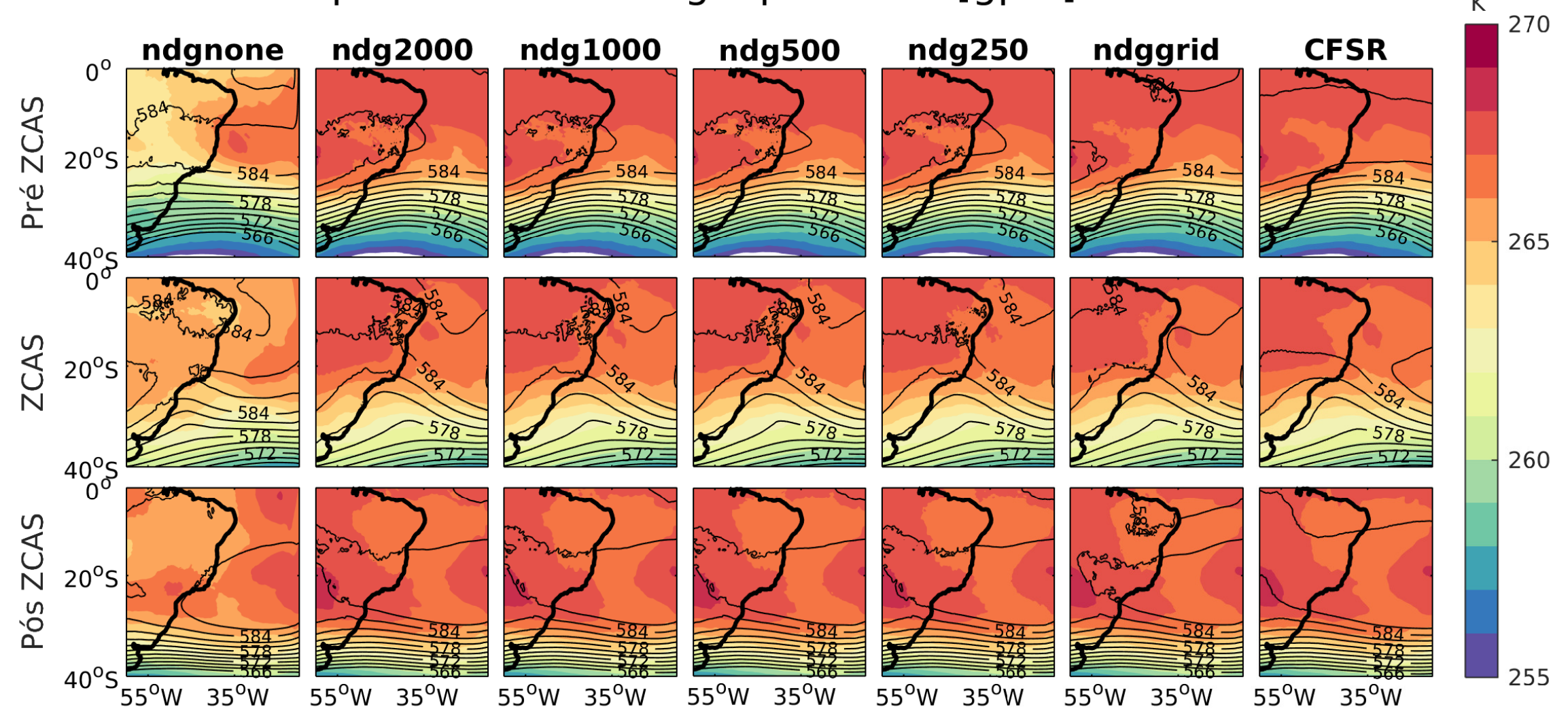

Figura 4.5: Mesma esqumatização da figura 4.4 porém para temperatura e algura geopotencial em 500hPa. 


\section{Linhas de corrente e velocidade do vento em $200 \mathrm{hPa}$}

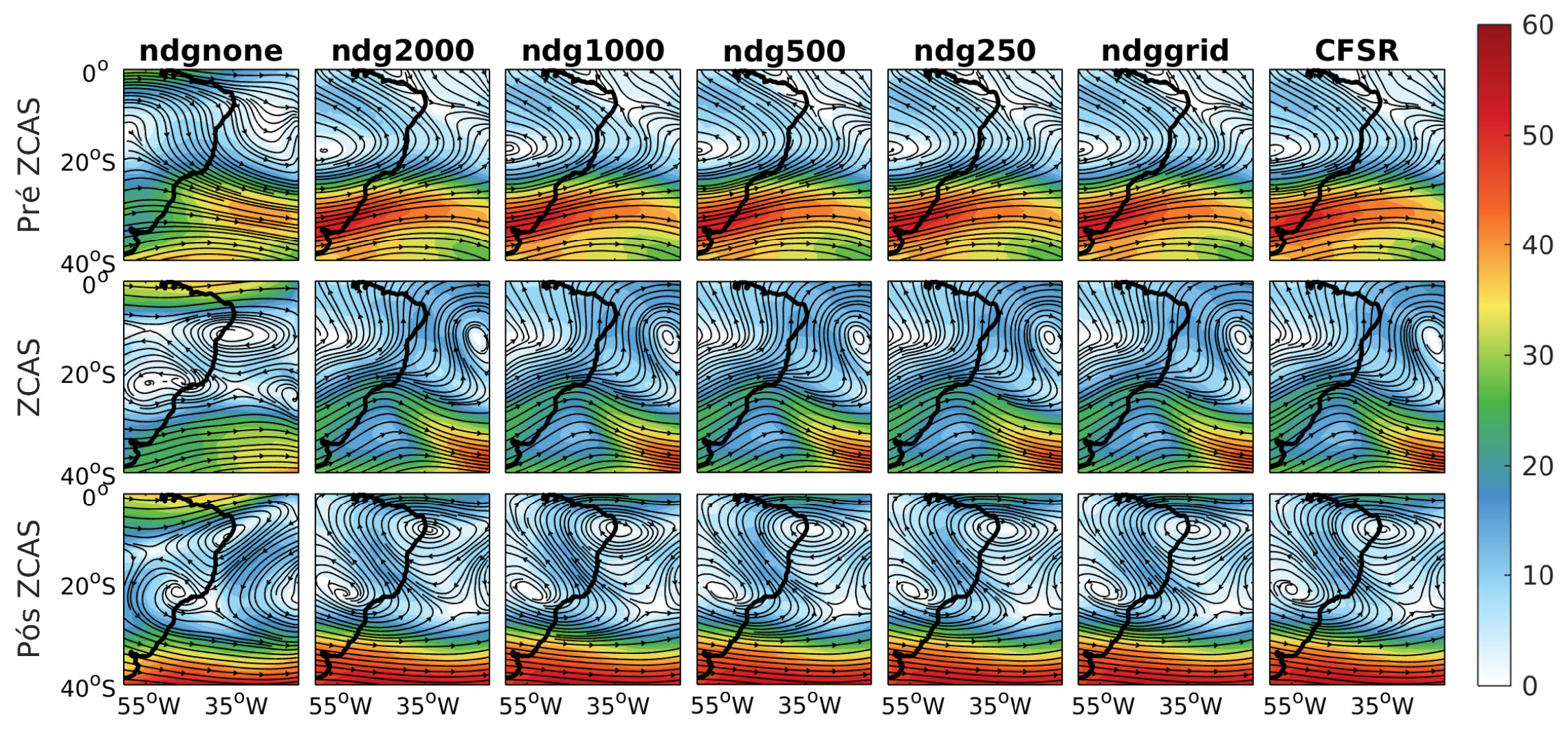

Figura 4.6: Mesma esquematização da figura 4.4 porém para linhas de corrente e velocidade do vento em 200hPa 
Uma vez estabelecida a estrutura geral que suporta dinamicamente o sistema através da aplicação do nudging, mapas com os mesmos campos representando a progressão média do evento a cada cinco dias encontram-se nas figuras 4.7, 4.8 e 4.9. Para os mapas em baixos níveis (figura 4.7) é possível visualizar algumas diferenças entre os campos de cada experimento, principalmente na região de formação do vórtice ciclônico. Além disso, a umidade na região continental da ZCAS mostra-se ligeiramente menor para aplicações de nudging mais restritivas (ndg500,ndg260,ndggrid). Quando comparados com o CFSR, todos os resultados parecem subestimar a umidade no domínio, principalmente ao redor da estrutura da ZCAS. As figuras de temperatura e geopotencial em 500hPa (ilustradas em 4.8 também exibem diferenças em relação ao campo de referência do CFSR, também sobre a região de atuação do vórtice ciclônico. Isso é um bom indicativo de que o modelo demonstra ter liberdade para atuar nas escalas mais baixas, muito embora esteja restrito à condição de referência para a larga escala. Em altos níveis, o cavado sobre a região de atuação do vórtice ciclônico em baixos níveis oferecendo suporte dinâmico para o posicionamento da ZCAS sobre a região costeira do Espírito Santo, está presente em todos os experimentos e apresenta notável semelhança em relação à sua referência. Esse resultado é esperado uma vez que as variáveis ilustradas sofreram nudging e muitas das estruturas presentes nessa camada da atmosfera pertencem à larga escala. 
Linhas de corrente e umidade específica em 850hPa

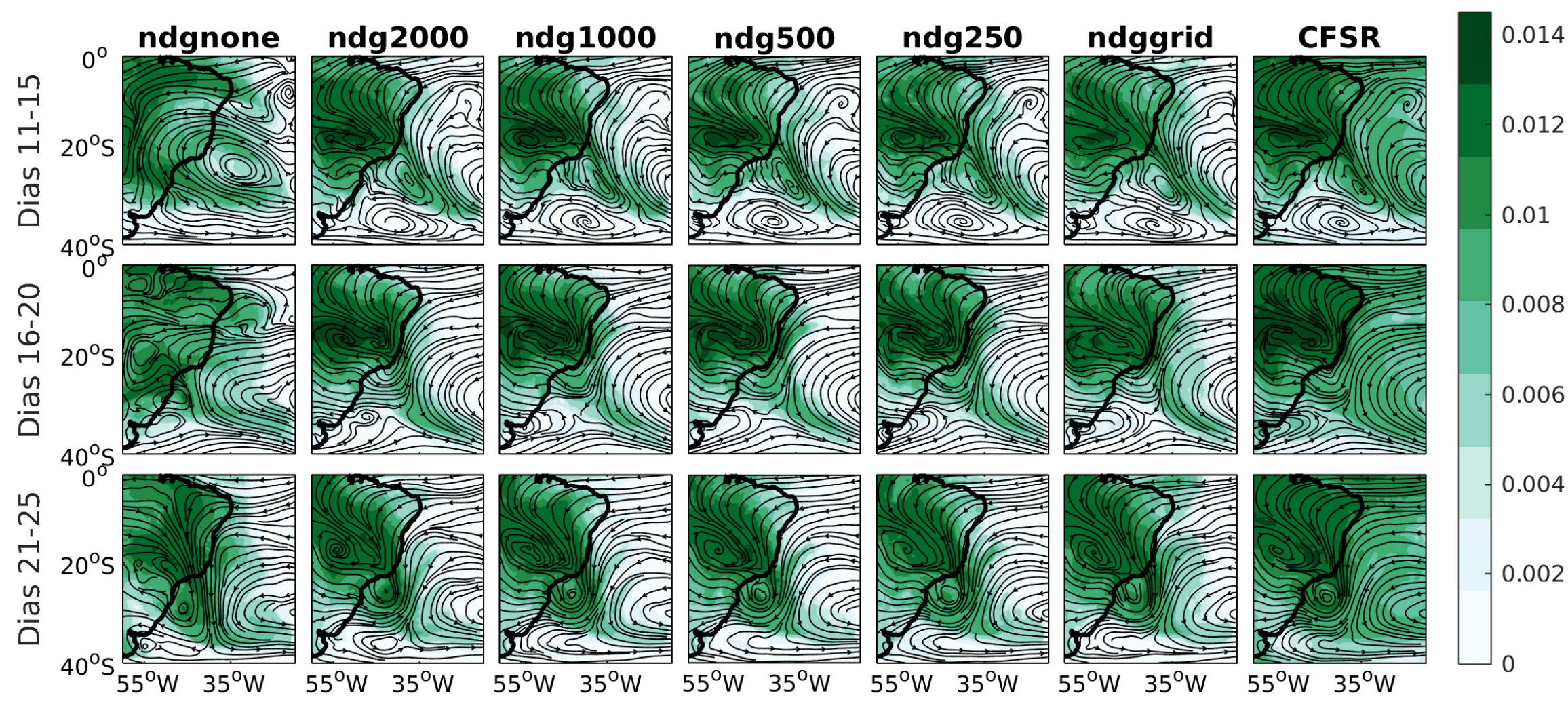

Figura 4.7: Umidade específica e linhas de corrente em 850hPa. Campos médios entre os dias 11/12-15/12 (painéis superiores), 16/12-20/12 (painéis centrais) e 21/12-25/12 (painéis inferiores) 
Temperatura e altura geopotencial [gpm] em $500 \mathrm{hPa}$

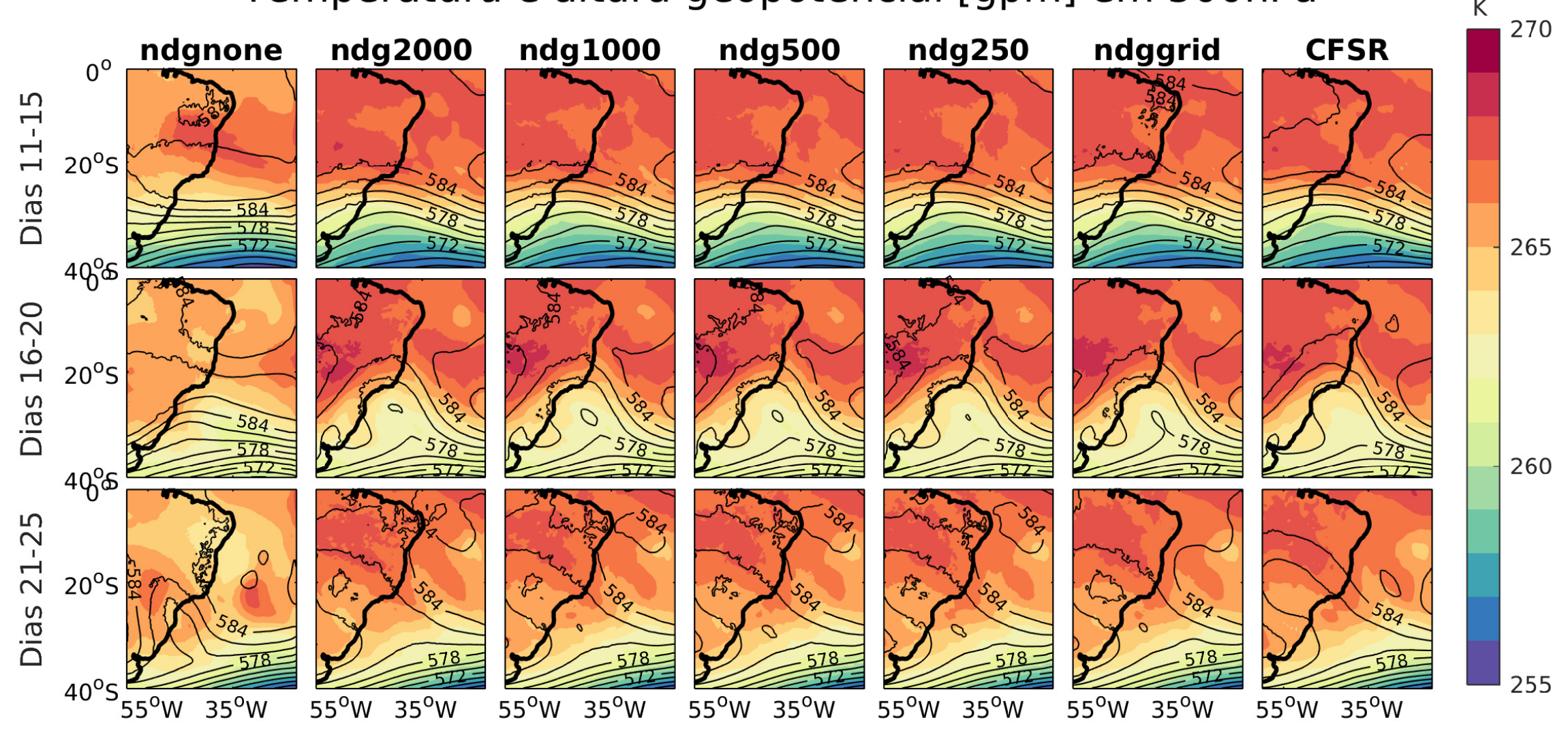

Figura 4.8: Mesma esqumatização da figura 4.7, para temperatura e algura geopotencial em 500hPa. 
Linhas de corrente e velocidade do vento em $200 \mathrm{hPa}$

$\mathrm{m} / \mathrm{s}$

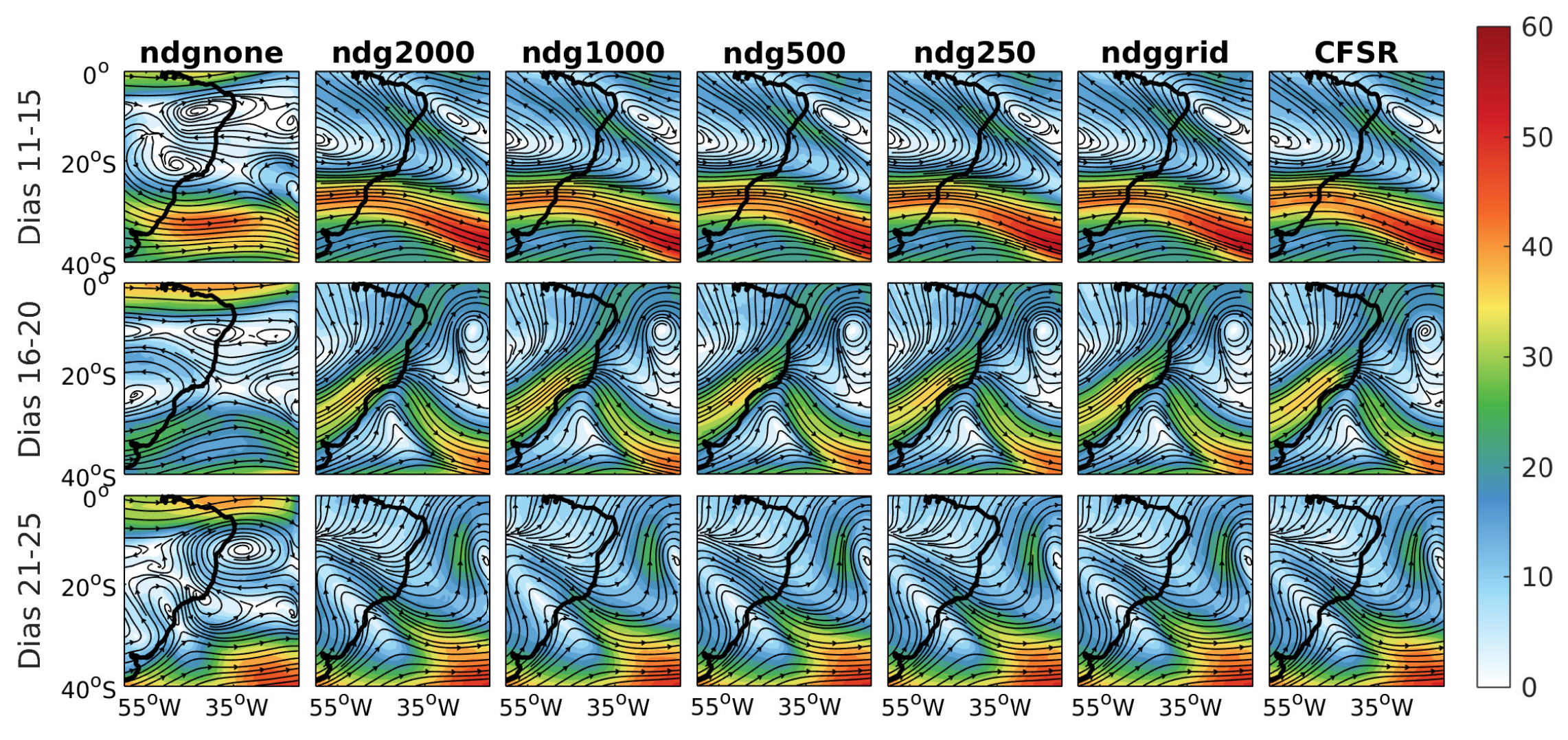

Figura 4.9: Mesma esqumatização da figura 4.7. para linhas de corrente e velocidade do vento em 200hPa 
Os mapas descritos anteriormente apontam para a necessidade de utilização do nudging espectral para a representação adequada do fenômeno de ZCAS determinado para estudo numérico de duração subsazonal. Os campos médios, tanto para o período completo da simulação quanto para o evento especificamente, apontam para a constatação de que a utilização do nudging, de qualquer tipo em qualquer escala, implica em uma grande melhora de desempenho e significativa diminuição no viés. Porém, essa alternativa não deve ser utilizada indiscriminadamente, uma vez que o nudging de um espectro muito amplo pode inibir a participação do modelo na solução numérica. As figuras 4.10 e 4.11 ilustram os campos de precipitação acumulada durante todo o período de simulação e especificamente para o período de atuação da ZCAS, respectivamente. Nota-se que a precipitação associada à ZCAS esteve bem representada em todas as simulações com a ulização do nudging quando comparadas com os acumulados do TRMM. A ausência de uma banda convectiva bem definida para o experimento ndgnone é esperada, uma vez que os campos mostrados anteriormente apontam para a ausência de uma estrutura para suportar o sistema nas soluções desse teste. Em ambas as figuras (4.10 e 4.11), muito embora a banda de precipitação associada à zona de convergência esteja bem posicionada em comparação com o TRMM para todos os experimentos com nudging, há diferenças importantes entre os resultados desses experimentos. Especialmente quanto a localização de núcleos convectivos ao longo do eixo da ZCAS. 


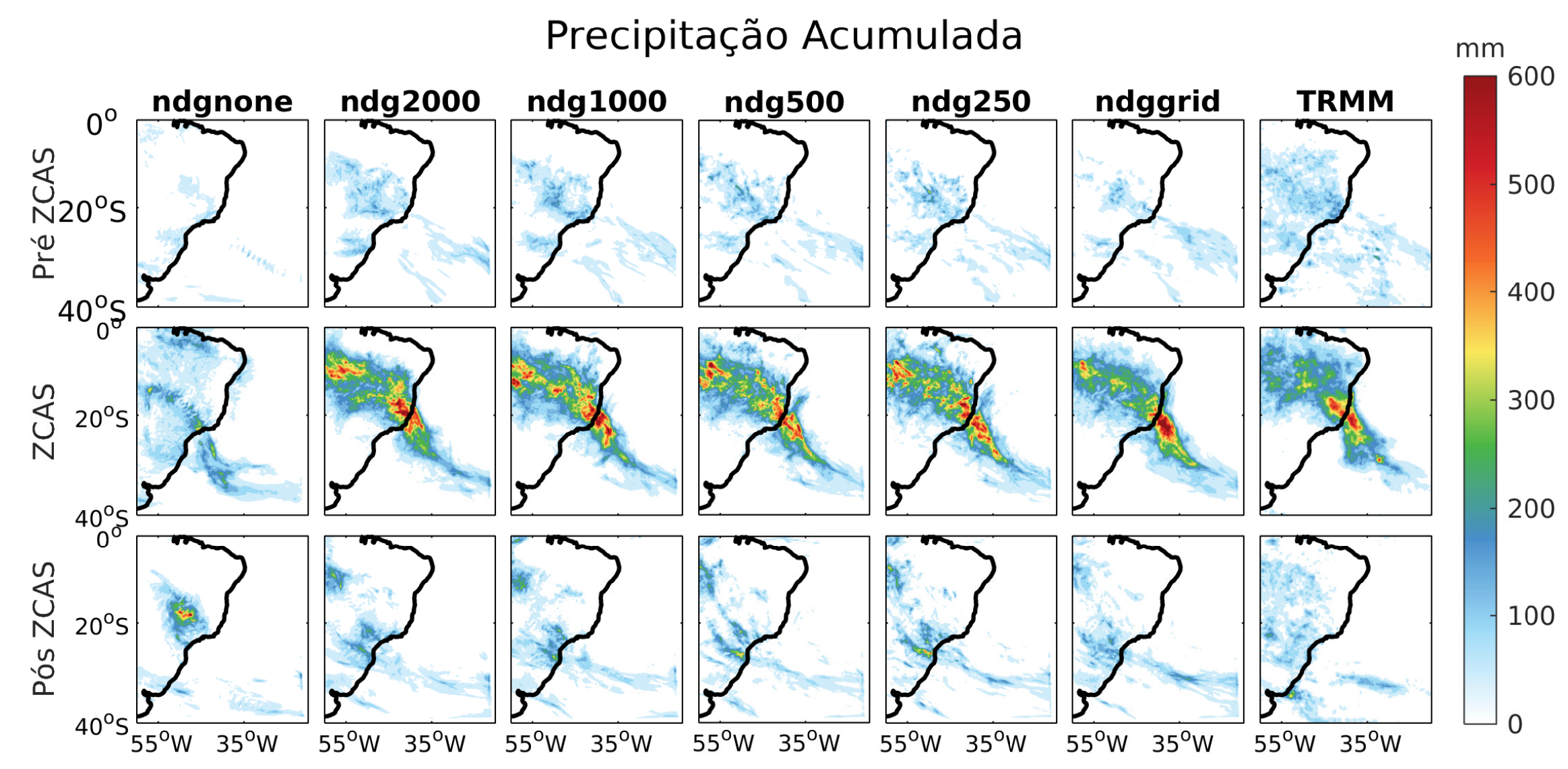

Figura 4.10: Precipitação acumulada nos períodos anteriores (painéis superiores) e posteriores (painéis inferiores) do evento de ZCAS (painéis centrais) 


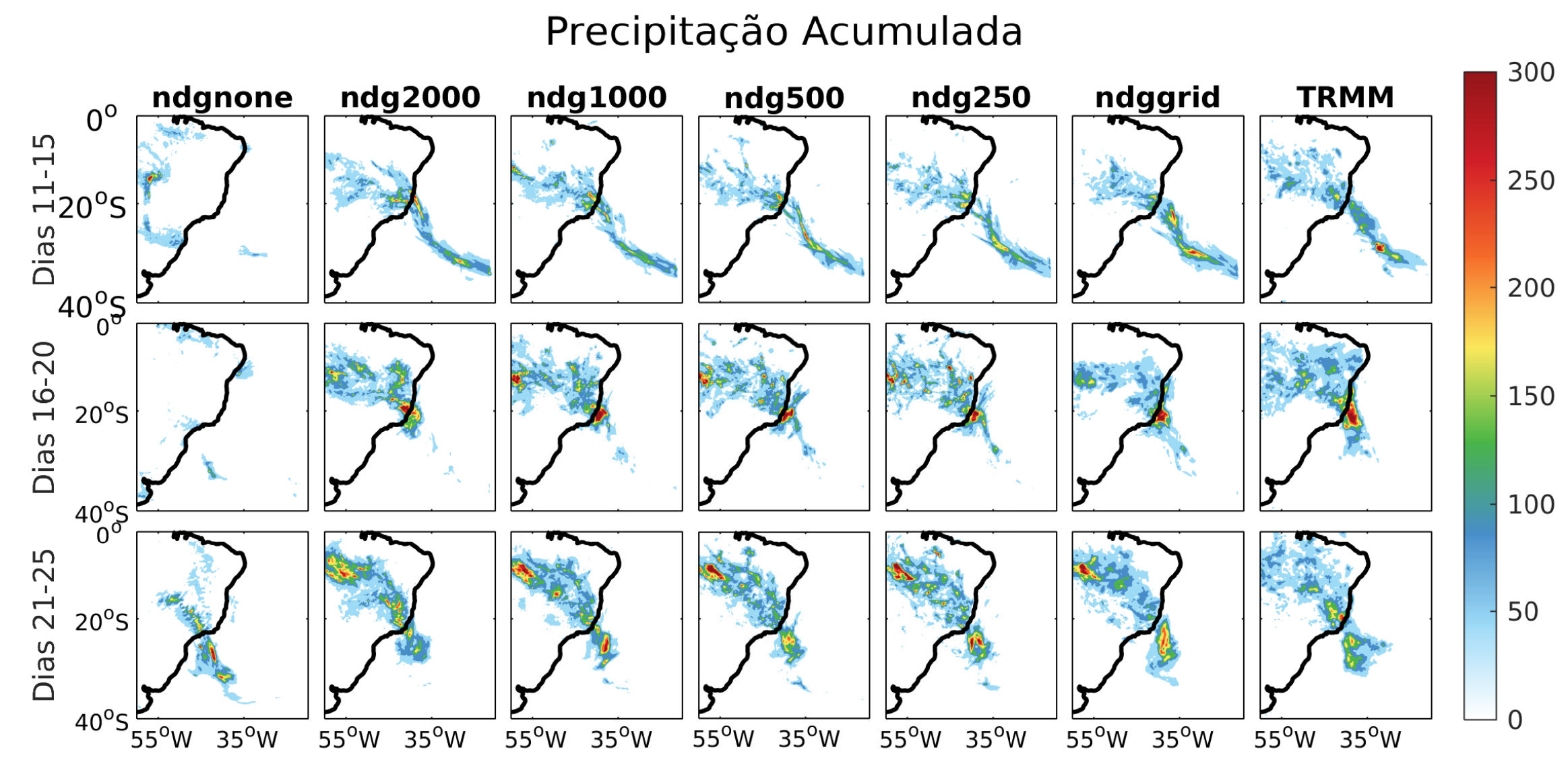

Figura 4.11: Precipitação acumulada entre os dias 11/12-15/12 (superiores), 16/12-20/12 (centrais) e 21/12-25/12 (inferiores) 
Os resultados descritos indicam que, para uma representação numérica adequada da ZCAS em simulações mais longas (subsazonais), a utilização do método de relaxação newtoniana é necessário para que a estrutura que suporta dinamicamente esse sistema seja formada. E, muito embora os resultados sejam satisfatórios para todos testes com diferentes números de onda na aplicação do nudging espectral, diferenças entre a maneira com que cada caso representa a convecção são notáveis. Assim, deve-se buscar sempre a alternativa menos restritiva na aplicação do nudging para os módulos físicos do modelo contribuam ativamente para a representação da convecção. Dentre os experimentos supramencionados, a alternativa com números de onda referentes a comprimentos de $2000 \mathrm{~km}$ é ideal. E a maneira como o modelo WRF atua na geração de chuva com essa configuração será abordada no capítulo a seguir. 
Capítulo 5

\section{Experimentos Numéricos: Impactos das Parametrizações de Cumulus e Microfísica}

Modelos numéricos usualmente incorporam dois tipos de parametrização para a geração de precipitação, convectiva e de microfísica. Esquemas de microfísica tendem a emular atividades no interior da nuvem e representar processos para a remoção da umidade da atmosfera. Já a parametrização da convecção não atua exclusivamente na geração de precipitação, mas também no transporte de calor entre camadas atmosféricas, na redistribuição de umidade e, consequentemente, estabilização da camada atmosférica. Se um núcleo de convecção se estender por uma ampla cobertura, pode-se gerar correntes de jato e vórtices que interagem com a atmosfera local e modificam as condições em sua área de atuação (Stensrud, 2003). Uma vez que a convecção só é explicitamente resolvida por modelos numéricos com resoluções maiores do que 3km (Stensrud, 2003), as parametrizações dos processos físicos associados à presença desses sistemas se encarregam de atuar no transporte de calor e estabilização da camada atmosférica numericamente representada.

\subsection{Configuração dos Experimentos}

\subsubsection{Parametrizações de Cumulus}

- Kain-Fritsch - CTRL (Kain, 2004): a parametrização utilizada como controle é baseada no fluxo de massa vertical. Seu gatilho, i.e. disparo para a convecção, é acionado quando o algoritmo identifica elementos suficientes para o início do processo. Tais elementos baseiam-se nas condições termodinâmicas locais favoráveis para o levantamento de uma parcela a fim de se estabilizar o ambiente. 
- Betts-Miller-Janjic - BMJ (Janjić, 1994): Com esse esquema, a convecção é gerada parar o ajuste do perfil vertical de temperatura e umidade para um estado de referência baseado em uma climatologia. Tal esquema ainda conta com caracterizações distintas para convecção rasa e profunda, que depende de um termo proporcional à temperatura média da nuvem e à transição de entropia.

- Grell3D Ensemble (Grell e Dévényi, 2002): Esse esquema utiliza um ensemble, i.e. um conjunto de diversas representações de nuvens do tipo cumulus através do fluxo de massa. Com esse esquema, duas circulações estacionárias, updraft,downdraft, são representadas no processo de formação de nuvens.

\subsubsection{Parametrizações de Microfísica}

Foram realizados testes para a verificação do desempenho das simulações a partir de diferentes esquemas de parametrização de microfísica, muito embora a baixa resolução dos experimentos contribua para menor realismo dos resultados. Ainda assim, trata-se de um processo necessário para a resolução da saturação da atmosfera em grande escala. Ainda de acordo com Stensrud (2003), as equações dos modelos de microfísica possuem a seguinte forma geral:

$$
\frac{\partial q_{x}}{\partial t}=-A D V\left(q_{x}\right)+T U R B\left(q_{x}\right)+\left(P_{1}+P_{2}+P_{3}+P_{4}+P_{5}+\ldots\right)
$$

Onde $q_{x}$ é a variável sendo tratada na parametrização de microfísica (razão de mistura, água na nuvem, gelo, etc.), $A D V$ representa os termos advectivos, $T U R B$ representa os termos turbulentos e $P_{i}$ representa as relações entre espécies nas parametrizações de microfísica. Tais relações são geradas por processos de: (1) condensação, (2) autoconversão, (3) acresção, (4) evaporação, (5) geração de gelo, (6) agregados de gelo e neve, (7) acresção por partículas congeladas, (8) deposição, (9) derretimento. Os principais esquemas de microfísica, em geral, diferem entre si pelo número de interações que realizam. No presente trabalho, foram testados três esquemas de microfísica:

- WRF Single Moments 6-Class - CTRL (Hong et al., 2004): Possui 6 classes de hidrometeoros representados e prevê apenas a razão de mistura; 
- WRF Single Moments 3-Class - WSM3 (Hong et al., 2004): Nesse caso, conta com 3 classes de hidrometeoros e também prevê apenas a razão de mistura;

- Morrison Double Moment - MORR (Morrison et al., 2009): Essa opção conta com 6 classes de hidrometeoros e, nesse caso, além da razão de mistura, o esquema prevê a concentração das partículas.

A escolha de parametrizações de processos físico em uma simulação não deve ser feita indiscriminadamente, uma vez que seus processos interagem, como o ilustrado pelo diagrama 5.1 extraído de Zittis et al. (2014). Nos casos testados no presente trabalho, é possível que o sub-modelo de convecção consuma energia para estabilizar o sistema. Esse esquema também influencia diretamente as parametrizações de microfísica, através dos processos de entranhamento/desentranhamento (condições para mudança de fase entre hidrometeoros) e superfície, através da geração de chuvas. Parametrizações de microfísica por sua vez, podem interagir com esquemas de radiação, através de efeitos nas nuvens causados pelas relações entre espécies distintas de hidrometeoros. E também podem interagir com a superfície através da geração de chuvas.

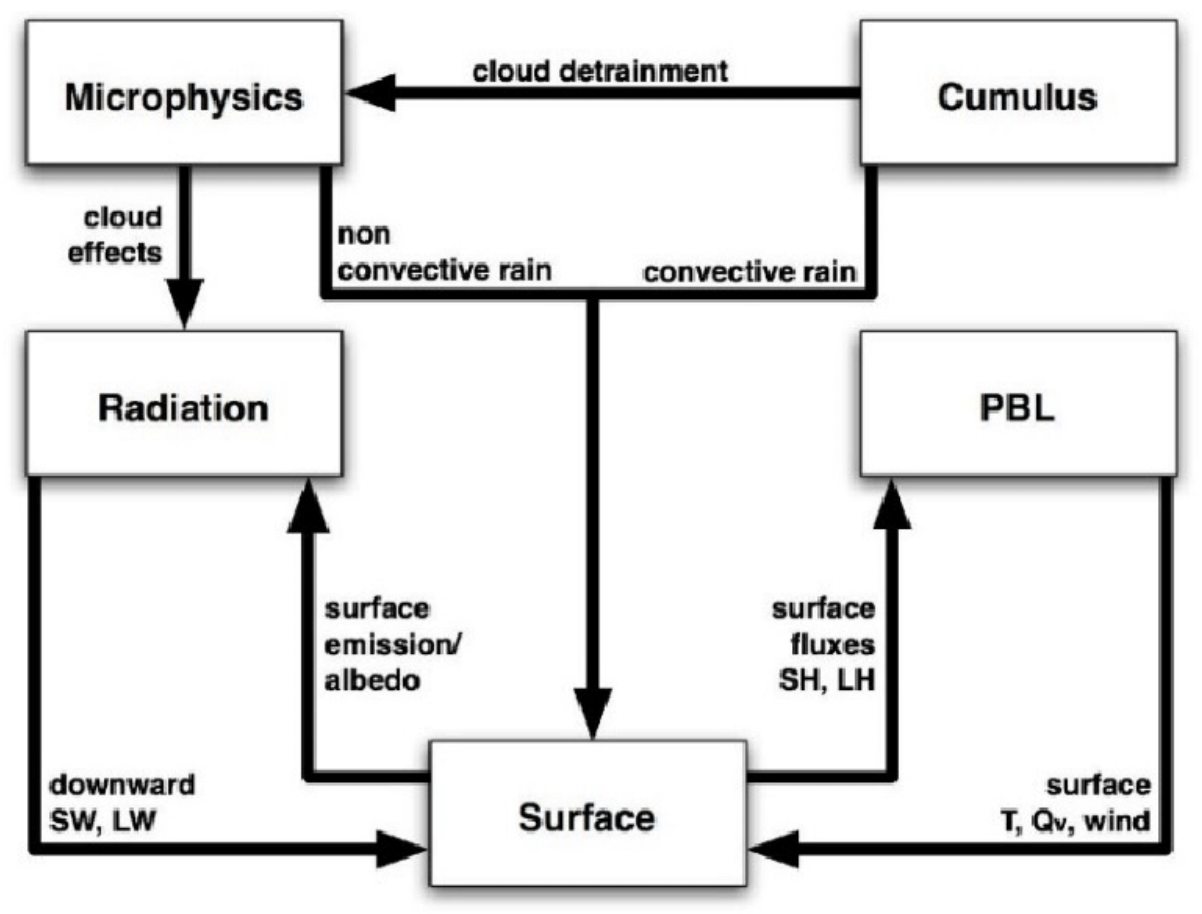

Figura 5.1: Interação entre principais esquemas de parametrização presentes no modelo WRF. Figura extraída de Zittis et al. (2014) 


\subsection{Resultados}

O campo com os acumulados de precipitação para o período de atuação da ZCAS calculado com os dados do TRMM encontra-se ilustrado na figura 5.2. Na figura também está ilustrado o eixo de atuação desse sistema. Nas regiões mais afetadas pelos excessos de chuva, os acumulados atingiram quase $600 \mathrm{~mm}$ ao longo dos 16 dias de evento. Além disso, é notável a projeção oceânica do sistema, o que sugere dois mecanismos distintos atuando na convergência de umidade do sistema (Carvalho et al., 2004). As chuvas na região costeira e oceânica também foram moduladas pela presença do vórtice ciclônico em baixos níveis, posicionado na região da costa sudeste do Brasil.

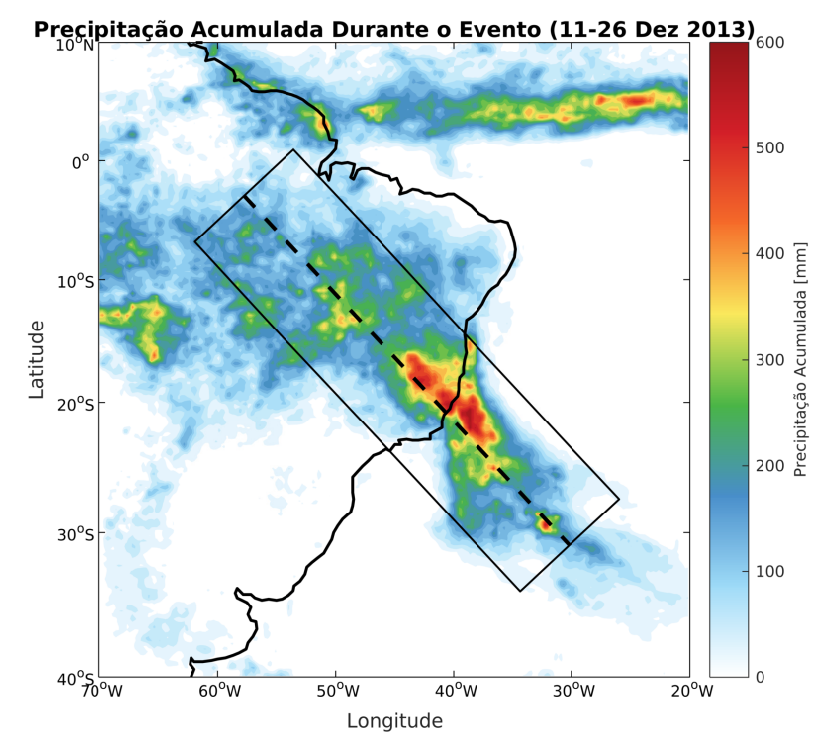

Figura 5.2: Precipitação acumulada durante o evento de ZCAS e eixo de atuação.

Já os campos de precipitação total acumulada durante o evento de ZCAS para os experimentos realizados encontram-se na figura 5.3. Assim como para a figura 5.2, o eixo de atuação do sistema está assinalado. Em todos os casos, o posicionamento da ZCAS representada pelos modelos foi adequado, até mesmo para a projeção oceânica da banda de precipitação. Porém, nota-se que a precipitação está muito mais concentrada em núcleos convectivos, ao passo que na figura 5.2 para os dados do TRMM, há uma maior distribuição da umidade. O teste G3D foi o teste que mais subestimou a precipitação na região amazônica do eixo de atuação da ZCAS. 


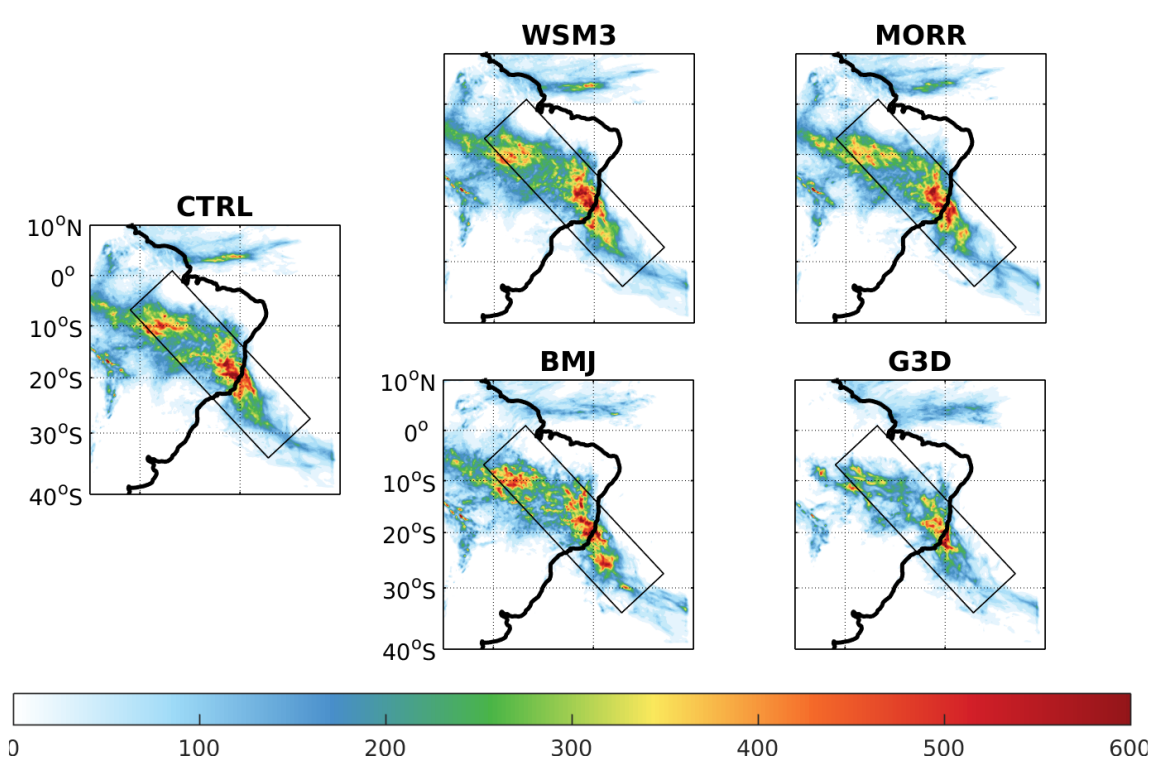

Figura 5.3: Precipitação acumulada durante o evento de ZCAS para todos os testes numéricos e o eixo de atuação correspondente ao posicionamento do TRMM.

Para a comparação da distribuição dos valores de precipitação acumulados durante o evento ao longo do eixo da ZCAS, foram tomadas as integrais nos eixos assinalados nas figuras 5.2 e 5.3 . Os resultados encontram-se na figura 5.4 e contam com outros conjuntos de observação para a verificação da representação oferecida pelos modelos. Foram calculados os acumulados para o GPCP (Xie et al., 2003), para o Climate Hazards Group InfraRed Precipitation with Station - CHIRPS - (Funk et al., 2015), e também foram assinalados os valores obtidos por estações do Instituto Nacional de Meteorologia - INMET - ao longo do eixo. Ambos CHIRPS e INMET não possuem dados sobre a região oceânica. Mesmo entre os conjuntos de observações, muitas vezes tomados como referências para a avaliação de desempenho dos modelos, notam-se diferenças importantes para esse evento, como uma projeção oceânica melhor distribuída para os dados do GPCP e nenhum dos conjuntos baseados em estimativas por satélites apresentou valores tão extremos quanto os das estações meteorológicas do INMET. Quando são comparados os resultados das simulações, nota-se que os testes de microfísica não causaram tanto impacto nessa representação, uma vez que tanto o experimento CTRL quanto os experimentos WSM3/MORR apresentam similaridades e acompanham as observações. O baixo impacto dos esquemas de microfísica na distribuição de chuvas ao longo do eixo da ZCAS é um resultado esperado, dada a baixa resolução dos experimentos. Uma exceção encontra-se na distribuição de chuvas na região oceânica, subestimada em todos os experimentos numéricos. Já a escolha de parametrizações convectivas acarreta em um impacto substancial nessa representação. As chuvas ao longo do eixo da ZCAS foram subestimadas pelo experimento G3d. Muito embora o esquema BMJ seja baseado em um processo que difere do esquema da simulação CTRL, 
a distribuição das chuvas nesse eixo não diferem muito dos demais experimentos e das observações.

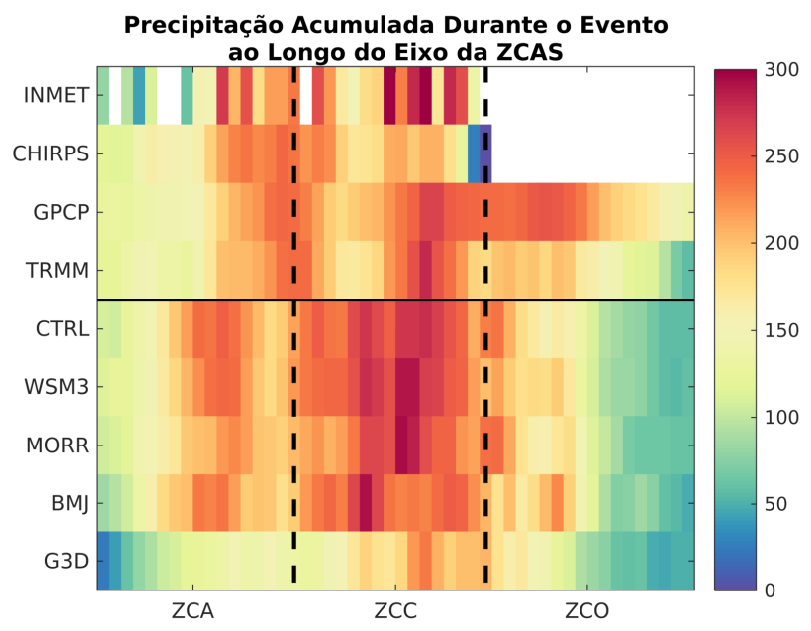

Figura 5.4: Integral de precipitação acumulada no eixo de atuação da ZCAS.

Para se visualizar a contribuição de cada esquema de parametrizção, convectiva e de microfísica, na precipitação total do evento as figuras 5.5 e 5.6 apresentam os mapas com os acumulados das chuvas convectivas, resultantes do esquema de parametrização de cumulus. Ao passo que as figuras 5.7 e 5.8 demonstram os mapas com os acumulados de chuvas nãoconvectivas, resultantes da atuação dos esquemas de microfísica. Em geral, nota-se que a parcela não-convectiva contribui mais para chuvas na região costeira e oceânica, ao passo que a microfísica gera mais precipitação para a região costeira e continental. Também nota-se que os esquemas de parametrizações de cumulus testados, BMJ e G3D, pouco contribuem para a geração de precipitação associada a ZCAS, sendo essa basicamente suportada pelo esquema de microfísica do experimento controle WSM6. É possível que esses esquemas tenham contribuído para garantir a estabilidade atmosférica e atuado com mais força na redistribuição vertical de umidade e calor.
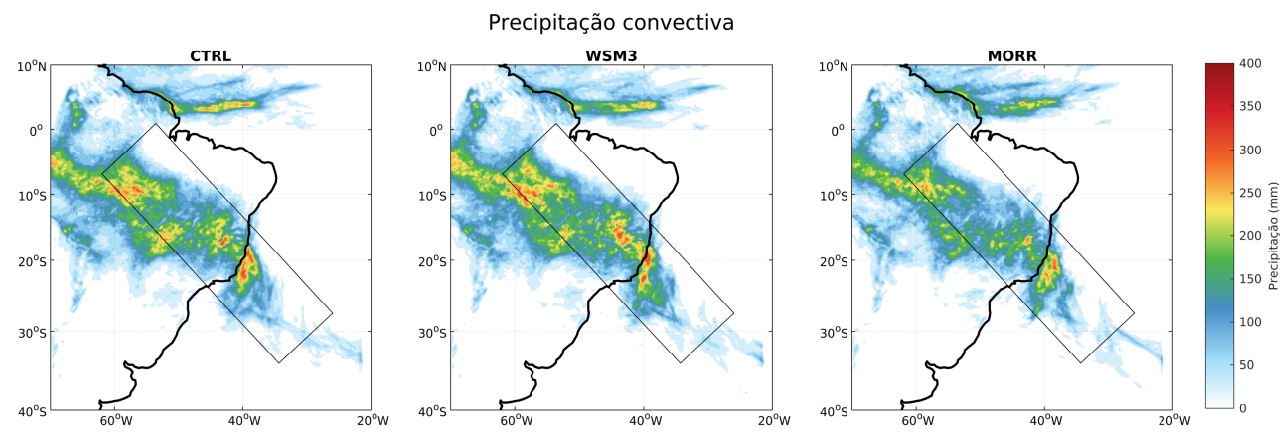

Figura 5.5: Acumulado de chuva convectiva para os experimentos CTRL, WSM3 e MORR. 

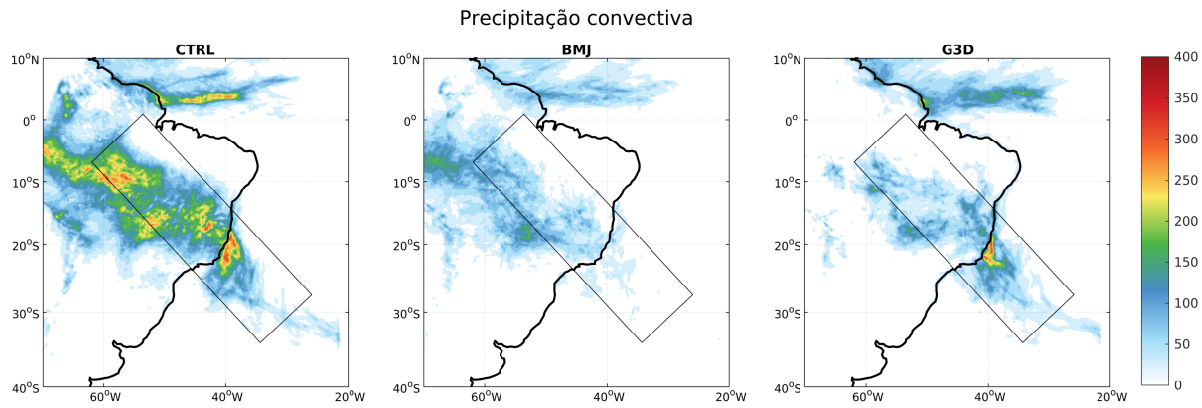

Figura 5.6: Acumulado de chuva convectiva para os experimentos CTRL, BMJ e G3D.
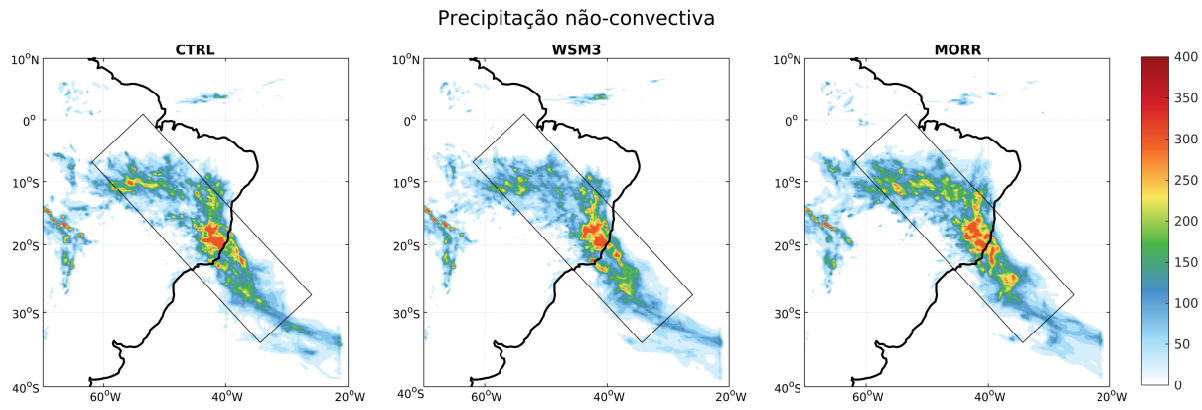

Figura 5.7: Acumulado de chuva em pontos de grade (microfísica) para os experimentos CTRL, WSM3 e MORR.
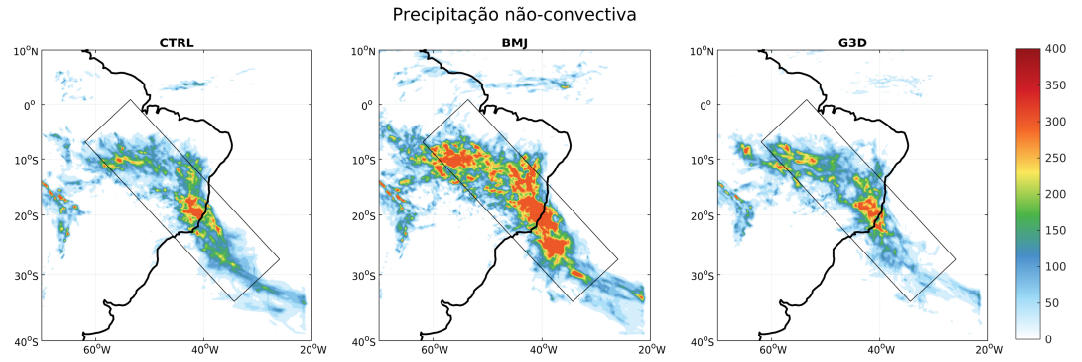

Figura 5.8: Acumulado de chuva em pontos de grade (microfísica) para os experimentos CTRL, BMJ e G3D.

A partir dos resultados apresentados, é possível inferir que a banda de precipitação associada ao sistema ZCAS foi apropriadamente representada em todos os experimentos realizados, com exceção do teste G3D que apresentou uma subestimativa dos acumulados de chuva na região. Uma vez que o esquema G3D utiliza um ensemble de aplicações, sua aplicação utiliza diferentes estruturas para o disparo da convecção, diversos mecanismos de ajuste e diferentes hipóteses de fechamento. Esse esquema oferece ao usuário diversas 
opções de ajuste fino para cada uma dessas características, o que não foi explorado no presente estudo. Assim, é possível que o esquema padrão para esses parâmetros não ofereçam as melhores condições para o evento em estudo. Além disso, segundo Skamarock e Klemp (2008), a parametrização G3D inclui efeitos de subsidência nos pontos de grade vizinhos, o que torna o método mais adequado para aplicações em grades com espaçamento inferior a $10 \mathrm{~km}$. Os autores argumentam que esse esquema pode ser utilizado em aplicações com espaçamento de grade maior, porém os efeitos de subsidência podem ocorrer no mesmo ponto de grade do processo de convecção, tornando-o menos eficiente. Apenas na simulação controle houve contribuição de ambos os esquemas de precipitação (KF e WSM6) para a geração da precipitação associada à ZCAS. Isso não invalida totalmente o papel das parametrizações BMJ e G3D, uma vez que sua atuação pode ter sido acentuada na estabilização termodinâmica das camadas atmosféricas e na redistribuição vertical de propriedades, também contribuindo para o desempenho das parametrizações de microfísica. Os resultados também apontam para uma possibilidade de se utilizar um esquema de microfísica mais simples (WSM3) para a representação do sistema, uma vez que os desempenhos entre diferentes testes em microfísica foram semelhantes. Isso está diretamente associado à resolução escolhida para os experimentos. Tendo em vista a baixa resolução determinada, a contribuição dos esquemas de microfísica se torna menos impactante. 
Capítulo 6

\section{Conclusões}

\subsection{Conclusões Gerais}

No presente estudo, buscou-se contribuir com o conhecimento dos mecanismos de formação e manutenção de um episódio especialmente intenso de ZCAS. Para tal, foi realizada uma análise observacional para a identificação desse sistema para a implementação de um estudo numérico em escala sub-sazonal. Estudos sobre a sua previsibilidade são extremamente importantes, tendo em vista que a ZCAS atua diretamente sobre uma das regiões mais socioeconomicamente importantes da América do Sul. Através da análise dos índices LISAM/ZCAS, o episódio de 11/12/2013 a 26/12/2013 foi diagnosticado para uma análise numérica, uma vez que se mostrou anomalamente intenso e duradouro. Esse evento de ZCAS foi sustentado por uma estrutura em larga escala que contou com a atuação de um vórtice ciclônico na região costeira do sudeste do Brasil com suporte em altos níveis. A presença desse vórtice foi fundamental para manter a ZCAS a norte de sua posição climatológica. Além disso, a análise sinótica do caso apontou para a geração de ondulações associadas à presença desse vórtice. Aliada a isso, a configuração da divergência de umidade em baixos níveis corroborou para a atuação dessa feição na retenção de umidade e sustentação do movimento ascendente em médios níveis e intensificação da divergência em altos níveis. Esses processos mostraram-se fundamentais na organização da convecção na manutenção das condições favoráveis ao desenvolvimento dessa situação de ZCAS. A representação numérica de um caso de ZCAS nesse contexto mostrou-se particularmente desafiadora, uma vez que a ZCAS constitui um sistema bastante complexo, com seu desenvolvimento e evolução atrelados a essas feições atmosféricas de larga-escala.Em estudos numéricos desse tipo, muitas vezes as informações externas conduzidas para o interior da 
grade numérica não são incorporadas nas soluções finais. Aplicações de relaxação espectral para seis opções de número de onda foram conduzidas, a fim de garantir a representação desse evento, fortemente influenciados por estruturas de larga escala. Verificou-se que a aplicação da relaxação em todos os experimentos contribuiu para uma substancial melhora no desempenho da simulação. Porém, é aconselhável utilizar a alternativa menos restritiva na aplicação da relaxação para os componentes físicos do modelo contribuam ativamente para a representação da atmosfera em menor escala. Dentre os experimentos realizados, a alternativa com números de onda referentes a comprimentos de 2000 km é a ideal. Porém, não foram realizados testes com diferentes configurações de relaxação no tempo. O valor utilizado no presente estudo foi de $0.0003 s^{-1}$ (aproximadamente 1 hora) e, muito embora seja comumente utilizado, é bastante restritivo e garante ao processo de relaxação uma influência recorrente que pode ter inibido a resposta dos núcleos internos do modelo. A partir do experimento menos restritivo nas configurações propostas, foram conduzidos novos experimentos numéricos para uma avaliação de como diferentes parametrizações convectivas e de microfísica representam a banda de precipitação associada ao sistema. Os resultados apontaram para representações adequadas, com exceção do teste com a parametrização de cumulus Grell3D Ensemble (G3D), que subestimou acumulados de chuva na região. Isso pode estar associado à presença de processos de subsidência na representação da convecção por esse esquema. Como o espaçamento de grade utilizado nos testes propostos é considerável $(25 \mathrm{~km})$, a subsidência associada ao processo de convecção representado pela G3D pode não ter alcançado pontos de grade vizinhos e, consequentemente, atenuado a convecção. A configuração controle, integrada com uma parametrização de microfísica WRF Single Moment 6-Class (WSM6) e cumulus Kain-Fritsch (KF) foi a única a ter a banda de precipitação da ZCAS construída com contribuições de ambos os esquemas. Os resultados também apontam para a possibilidade de se utilizar um esquema de microfísica mais simples (WSM3) para a representação do sistema, uma vez que os desempenhos entre diferentes testes em microfísica foram semelhantes. Isso pode ser um reflexo da escolha do espaçamento de grade para os testes numéricos e também da própria estrutura de eventos de ZCAS, que contam com grande contribuição de convecção estratiforme. Revisitando o diagrama apresentado na figura 2.6 do Capítulo 2, o presente estudo almejou oferecer alguma contribuição para o entendimento desse complexo sistema nas áreas destacadas na figura 6.1 . 


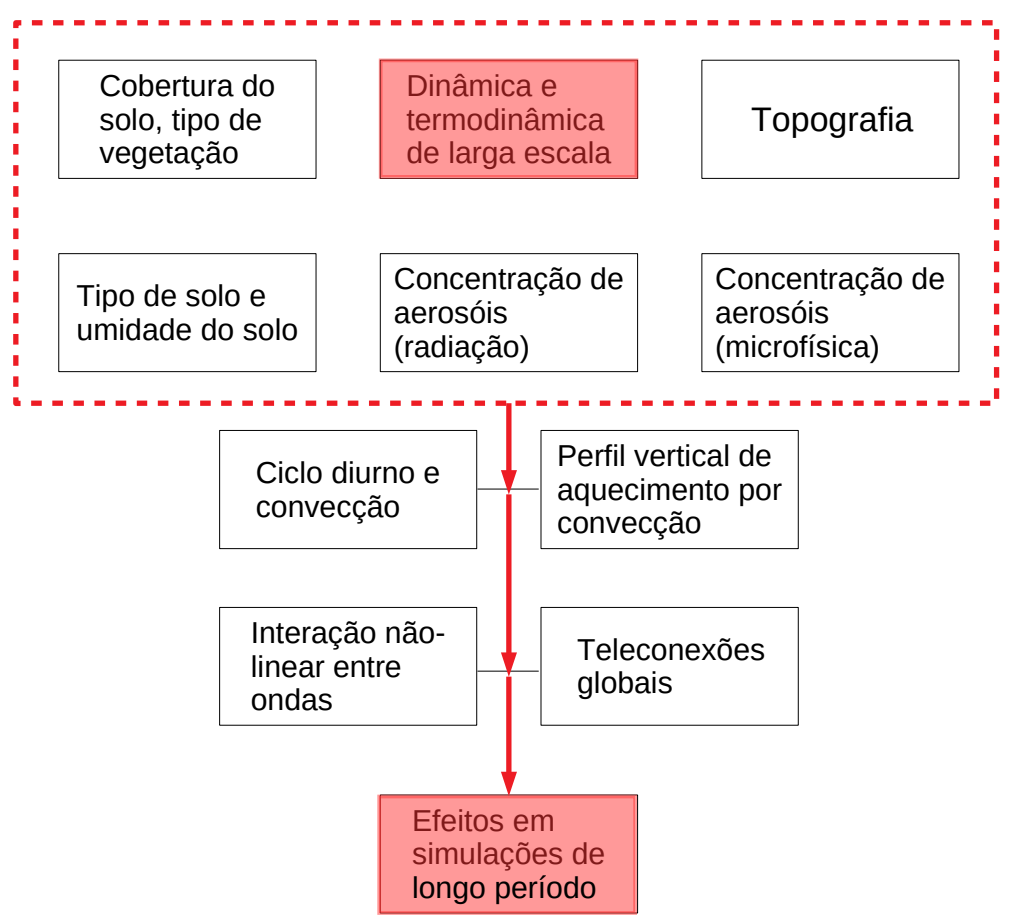

Figura 6.1: Diagrama representando os diversos fatores que influenciam o sistema SMAS/ZCAS. Adaptado de Silva Dias (2015) e com destaque para as áreas de contribuição do presente trabalho.

\subsection{Sugestões para Trabalhos Futuros}

O presente trabalho buscou oferecer alguma contribuição para o entendimento de um sistema altamente complexo.

Certamente, trata-se de uma área com elevada complexidade e na lista a seguir são apontadas algumas sugestões baseadas nas conclusões do presente estudo:

- Buscar uma climatologia de casos de ZCAS com a configuração destacada e com o suporte do vórtice ciclônico presente nesse caso. A presença dessa feição foi fundamental para o posicionamento da ZCAS a norte da sua posição climatológica. Portanto, a verificação de outros casos com essa configuração é de grande importância;

- Testar aplicações de relaxação com diferentes escalas temporais, buscando atenuar ainda mais a interferência do processo nos resultados numéricos; 
- Avaliar o impacto na distribuição vertical de calor durante a evolução do sistema;

- Realizar testes numéricos para episódios de ZCAS com o suporte de larga escala em outras configurações numéricas;

- Testar a sensibilidade do tamanho e posicionamento do domínio na representação de casos de ZCAS;

- Investigar interações entre outras parametrizações de processos físicos e como elas podem impactar o desempenho na representação numérica de eventos de ZCAS;

- Avaliar detalhadamente como cada esquema de parametrização de microfísica de nuvens e convecção gera núcleos convectivos, tanto no continente como no oceano; 


\section{Referências Bibliográficas}

Adler R. F., Huffman G. J., Chang A., Ferraro R., Xie P.-P., Janowiak J., Rudolf B., Schneider U., Curtis S., Bolvin D., Gruber A., Susskind J., Arkin P., Nelkin E., The Version2 Global Precipitation Climatology Project (GPCP) Monthly Precipitation Analysis (1979-Present), Journal of Hydrometeorology, 2003, vol. 4, p. 1147

Banzon V., Smith T. M., Chin T. M., Liu C., Hankins W., A long-term record of blended satellite and in situ sea-surface temperature for climate monitoring, modeling and environmental studies, Earth System Science Data, 2016, vol. 8, p. 165

Bjornsson H., Venegas S. A., , 1997 A Manual for EOF and SVD analysis of Climatic Data

Bombardi R. J., Carvalho L. M. V., The South Atlantic dipole and variations in the characteristics of the South American Monsoon in the WCRP-CMIP3 multi-model simulations, Climate Dynamics, 2011, vol. 36, p. 2091

Bretherton C. S., Smith C., Wallace J. M., An Intercomparison of Methods for Finding Coupled Patterns in Climate Data, Journal of Climate, 1992, vol. 5, p. 541

Carvalho L. M. V., Intraseasonal large-scale circulations and mesoscale convective activity in tropical South America during the TRMM-LBA campaign, Journal of Geophysical Research, 2002, vol. 107, p. 8042

Carvalho L. M. V., Jones C., Liebmann B., The South Atlantic Convergence Zone: Intensity, Form, Persistence, and Relationships with Intraseasonal to Interannual Activity and Extreme Rainfall, Journal of Climate, 2004, vol. 17, p. 88

Carvalho L. M. V., Jones C., Silva A. E., Liebmann B., Silva Dias P. L., The South 
American Monsoon System and the 1970s climate transition, International Journal of Climatology, 2011, vol. 31, p. 1248

Carvalho L. M. V., Silva A. E., Jones C., Liebmann B., Dias P. L. S., Rocha H. R., Moisture transport and intraseasonal variability in the South America monsoon system, Climate Dynamics, 2010, vol. 36, p. 1865

Casarin D. P., Kousky V. E., Anomalias de precipitação no sul do Brasil e variações na circulação atmosférica., Revista Brasileira de Meteorologia, 1986

Cavalcanti I. F. A., Marengo J. A., Satyamurty P., Nobre C. A., Trosnikov I., Bonatti J. P., Manzi A. O., Tarasova T., Pezzi L. P., D’Almeida C., Sampaio G., Castro C. C., Sanches M. B., Camargo H., Global Climatological Features in a Simulation Using the CPTEC-COLA AGCM, Journal of Climate, 2002, vol. 15, p. 2965

Chaves R. R., Interactions between sea surface temperature over the South Atlantic Ocean and the South Atlantic Convergence Zone, Geophysical Research Letters, 2004, vol. 31

Chen F., Manning K. W., LeMone M. A., Trier S. B., Alfieri J. G., Roberts R., Tewari M., Niyogi D., Horst T. W., Oncley S. P., Basara J. B., Blanken P. D., Description and Evaluation of the Characteristics of the NCAR High-Resolution Land Data Assimilation System, Journal of Applied Meteorology and Climatology, 2007, vol. 46, p. 694

CLIMANALISE, 2013 resreport Boletim de Monitoramento e Análise Climática. Instituto Nacional de Pesquisas Espaciais - INPE. Centro de Previsão de Tempo e Estudos Climáticos - CPTEC

Coelho C. A. S., Cardoso D. H. F., Firpo M. A. F., Precipitation diagnostics of an exceptionally dry event in São Paulo, Brazil, Theoretical and Applied Climatology, 2015, vol. 125 , p. 769

Collins W. D., Rasch P. J., Boville B. A., Hack J. J., McCaa J. R., Williamson D. L., Kiehl J. T., Briegleb B., Bitz C., Lin S.-J., Zhang M., Dai Y., , 2004 techreport Description of the NCAR Community Atmosphere Model (CAM 3.0). National Center For Atmospheric Research 
da Silva A. E., de Carvalho L. M. V., Large-scale index for South America Monsoon (LISAM), Atmospheric Science Letters, 2007, vol. 8, p. 51

Davidson N. E., McBride J. L., McAvaney B. J., The Onset of the Australian Monsoon During Winter MONEX: Synoptic Aspects, Monthly Weather Review, 1983, vol. 111, p. 496

Davies H. C., Limitations of Some Common Lateral Boundary Schemes used in Regional NWP Models, Monthly Weather Review, 1983, vol. 111, p. 1002

Davies H. C., Turner R. E., Updating prediction models by dynamical relaxation: an examination of the technique, Quarterly Journal of the Royal Meteorological Society, 1977, vol. 103, p. 225

de Figueiredo Monteiro C. A., Análise ritmica em climatologia: problemas da atualidade climática em São Paulo e achegas para um programa de trabalho., Climatologia, 1971

de Quadro M. F. L., Dias M. A. F. d. S., Herdies D. L., Análise de um Vórtice Ciclônico e Mesoescala Associado a ZCAS em Janeiro de 2009, Revista Brasileira de Meteorologia, 2016, vol. 31, p. 273

Dee D. P., et al. The ERA-Interim reanalysis: configuration and performance of the data assimilation system, Quarterly Journal of the Royal Meteorological Society, 2011, vol. 137, p. 553

Dias J., Silva Dias P. L., Kiladis G. N., Gehne M., Modulation of Shallow-Water Equatorial Waves due to a Varying Equivalent Height Background, Journal of the Atmospheric Sciences, 2013, vol. 70, p. 2726

Errico R. M., Spectra Computed from a Limited Area Grid, Monthly Weather Review, 1985, vol. 113, p. 1554

Ferraz S. E. T., Variabilidade Intrasazonal no Brasil e Sul da América do Sul, Universidade de São Paulo, 2004, Tese de Doutorado

Ferraz S. E. T., Souto R., Dias P., Velho H. D. C., Ruivo H., ANALYSIS FOR PRECIPITATION CLIMATE PREDICTION ON SOUTH OF BRAZIL, Ciência e Natura, 2013 
Figueroa S. N., Satyamurty P., Da Silva Dias P. L., Simulations of the Summer Circulation over the South American Region with an Eta Coordinate Model, Journal of the Atmospheric Sciences, 1995, vol. 52, p. 1573

Funk C., Peterson P., Landsfeld M., Pedreros D., Verdin J., Shukla S., Husak G., Rowland J., Harrison L., Hoell A., Michaelsen J., The climate hazards infrared precipitation with stations - a new environmental record for monitoring extremes, Scientific Data, 2015, vol. 2, p. 150066

Gan M. A., Kousky V. E., Ropelewski C. F., The South America Monsoon Circulation and Its Relationship to Rainfall over West-Central Brazil, Journal of Climate, 2004, vol. 17, p. 47

Gan M. A., Rao V. B., Moscati M. C. L., South American monsoon indices, Atmospheric Science Letters, 2006, vol. 6, p. 219

Gandu A. W., Silva Dias P. L., Impact of tropical heat sources on the South American tropospheric upper circulation and subsidence, Journal of Geophysical Research: Atmospheres, 1998, vol. 103, p. 6001

Gómez B., Miguez-Macho G., The impact of wave number selection and spin-up time in spectral nudging, Quarterly Journal of the Royal Meteorological Society, 2017, vol. 143, p. 1772

Grell G. A., Dévényi D., A generalized approach to parameterizing convection combining ensemble and data assimilation techniques, Geophysical Research Letters, 2002, vol. 29, p. 38

Grimm A. M., Ambrizzi T., , 2009 in , Past Climate Variability in South America and Surrounding Regions. Springer Netherlands pp 159-191

Grimm A. M., Silva Dias P. L., Analysis of Tropical-Extratropical Interactions with Influence Functions of a Barotropic Model, Journal of the Atmospheric Sciences, 1995a, vol. 52 , p. 3538

Grimm A. M., Silva Dias P. L., Analysis of Tropical-Extratropical Interactions with Influence Functions of a Barotropic Model, Journal of the Atmospheric Sciences, 1995b, vol. 52, p. 3538 
Hastenrath S., Greischar L., van Heepden J., Prediction of the Summer Rainfall over South Africa, Journal of Climate, 1995, vol. 8, p. 1511

Herdies D. L., Silva A., Silva Dias M. A. F., Nieto-Ferreira R., Moisture budget of the bimodal pattern of the summer circulation over South America, Journal of Geophysical Research, 2002, vol. 107

Higgins R. W., Yao Y., Wang X. L., Influence of the North American Monsoon System on the U.S. Summer Precipitation Regime, Journal of Climate, 1997, vol. 10, p. 2600

Hirata F. E., Grimm A. M., The role of synoptic and intraseasonal anomalies on the life cycle of rainfall extremes over South America: non-summer conditions, Climate Dynamics, 2016, vol. 49, p. 313

Hong S., Lim J.-O. J., The WRF Single-Moment 6-Class Microphysics Scheme (WSM6), Journal of the Korean Meteorological Society, 2006, vol. 42, p. 129

Hong S.-Y., Dudhia J., Chen S.-H., A Revised Approach to Ice Microphysical Processes for the Bulk Parameterization of Clouds and Precipitation, Monthly Weather Review, 2004, vol. 132, p. 103

Horel J. D., Hahmann A. N., Geisler J. E., An investigation of the Annual Cycle of Convective Activity over the Tropical Americas, Journal of Climate, 1989, vol. 2, p. 1388

Huffman G. J., Adler R. F., Bolvin D. T., Gu G., Improving the global precipitation record: GPCP Version 2.1, Geophysical Research Letters, 2009, vol. 36, p. L17808

Huffman G. J., Bolvin D. T., Nelkin E. J., Wolff D. B., Adler R. F., Gu G., Hong Y., Bowman K. P., Stocker E. F., The TRMM Multisatellite Precipitation Analysis (TMPA): Quasi-Global, Multiyear, Combined-Sensor Precipitation Estimates at Fine Scales, Journal of Hydrometeorology, 2007, vol. 8, p. 38

Janjić Z. I., The Step-Mountain Eta Coordinate Model: Further Developments of the Convection, Viscous Sublayer, and Turbulence Closure Schemes, Monthly Weather Review, 1994, vol. 122, p. 927

Jones C., Carvalho L. M. V., Active and Break Phases in the South American Monsoon System, Journal of Climate, 2002, vol. 15, p. 905 
Jones C., Schemm J.-K. E., The Influence of Intraseasonal Variations on Medium- to Extended-Range Weather Forecasts over South America, Monthly Weather Review, 2000, vol. 128 , p. 486

Jorgetti T., A zona de convergência do Atlântico Sul e os processos oceânicos do Atlântico e do Pacífico, Universidade de São Paulo, 2009, Tese de Doutorado

Kain J. S., The Kain-Fritsch Convective Parameterization: An Update, Journal of Applied Meteorology, 2004, vol. 43, p. 170

Kalnay E., Kanamitsu M., Kistler R., Collins W., Deaven D., Gandin L., Iredell M., Saha S., White G., Woollen J., Zhu Y., Leetmaa A., Reynolds R., Chelliah M., Ebisuzaki W., Higgins W., Janowiak J., Mo K. C., Ropelewski C., Wang J., Jenne R., Joseph D., The NCEP/NCAR 40-Year Reanalysis Project, Bulletin of the American Meteorological Society, 1996, vol. 77, p. 437

Kitoh A., Kusunoki S., Nakaegawa T., Climate change projections over South America in the late 21st century with the 20 and $60 \mathrm{~km}$ mesh Meteorological Research Institute atmospheric general circulation model ( $\{\mathrm{MRI}\}-\{\mathrm{AGCM}\})$, Journal of Geophysical Research, 2011, vol. 116

Kodama Y., Large-Scale Common Features of Subtropical Precipitation Zones (the Baiu Frontal Zone, the SPCZ, and the SACZ) Part I: Characteristics of Subtropical Frontal Zones, Journal of the Meteorological Society of Japan. Ser. II, 1992, vol. 70, p. 813

Kodama Y.-M., Large-Scale Common Features of Sub-Tropical Convergence Zones (the Baiu Frontal Zone, the SPCZ, and the SACZ) Part II : Conditions of the Circulations for Generating the STCZs, Journal of the Meteorological Society of Japan. Ser. II, 1993, vol. 71 , p. 581

Kousky V. E., Pentad outgoing longwave radiation climatology for the South American sector, Revista Brasileira de Meteorologia, 1988

Lenters J. D., Cook K. H., On the Origin of the Bolivian High and Related Circulation Features of the South American Climate, Journal of the Atmospheric Sciences, 1997, vol. 54 , p. 656 
Liebmann B., Camargo S. J., Seth A., Marengo J. A., Carvalho L. M. V., Allured D., Fu R., Vera C. S., Onset and End of the Rainy Season in South America in Observations and the ECHAM 4.5 Atmospheric General Circulation Model, Journal of Climate, 2007, vol. 20, p. 2037

Liebmann B., Marengo J., Interannual Variability of the Rainy Season and Rainfall in the Brazilian Amazon Basin, Journal of Climate, 2001, vol. 14, p. 4308

Liebmann B., Smith C., Description of a Complete (Interpolated) Outgoing Longwave Radiation Dataset, Bulletin of the American Meteorological Society1, 1996, vol. 77, p. 1275

Madden R. A., Julian P. R., Observations of the 40-50-Day Tropical Oscillation-A Review, Monthly Weather Review, 1994, vol. 122, p. 814

Marengo J. A., Liebmann B., Grimm A. M., Misra V., Dias P. L. S., Cavalcanti I. F. A., Carvalho L. M. V., Berbery E. H., Ambrizzi T., Vera C. S., Saulo A. C., Nogues-Paegle J., Zipser E., Seth A., Alves L. M., Recent developments on the South American monsoon system, International Journal of Climatology, 2010, vol. 32, p. 1

Marengo J. A., Soares W. R., Saulo C., Nicolini M., Climatology of the Low-Level Jet East of the Andes as Derived from the NCEP-NCAR Reanalyses: Characteristics and Temporal Variability, Journal of Climate, 2004, vol. 17, p. 2261

Miguez-Macho G., Stenchikov G. L., Robock A., Spectral nudging to eliminate the effects of domain position and geometry in regional climate model simulations, Journal of Geophysical Research: Atmospheres, 2004, vol. 109, p. n/a

Miguez-Macho G., Stenchikov G. L., Robock A., Regional Climate Simulations over North America: Interaction of Local Processes with Improved Large-Scale Flow, Journal of Climate, 2005, vol. 18, p. 1227

Monahan A. H., Fyfe J. C., Ambaum M. H. P., Stephenson D. B., North G. R., Empirical Orthogonal Functions: The Medium is the Message, Journal of Climate, 2009, vol. 22, p. 6501 
Morrison H., Thompson G., Tatarskii V., Impact of Cloud Microphysics on the Development of Trailing Stratiform Precipitation in a Simulated Squall Line: Comparison of One- and Two-Moment Schemes, Monthly Weather Review, 2009, vol. 137, p. 991

Nastrom G. D., Gage K. S., Jasperson W. H., Kinetic energy spectrum of large-and mesoscale atmospheric processes, Nature, 1984, vol. 310, p. 36

Niu G.-Y., Yang Z.-L., Mitchell K. E., Chen F., Ek M. B., Barlage M., Kumar A., Manning K., Niyogi D., Rosero E., Tewari M., Xia Y., The community Noah land surface model with multiparameterization options (Noah-MP): 1. Model description and evaluation with local-scale measurements, Journal of Geophysical Research, 2011, vol. 116, p. D12109

Nogués-Paegle J., Byerle L. A., Mo K. C., Intraseasonal Modulation of South American Summer Precipitation, Monthly Weather Review, 2000, vol. 128, p. 837

Nogués-Paegle J., Mo K. C., Alternating Wet and Dry Conditions over South America during Summer, Monthly Weather Review, 1997, vol. 125, p. 279

Quadro M., Estudo de Vórtices Ciclônicos de Mesoescala associados à Zona de Convergência do Atlântico Sul, Universidade de São Paulo, 2012, Tese de Doutorado

Raia A., Cavalcanti I. F. A., The Life Cycle of the South American Monsoon System, Journal of Climate, 2008, vol. 21, p. 6227

Ramage C. S., Monsoon Meteorology. Academic Press, 1971

Raupp C. F. M., Silva Dias P. L., Resonant Wave Interactions in the Presence of a Diurnally Varying Heat Source, Journal of the Atmospheric Sciences, 2009, vol. 66, p. 3165

Reynolds R. W., Smith T. M., Liu C., Chelton D. B., Casey K. S., Schlax M. G., Daily High-Resolution-Blended Analyses for Sea Surface Temperature, Journal of Climate, 2007, vol. 20, p. 5473

Saha S., Moorthi S., Wu X., Wang J., Nadiga S., Tripp P., Behringer D., Hou Y.-T., Chuang H.-Y., Iredell M., Ek M., Meng J., Yang R., Mendez M. P., Van Den Dool H., Zhang Q., Wang W., Chen M., Becker E., , 2011 NCEP Climate Forecast System Version 2 (CFSv2) 6-hourly Products 
Saha S. e. a., The NCEP Climate Forecast System Reanalysis, Bulletin of the American Meteorological Society, 2010, vol. 91, p. 1015

Saraiva G. S. Z., Santos E. V., Coelho J. O. M., Egas H. M., Casagrande L., , 2015 A Atuação da ZCAS no Desastre de Dezembro de 2013 no Sudeste do Brasil. Apresentação Oral no Workshop ZCAS/Monção realizado pelo CPTEC/INPE entre 20 e 22 de julho de 2015.

Seluchi M. E., Marengo J. A., Tropical-midlatitude exchange of air masses during summer and winter in South America: climatic aspects and examples of intense events, International Journal of Climatology, 2000, vol. 20, p. 1167

Silva V. B. S., Kousky V. E., , 2012 in , Modern Climatology. InTech

Silva Dias P. L., , 2015 Reflexões sobre a ZCAS e as fontes de calor. Palestra Inaugural no Workshop ZCAS/Monção realizado pelo CPTEC/INPE entre 20 e 22 de julho de 2015.

Silva Dias P. L., Schubert W. H., DeMaria M., Large-Scale Response of the Tropical Atmosphere to Transient Convection, Journal of the Atmospheric Sciences, 1983, vol. 40, p. 2689

Siqueira J. R., Machado L. A. T., Influence of the Frontal Systems on the Day-to-Day Convection Variability over South America, Journal of Climate, 2004, vol. 17, p. 1754

Skamarock W. C., Klemp J. B., A time-split nonhydrostatic atmospheric model for weather research and forecasting applications, Journal of Computational Physics, 2008, vol. 227, p. 3465

Stauffer D. R., Seaman N. L., Use of Four-Dimensional Data Assimilation in a LimitedArea Mesoscale Model. Part I: Experiments with Synoptic-Scale Data, Monthly Weather Review, 1990, vol. 118, p. 1250

Stensrud D. J., Importance of Low-Level Jets to Climate: A Review, Journal of Climate, 1996, vol. 9, p. 1698

Stensrud D. J., Parameterization Schemes: Keys to Understanding Numerical Weather Prediction Models. Cambridge University Press, 2003 
Trenberth K. E., Stepaniak D. P., Caron J. M., The Global Monsoon as Seen through the Divergent Atmospheric Circulation, Journal of Climate, 2000, vol. 13, p. 3969

Vera C., Higgins W., Amador J., Ambrizzi T., Garreaud R., Gochis D., Gutzler D., Lettenmaier D., Marengo J., Mechoso C. R., Nogues-Paegle J., Dias P. L. S., Zhang C., Toward a Unified View of the American Monsoon Systems, Journal of Climate, 2006, vol. 19 , p. 4977

Vincent C. L., Hahmann A. N., The Impact of Grid and Spectral Nudging on the Variance of the Near-Surface Wind Speed, Journal of Applied Meteorology and Climatology, 2015, vol. 54, p. 1021

von Storch H., Langenberg H., Feser F., A Spectral Nudging Technique for Dynamical Downscaling Purposes, Monthly Weather Review, 2000, vol. 128, p. 3664

Vulquin A., Arguments en faveur d'une mousson en Amazonie, Tellus, 1971, vol. 23, p. 74

Waldron K. M., Paegle J., Horel J. D., Sensitivity of a Spectrally Filtered and Nudged Limited-Area Model to Outer Model Options, Monthly Weather Review, 1996, vol. 124, p. 529

Wang B., Ding Q., Changes in global monsoon precipitation over the past 56 years, Geophysical Research Letters, 2006, vol. 33

Wang B., Ding Q., Global monsoon: Dominant mode of annual variation in the tropics, Dynamics of Atmospheres and Oceans, 2008, vol. 44, p. 165

Wang B., Ding Q., Liu J., , 2011 in , The Global Monsoon System: Research and Forecast. World Scientific

Wang J., Kotamarthi V. R., Assessment of Dynamical Downscaling in Near-Surface Fields with Different Spectral Nudging Approaches Using the Nested Regional Climate Model (\{NRCM $\})$, Journal of Applied Meteorology and Climatology, 2013, vol. 52, p. 1576

Webster P. J., Magaña V. O., Palmer T. N., Shukla J., Tomas R. A., Yanai M., Yasunari T., Monsoons: Processes, predictability, and the prospects for prediction, Journal of Geophysical Research: Oceans, 1998, vol. 103, p. 14451 
Wheeler M. C., Hendon H. H., An All-Season Real-Time Multivariate MJO Index: Development of an Index for Monitoring and Prediction, Monthly Weather Review, 2004, vol. 132 , p. 1917

Xie P., Janowiak J. E., Arkin P. A., Adler R., Gruber A., Ferraro R., Huffman G. J., Curtis S., \{GPCP $\}$ Pentad Precipitation Analyses: An Experimental Dataset Based on Gauge Observations and Satellite Estimates, Journal of Climate, 2003, vol. 16, p. 2197

Yihui D., Chan J. C. L., The East Asian summer monsoon: an overview, Meteorology and Atmospheric Physics, 2005, vol. 89, p. 117

Zhang D., Anthes R. A., A High-Resolution Model of the Planetary Boundary Layer-Sensitivity Tests and Comparisons with SESAME-79 Data, Journal of Applied Meteorology, 1982, vol. 21, p. 1594

Zhou J., Lau K.-M., Does a Monsoon Climate Exist over South America?, Journal of Climate, 1998, vol. 11, p. 1020

Zittis G., Hadjinicolaou P., Lelieveld J., Comparison of WRF Model Physics Parameterizations over the MENA-CORDEX Domain, American Journal of Climate Change, 2014, vol. 03 , p. 490 